


\title{
Recuperación de la clasificación sinóptica de Font: reconstrucción con el reanálisis ERA40
}

Nota técnica 27 de AEMET

\author{
CARLOS SANTOS BURGUETE ${ }^{1}$ \\ ÁLVARO SUBÍAS DÍAZ-BLANCO² \\ ALEJANDRO ROA ALONSO ${ }^{2}$
}

${ }^{1}$ AEMET / Dirección de Producción e Infraestructuras / Centro Nacional de Predicción

${ }^{2}$ AEMET / Dirección de Producción e Infraestructuras / Área de Técnicas y Aplicaciones de Predicción 
Aviso Legal: los contenidos de esta publicación podrán ser reutilizados, citando la fuente y la fecha, en su caso, de la última actualización

\section{Edita:}

(C) Ministerio para la Transición Ecológica Agencia Estatal de Meteorología Madrid, 2019

Catálogo de Publicaciones de la Administración General del Estado: https://cpage.mpr.gob.es

NIPO: 639-19-013-7

https://doi.org/10.31978/639-19-013-7

Agencia Estatal de Meteorología (AEMET)

$\mathrm{C} /$ Leonardo Prieto Castro, 8

28040 Madrid

\section{http://www.aemet.es/}

@Aemet_Esp

https://www.facebook.com/AgenciaEstatalMeteorologia 


\section{Índice}

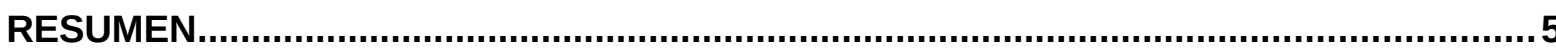

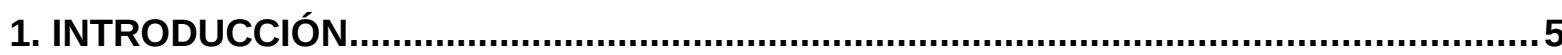

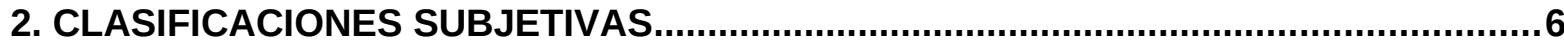

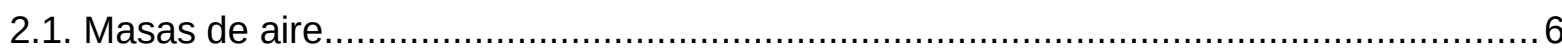

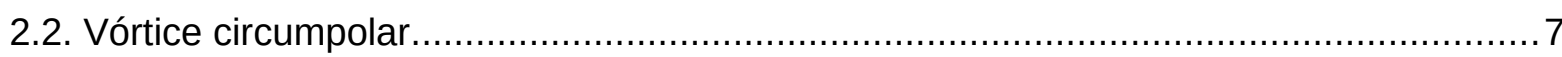

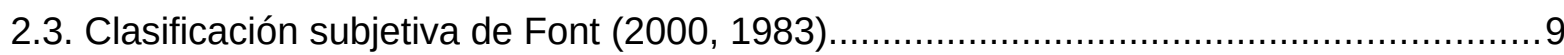

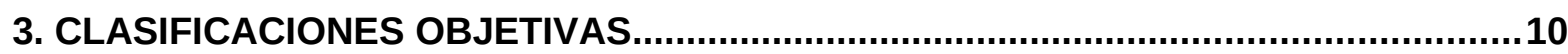

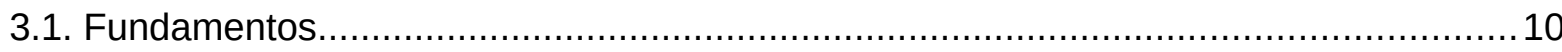

3.2. Clasificación objetiva de Ribalaygua y Borén (1995)............................................11

3.3. Modelos conceptuales de precipitación.................................................................. 14

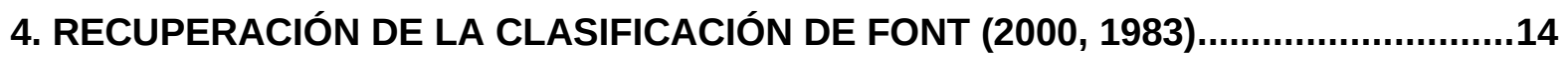

4.1. Técnica de presentación visual...................................................................... 14

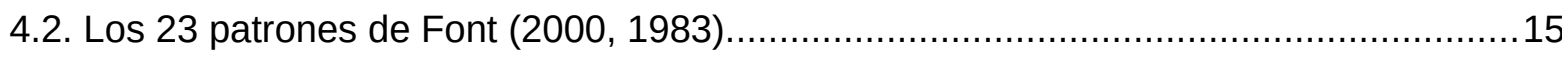

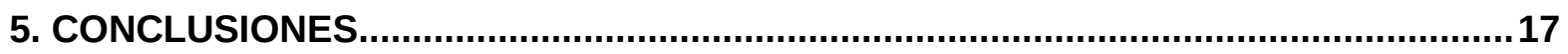

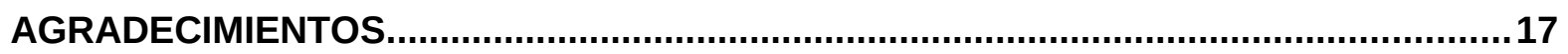

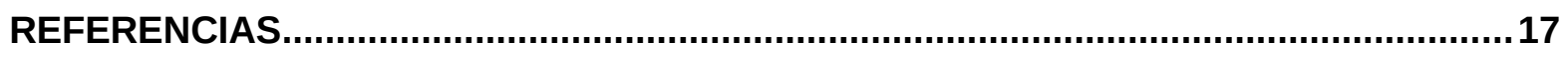

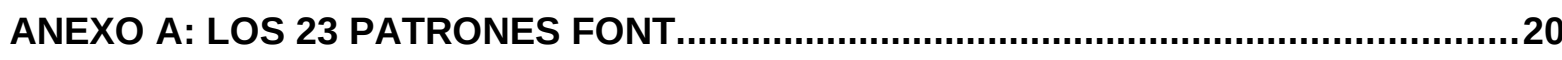

Tipo 1. IZ Altas presiones en el Atlántico subtropical.............................................20

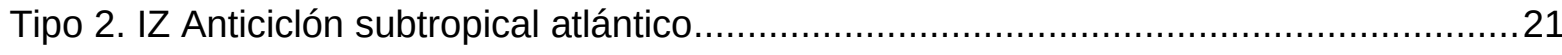

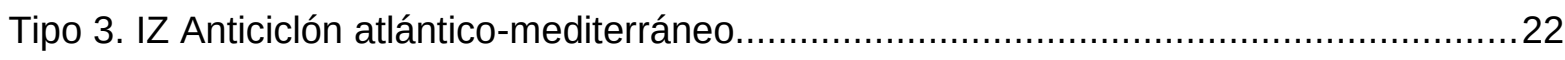

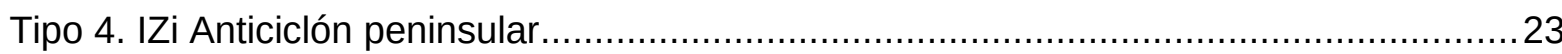


Tipo 5. IZe Anticiclón de las Azores y depresión térmica peninsular...............................24

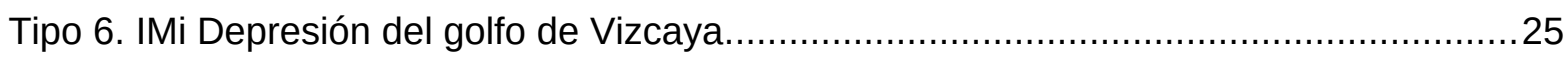

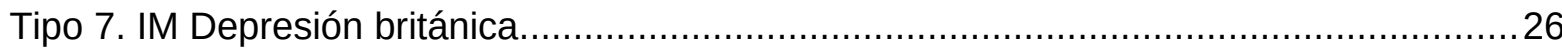

Tipo 8. IMe Anticiclón atlántico y depresión térmica peninsular......................................27

Tipo 9. IMe Altas presiones sobre el Atlántico y Europa..................................................28

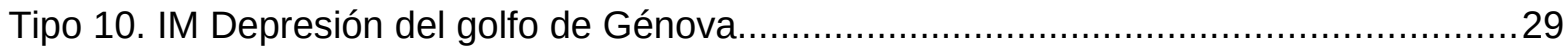

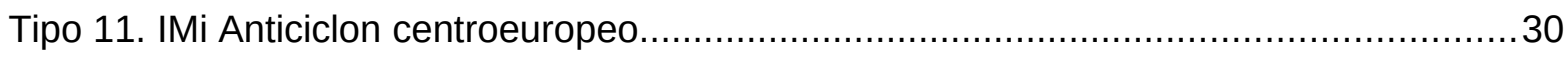

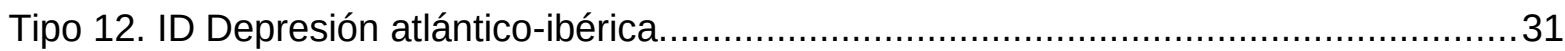

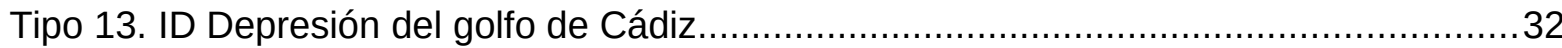

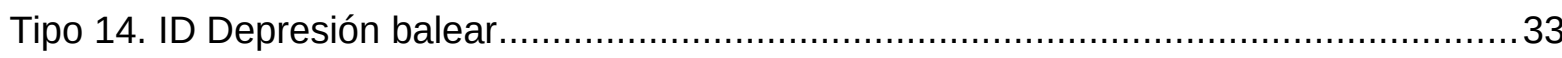

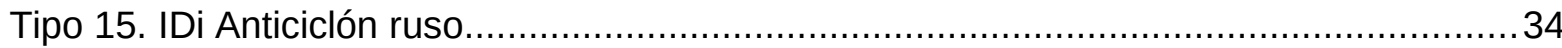

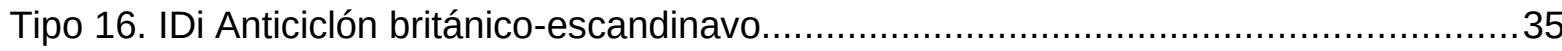

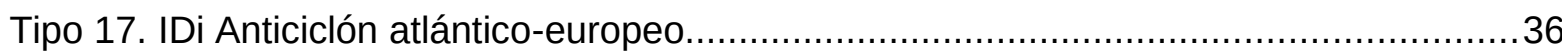

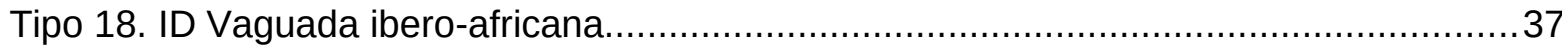

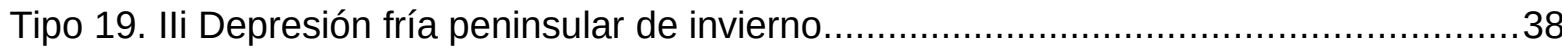

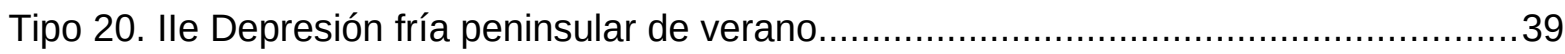

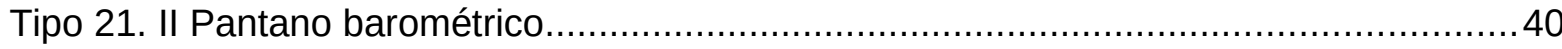

Tipo 22. Illi Intensa circulación zonal a bajas latitudes.............................................. 41

Tipo 23. Illi Circulación ondulada a bajas latitudes...................................................... 42 


\title{
Recuperación de la clasificación sinóptica de Font: reconstrucción con el reanálisis ERA40
}

\author{
Carlos Santos Burguete' (csantosb@aemet.es) \\ Álvaro Subías Díaz-Blanco²(asubiasd@aemet.es) \\ Alejandro Roa Alonso² (aroaa@aemet.es) \\ ${ }^{1}$ AEMET / Dirección de Producción e Infraestructuras / Centro Nacional de Predicción \\ ${ }^{2}$ AEMET / Dirección de Producción e Infraestructuras / Área de Técnicas y Aplicaciones de \\ Predicción
}

\begin{abstract}
RESUMEN
Las clasificaciones sinópticas ayudan a entender la variabilidad y complejidad de los llamados patrones meteorológicos a la escala sinóptica. Hay una gradación de clasificaciones, desde las subjetivas, con caracterizaciones conceptuales y diagnósticas, hasta las clasificaciones objetivas, basadas en soporte numérico y con un amplio abanico de familias de algoritmos asociados, pasando por clasificaciones intermedias que tienen carácter mixto. En este estudio se revisa la clasificación objetiva de Ribalaygua y Borén (1995) y se recupera con detalle la clasificación subjetiva de Font $(2000,1983)$ que propone 23 patrones sinópticos, ilustrados con situaciones de 23 fechas concretas, en general de la década de 1970-1980. Se utilizan los reanálisis ERA40 (Uppala et al., 2005) del Centro Europeo de Predicción a Plazo Medio (European Centre for Medium-range Weather Forecasts, ECMWF) correspondientes a esas 23 fechas y se dibujan los campos básicos con las herramientas actuales y estilo de visualización de predicción operativa de AEMET. Se compara así el llamado querer de la mano con el querer de la máquina y se muestra la clasificación completa de Font con ambos estilos visuales y texto detallado, intentando ser lo más completo posible. Se trata, en resumen, de recuperar un conocimiento conceptual y valioso, el de Font, conectándolo con el potencial de las herramientas numéricas actuales para, en definitiva, ver qué podemos aprender.
\end{abstract}

PALABRAS CLAVE: clasificaciones sinópticas; patrones sinópticos; predicción numérica; predicción operativa; modelos conceptuales; climatología sinóptica.

\section{INTRODUCCIÓN}

Los fenómenos meteorológicos se presentan en un amplio abanico de escalas espaciales y sus correspondientes escalas temporales. De forma sencilla puede resumirse que las escalas planetaria, sinóptica, mesoescala y microescala abarcan fenómenos desde los $10000 \mathrm{~km}$ hasta los centímetros y, en correspondencia, desde meses o semanas hasta segundos. La escala sinóptica alberga fenómenos de orden de magnitud de $1000 \mathrm{~km}$ y días de duración. Como ejemplo, pueden citarse las vaguadas y dorsales en niveles medio-altos y los anticiclones y borrascas en niveles bajos de la troposfera. Las llamadas meteorología sinóptica y climatología sinóptica (Font 2000, 1983) caracterizan, respectivamente, el tiempo y el clima en dicha escala basándose en los diversos factores que configuran tanto el tiempo como el clima. En meteorología sinóptica se presta especial atención a los diversos patrones de circulación atmosférica, tarea que, por la complejidad y cantidad de los mismos, requiere un esfuerzo importante de síntesis.

Estas clasificaciones de patrones sinópticos espaciales resultan útiles para el tiempo y el clima como herramientas tanto analíticas y predictivas como didácticas y de comunicación. Existen, por un lado, clasificaciones subjetivas (Linés, 1981; Font, 2000, 1983; Sánchez 
Rodríguez; 1993) basadas tradicionalmente en el conocimiento y la experiencia de profesionales de la predicción o la climatología, de carácter fundamentalmente cualitativo y con fuerte conexión con los efectos que produce cada patrón sobre el tiempo sensible. Por otro lado, desde la aparición de las técnicas de clustering o agrupamiento (Hartigan, 1975) con soporte computacional, existen clasificaciones objetivas basadas en algoritmos de similitud morfológica (Calvo 1993; Petisco y Martín, 1995; Ribalaygua y Borén, 1995; Gutiérrez y col., 2004). Ambos enfoques, subjetivo y objetivo, son importantes y aportan conocimiento y utilidad complementarios. Ofrecemos aquí dos ejemplos, uno de cada enfoque la clasificación subjetiva de Font $(2000,1983)$ y la objetiva de Ribalaygua y Borén (1995). Por un lado, estos dos ejemplos son suficientes para entender las bases, resultados y conclusiones de ambos métodos; por otro lado, ambos han sido utilizados en el anterior INM o en AEMET y, aunque no sean de publicación reciente, sí representan parte de la historia de AEMET como institución. Más allá de estas consideraciones, la consistencia entre ambos enfoques puede resultar una aproximación interesante para futuros estudios. En Tveito et al (2011) puede encontrarse una exposición exhaustiva y comparativa de distintas clasificaciones de tipos de tiempo sobre Europa, así como aplicaciones de las mismas y formas de evaluarlas. Estas clasificaciones, más allá de la interpretación sinóptica para fines operativos pueden permitir, por ejemplo, evaluar modelos numéricos (Casado et al., 2011 y 2012).

En la sección 2 mostramos las clasificaciones subjetivas, dando el ejemplo de la clasificación de Font $(2000,1983)$. En la sección 3 revisamos los fundamentos de las clasificaciones objetivas, ilustrándolas con el ejemplo de la clasificación de Ribalaygua y Borén (1995). En la sección 4 se recupera la clasificación de Font con una presentación o visualización moderna. Siguen las conclusiones y las referencias.

\section{CLASIFICACIONES SUBJETIVAS}

\subsection{Masas de aire}

En la caracterización meteorológica de los patrones sinópticos es crucial el concepto de masa de aire. Una región del planeta suficientemente grande y meteorológicamente homogénea, que llamaremos región fuente o manantial, puede conferir a la masa de aire que soporta propiedades particulares de opacidad, humedad, temperatura, etc. Esta masa de aire viajará y conservará estas propiedades un tiempo, durante el cual podrá afectar a otras regiones. La tabla 1 (Font, 2000, 1983) ofrece un detalle de aquellas masas de aire que afectan principalmente a la península ibérica. El indicativo de cada masa de aire se compone de una letra minúscula que indica su origen (m marítimo, c continental) y una mayúscula que denota su carácter (T Tropical, P Polar, A Ártica).

\begin{tabular}{|l|l|l|l|l|}
\hline \multicolumn{2}{|l|}{ Naturaleza } & Origen & Indicativo & Meses de más frecuencia \\
\hline \multirow{2}{*}{ Frías } & Marítimas & $\begin{array}{l}\text { Océano Ártico } \\
\text { Groenlandia, } \\
\text { Canadá }\end{array}$ & $\begin{array}{l}\mathrm{mA} \\
\mathrm{mP}\end{array}$ & $\begin{array}{l}\text { Invierno y abril } \\
\text { Invierno y ocasionalmente resto del año }\end{array}$ \\
\cline { 2 - 5 } Cálidas & Continentales & Rusia, Siberia & $\mathrm{cP}$ & Febrero, diciembre, enero \\
\cline { 2 - 5 } & Marítimas & $\begin{array}{l}\text { Atlántico } \\
\text { subtropical } \\
\text { Atlántico tropical }\end{array}$ & $\begin{array}{l}\mathrm{mT}(\mathrm{sub}) \\
\mathrm{mT}\end{array}$ & $\begin{array}{l}\text { Verano y ocasionalmente resto del año } \\
\text { Otoño, invierno y ocasionalmente } \\
\text { primavera }\end{array}$ \\
\cline { 2 - 5 } & Continentales & $\mathrm{N}$ África & $\mathrm{cT}$ & Verano principalmente \\
\hline
\end{tabular}

Tabla 1: Principales masas de aire que afectan a la península ibérica. 
La figura 1.a (Font, 2000, 1983), ilustra las trayectorias de las masas de aire que principalmente afectan a la península ibérica (PI). Ésta, a su vez, puede actuar sobre las masas de aire, modificando sus propiedades, si éstas permanecen el tiempo suficiente sobre la misma.

a)

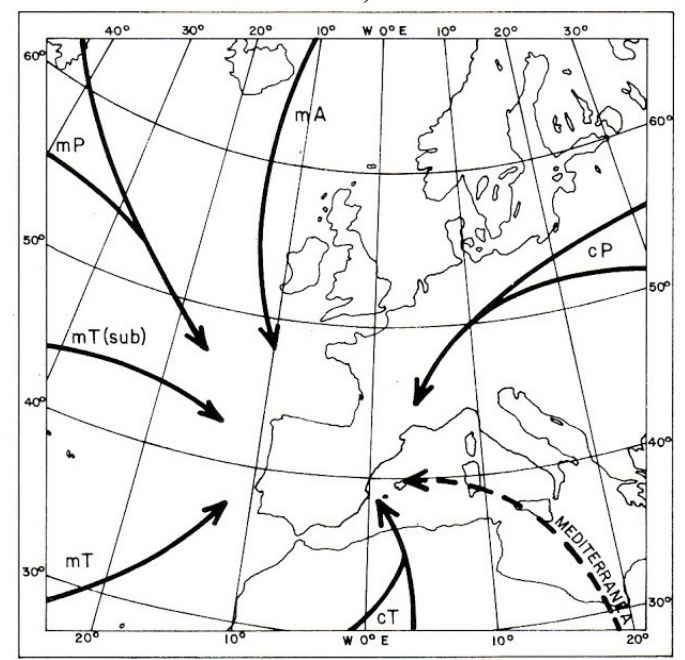

b)

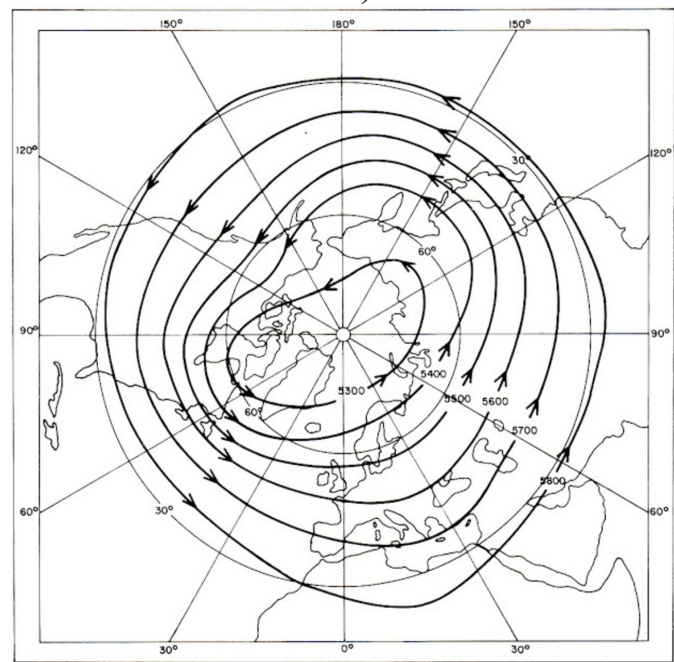

Figura 1: a) trayectorias de las masas de aire que llegan a la PI. b) media anual de la altura geopotencial en $500 \mathrm{hPa}$, estructura planetaria que llamamos vórtice circumpolar (Font, 2000, 1983).

\subsection{Vórtice circumpolar}

La configuración de flujo planetario y sinóptico en niveles medios-altos de la troposfera (500 $\mathrm{hPa}$ ) y sus variaciones son cruciales para la meteorología y la climatología sinópticas. En latitudes medias (aproximadamente $30^{\circ}-60^{\circ}$ ) predominan los vientos de componente oeste en casi todos los niveles por encima de $700 \mathrm{hPa}$, configuración que viene a llamarse vórtice circumpolar, ilustrado en la figuras 1.b (anual), 2.a y 2.b (media de enero y julio, respectivamente).

a)

Mean 500-mb Heights (gpm) for January, 1958-2005, based on NCEP/NCAR Reanalysis

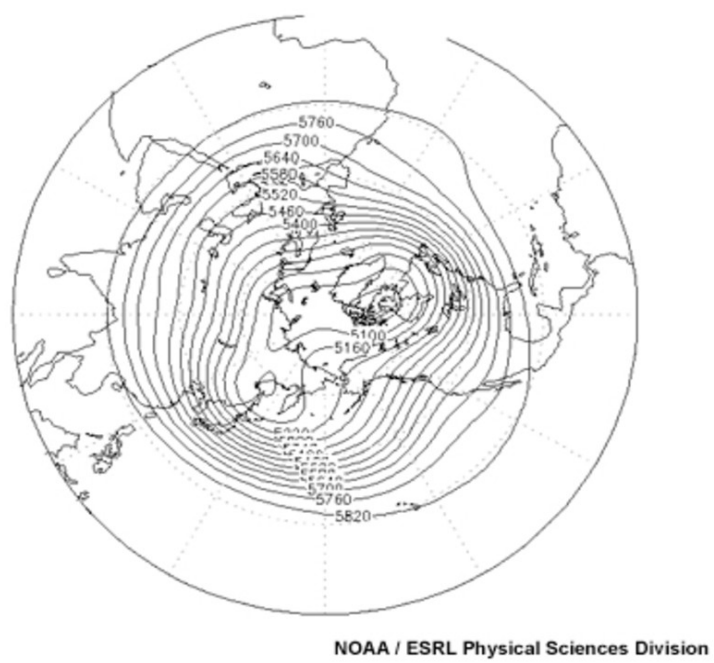

b) Mean $500-m b$ Heights (gpm) for July, 1958-2005,
based on NCEP/NCAR Reanalysis

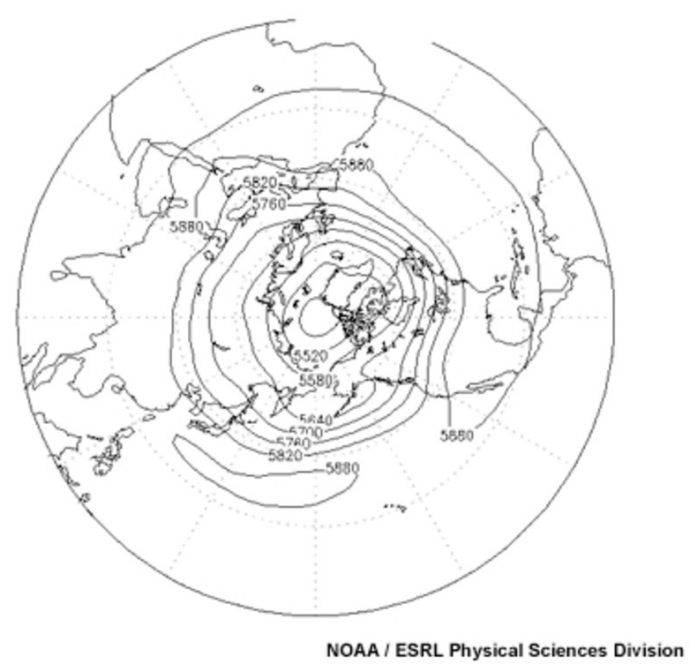

Figura 2: Vórtice circumpolar: altura geopotencial en $500 \mathrm{hPa}$, media de enero (a) y julio (b) (NOAA/ESRL, 2006). 
Las intensidades máximas (típicamente $300 \mathrm{~km} / \mathrm{h}$ ) se encuentran en las inmediaciones de la tropopausa (altitudes de 8-12 km) en la denominada corriente en chorro (jet stream). El chorro, al no tener posiciones fijas en el planeta, no aparece usualmente en los mapas climatológicos, en los que se realiza un promedio temporal, aunque sí aparece en los mapas meteorológicos. El vórtice circumpolar es más intenso en invierno que en verano. Además, sufre fluctuaciones no periódicas (esencialmente caóticas) entre lo que se denomina flujo zonal, siguiendo aproximadamente los paralelos y flujo meridiano $\mathrm{u}$ ondulado con componentes meridionales. En la figura 3.a se ofrece una primera ilustración de estos dos flujos sobre el entorno de Europa occidental, elaborada con datos del reanálisis del NCEP/NCAR (Kalnay et al., 1996).

a)

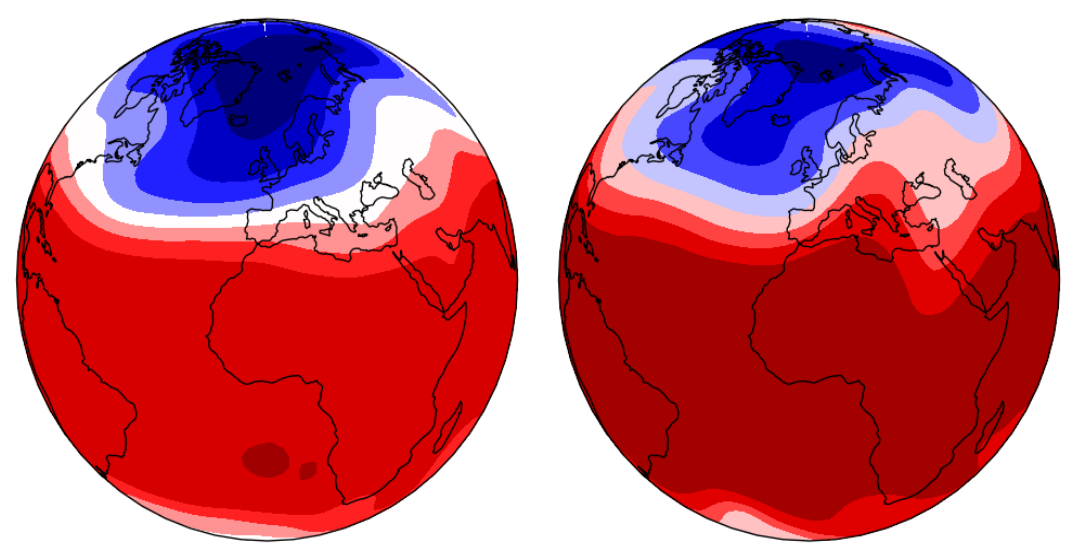

b)

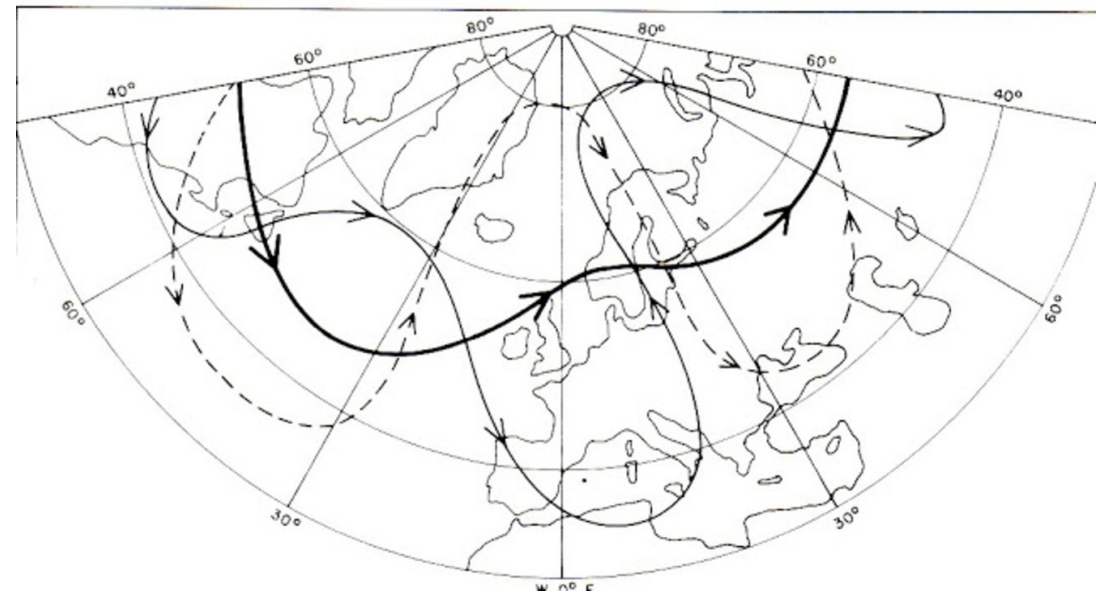

Figura 3: Flujos zonal y ondulado. a) Fluctuaciones del flujo del oeste sobre el entorno de Europa occidental entre flujo zonal (izquierda) y flujo meridiano (derecha), figuras elaboradas con datos del reanálisis de NCEP/NCAR (Kalnay et al., 1996). b) Flujo zonal en línea gruesa, flujos meridianos en línea fina y línea discontinua (Font, 2000, 1983).

En el flujo ondulado se desarrollan bajas frías (así como altas cálidas, referido al nivel de $500 \mathrm{hPa}$ ) en altura a latitudes usualmente más bajas que las borrascas del frente polar. Un caso particular muy importante en España es la estructura denominada depresión aislada en niveles altos (DANA) que favorece precipitaciones intensas en el Mediterráneo peninsular (fenómeno denominado popularmente gota fría, denominación que puede dar lugar a confusión). En general, las bajas pueden o no tener reflejo en superficie y, en caso de tenerlo, la parte superior suele estar retrasada (posición más al oeste) con respecto a la de superficie 
en el estado inicial. Así mismo, el vórtice circumpolar desarrolla de forma no periódica contracciones y expansiones que desplazan los máximos de viento al norte o al sur. De forma muy general (ilustrada en la figura 3.b), podemos decir que la circulación zonal en altura va asociada a pequeñas borrascas de paso rápido que, si pasan sobre la PI, pueden dejar precipitación y, si pasan más al norte de la PI, es más probable que dejen tiempo seco. La circulación meridiana, según la posición relativa de los meandros puede, por un lado, traer aire frío en altura que, en conjunción con el flujo del Mediterráneo relativamente cálido, puede generar condiciones muy inestables; o bien puede, por otro lado, traer aire subtropical cálido y más seco.

Denominamos tipo de tiempo a la distribución particular de los sistemas de presión y de las masas de aire sobre una región geográfica especificada, asociados con características generales típicas de los fenómenos meteorológicos. En las clasificaciones de tipos de tiempo, los miembros de un mismo grupo comparten características comunes y presentan grandes diferencias entre los distintos grupos, normalmente en las variables climáticas típicas y, singularmente, la precipitación. La clasificación sinóptica de tipos de tiempo sobre la PI es compleja y, en el caso de clasificaciones tradicionales, subjetiva. Un ejemplo famoso es la clasificación de Font $(2000,1983)$.

\subsection{Clasificación subjetiva de Font $(2000,1983)$}

Font utiliza dos factores: el primero, la contracción-expansión del vórtice circumpolar que va asociada a la posición de la circulación en altura del oeste. En el caso de darse la misma en latitudes medias, se añade un segundo factor que es el tipo de circulación (zonal, meridiana o depresión fría). Se distingue además, cuando se da el caso, si es predominantemente invernal o más bien estival. Ver tabla 2.

\begin{tabular}{|l|l|}
\hline Circulación en altura del oeste \\
\hline Latitud & Forma \\
\hline \multirow{4}{*}{ I Latitudes medias } & Z Zonal \\
\cline { 2 - 2 } & M Meridiana \\
\cline { 2 - 2 } & D Depresión fría claramente separada del vórtice \\
\hline II Latitudes altas & \\
\hline III Latitudes bajas & \\
\hline
\end{tabular}

Tabla 2: Factores para la clasificación sinóptica subjetiva de Font (2000, 1983).

Estudiando las situaciones meteorológicas de la década 1970-1980 aproximadamente, atendiendo a estos factores combinados citados, Font encuentra 23 grupos subjetivos que representan tipos de tiempo. Estos tipos mantienen sus rasgos generales tres días o más, con periodos de transición muy difícilmente caracterizables. En Font $(2000,1983)$ se presentan estos tipos de tiempo mostrando los mapas delineados manualmente (lo que se llamaba en la época el querer de la $\operatorname{mano}^{l}$ ), correspondiendo cada caso a una fecha del citado periodo

1 La expresión el querer de la mano no se refería tanto a que los mapas estuvieran realizados en su versión final por delineantes, sino a que cuando se enseñaba a analizarlos manualmente a partir de los datos transcritos, algún profesor animaba a suavizar el contorneado porque así el flujo del aire no hacía "picos". Esta técnica puede valer hasta cierto punto para mapas de altura, pero no en superficie donde, a escala sinóptica, en los frentes sí que puede decirse que el flujo "hace picos" (Nota de Ángel Rivera). 
1970-1980. Se muestra un ejemplo en la figura 4.a y una panorámica de los 23 patrones en la figura 4.b.

192
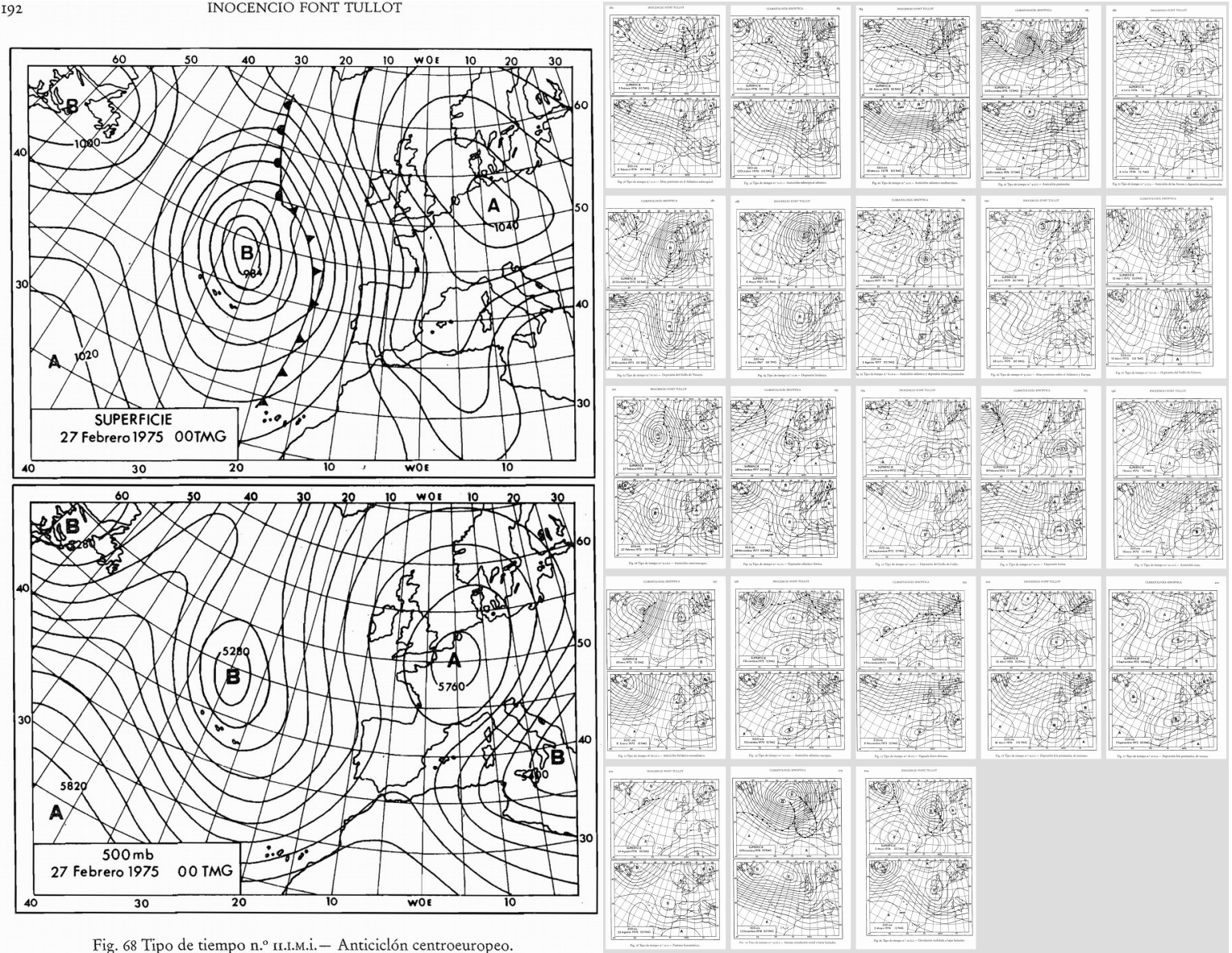

Figura 4: a) Situación del 27 de febrero de 1975 tipo Font 11 "Anticiclón centroeuropeo", con la reproducción original de los mapas delineados. b) Mosaico con los 23 patrones originales de Font.

\section{CLASIFICACIONES OBJETIVAS}

\subsection{Fundamentos}

Desde el surgimiento de los modelos atmosféricos de predicción, las predicciones existen en forma de números, cubriendo habitualmente un dominio espacial tanto en superficie como en una serie de niveles verticales que suelen abarcar la troposfera y, últimamente, parte de la estratosfera o incluso la mesosfera, con una densidad o resolución que depende de la escala. En la escala sinóptica las resoluciones actuales (2019) rondan los 10-30 km para los modelos deterministas.

¿Cómo funcionan las clasificaciones basadas en técnicas de agrupamiento con soporte computacional? En los algoritmos más sencillos, para clasificar se agrupan las situaciones según un criterio numérico de similitud. Dado que cada situación es un campo numérico, la similitud entre situaciones puede calcularse, por ejemplo, como la distancia euclídea (o alguna otra medida de distancia) entre dos campos. Cuando esa distancia está por debajo de un umbral prefijado, las dos situaciones pertenecerán a un mismo grupo. Así sucesivamente hasta haber recorrido todas las comparaciones posibles. Este algoritmo básico puede mejorarse y hacerse más eficaz y sutil, incluyendo varianza explicada, número de grupos, 
etc. En la actualidad, el agrupamiento conforma toda una disciplina científica y técnica y existe una gran variedad de familias de algoritmos. Son populares, por ejemplo, algoritmos como el Análisis de Componentes Principales (PCA por sus siglas en inglés; Jolliffe, 1986; Jolliffe y Cadima, 2016), etc.

Según la capacidad computacional de la que se disponga, las clasificaciones pueden ser más o menos exhaustivas. Con poca capacidad, se reduce la agrupación a la similitud en un solo campo. En esos casos, desde un punto de vista práctico, para la escala sinóptica se escoge a menudo un campo de naturaleza dinámica, como es la altura geopotencial en niveles medios-altos o la presión reducida al nivel del mar. Estos campos presentan variabilidades relativamente suaves en la escala sinóptica, lo que facilita la eficacia y utilidad del algoritmo. Campos de tiempo sensible como son la precipitación o la temperatura en superficie son mucho más ruidosos, por lo que las clasificaciones son, en principio, más complejas y requieren normalmente consideraciones adicionales. Con más capacidad computacional puede trabajarse con varios campos simultáneamente lo que enriquece, como es natural, la clasificación pero a la vez la hace más compleja: más grupos y más características a describir. En cualquier caso, se necesita una base de datos adecuada en tamaño, así como fiabilidad y representatividad de los mismos.

\subsection{Clasificación objetiva de Ribalaygua y Borén (1995)}

Esta clasificación (Ribalaygua y Borén, 1995), aunque no es de las más modernas, ha sido elegida al presentar un interés especial porque es consistente con clasificaciones subjetivas tradicionales, puede interpretarse bien en términos diagnósticos (aquellos expresados en lenguaje meteorológico) y, además, la agrupación se basa en una variable de tiempo sensible como es la precipitación (también puede encontrarse en Romero y col, 1999). El procedimiento se ilustra en la figura 5.a. En un primer paso se aplica el algoritmo de agrupamiento al campo de precipitación diaria acumulada. Una vez que se tienen los grupos, se caracteriza cada grupo sinópticamente por los campos de altura geopotencial en $500 \mathrm{hPa}$ (Z500) y presión reducida al nivel medio del mar (MSLP), promediados a partir de los elementos de cada grupo. 


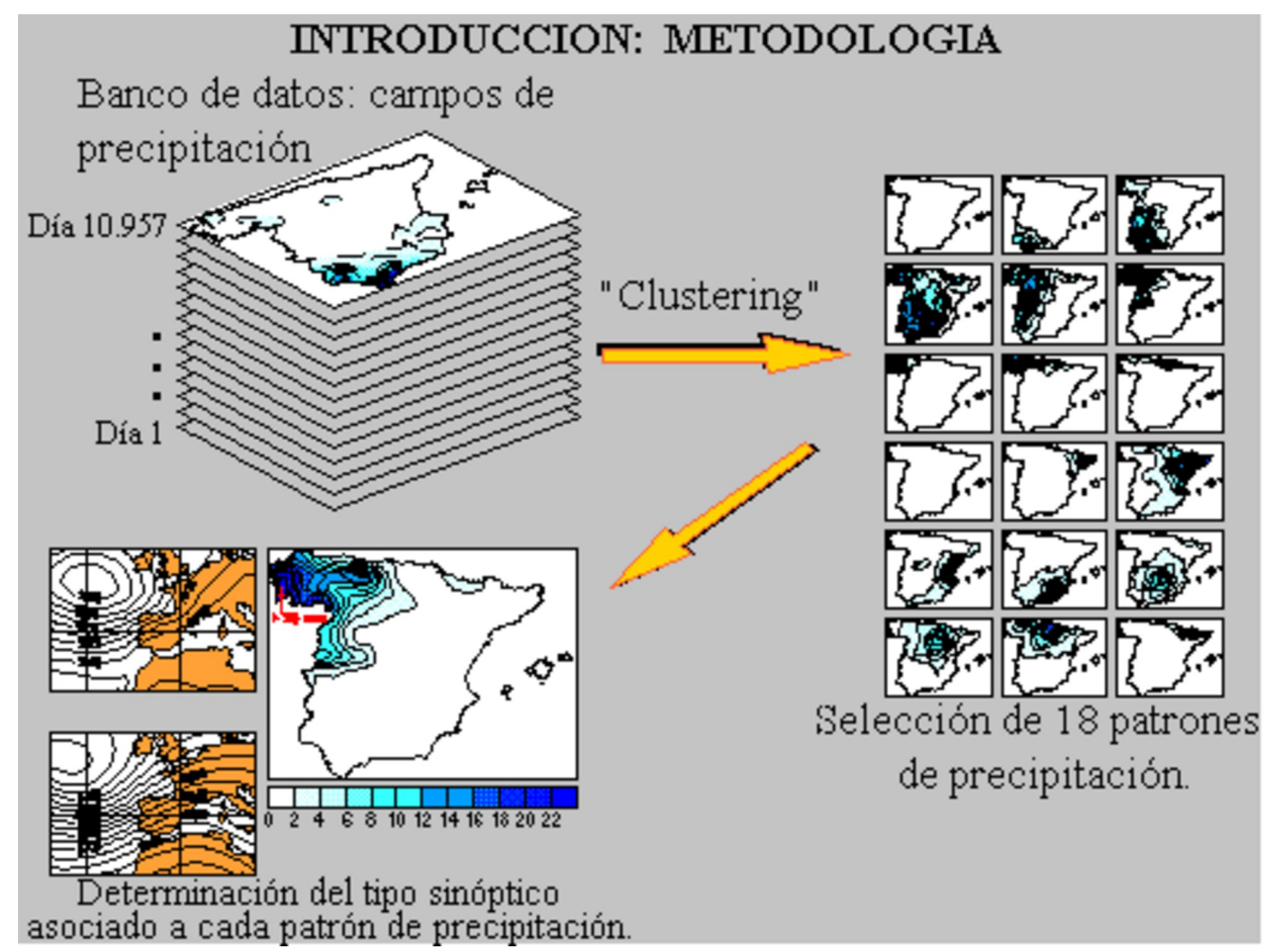

b)

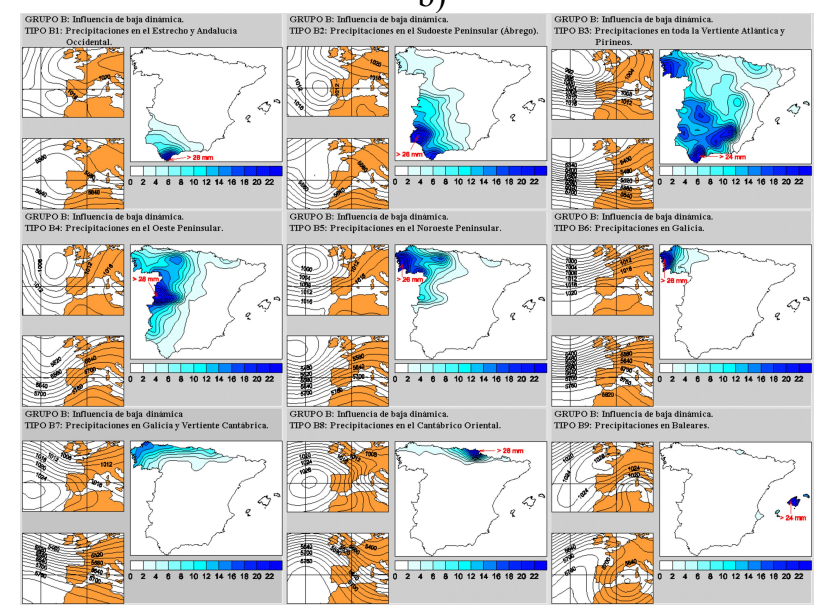

c)

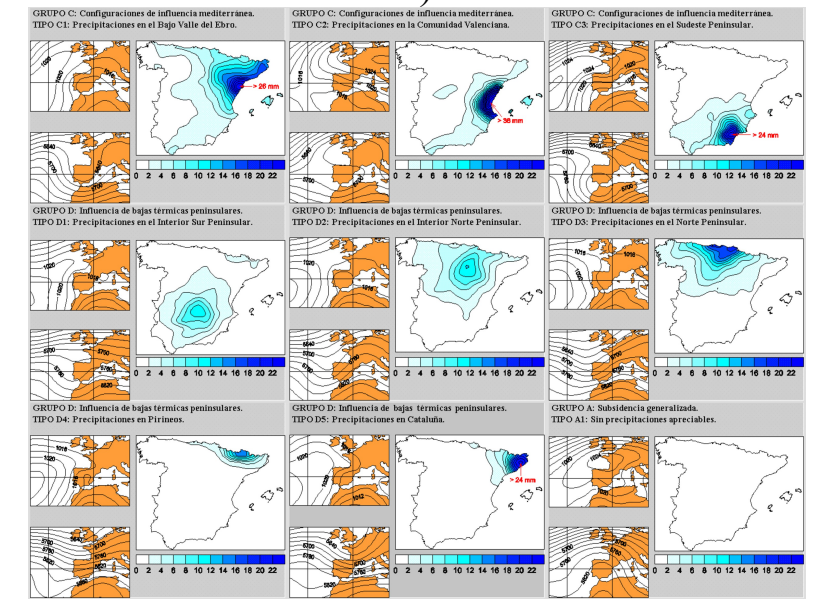

Figura 5: Agrupación de situaciones meteorológicas de Ribalaygua y Borén (1995) que produce 18 patrones meteorológicos en 4 grupos, ver texto. a) Esquema del procedimiento. b) Grupo B con 9 patrones. c) Grupos C, D y A con 9 patrones en total. Fuente: AEMET. 
Hay varias ventajas en este procedimiento: el campo de precipitación (PCP), si no se llega a resoluciones altas y, debido a la influencia compartimentadora de la orografía, suele presentar un número limitado de patrones. Así mismo, las clases sinópticas resultantes tendrán alta capacidad predictiva, dado que la clasificación se ha basado en el efecto en superficie. La base de datos abarca el periodo 1961-1990 con PCP de 10957 días, en un dominio sobre la PI y Baleares, con más de 3000 estaciones. Las configuraciones sinópticas se representan en una malla regular con resolución de $3^{\circ} \times 4^{\circ}$.

Como resultado, se obtienen 18 patrones de precipitación y sus 18 configuraciones sinópticas asociadas. La relación entre la configuración sinóptica de cada grupo y el patrón de precipitación asociado puede interpretarse en términos de modelos conceptuales meteorológicos de precipitación descritos, por su interés, en el siguiente apartado. Los 18 patrones se pueden ordenar conceptualmente según la naturaleza de la configuración y según la zona de descarga de precipitaciones. Tendremos así los grupos A, B, C y D, presentados resumidamente en la tabla 3 y la figuras 5.b (Grupo B) y 5.c (grupos C, D y A). En conjunto, los 18 patrones quedan ordenados de forma que la trayectoria de las sucesivas zonas de precipitación describe una especie de espiral, que comienza en el área del Estrecho con el tipo B1 y termina en Cataluña con el tipo D5.

\begin{tabular}{|c|c|c|}
\hline Grupo & Patrón sinóptico & Precipitaciones \\
\hline $\begin{array}{l}\text { Grupo A: } \\
\text { subsidencia } \\
\text { generalizada }\end{array}$ & $\begin{array}{l}\text { Predominan los descensos (subsidencias) de aire } \\
\text { sobre la PI y Baleares, impidiendo la precipitación. } \\
\text { Aparecen con frecuencia similar en todas las } \\
\text { estaciones del año. }\end{array}$ & $\begin{array}{l}\text { Sin precipitaciones } \\
\text { apreciables. }\end{array}$ \\
\hline $\begin{array}{l}\text { Grupo B: baja } \\
\text { dinámica }\end{array}$ & $\begin{array}{l}\text { Predominan los forzamientos frontal y orográfico. } \\
\text { La presencia de una baja o borrasca de origen } \\
\text { dinámico genera frentes más o menos activos o } \\
\text { líneas de inestabilidad. Los flujos superficiales } \\
\text { están bien definidos, con precipitaciones muy } \\
\text { influidas por la orografía. Z500 tiene una } \\
\text { importancia secundaria. Frecuencia mínima en } \\
\text { verano y superior en invierno, cuando el frente } \\
\text { polar y el cinturón de borrascas extratropicales } \\
\text { asociado bajan a nuestras latitudes. }\end{array}$ & $\begin{array}{l}\text { En las vertientes atlántica } \\
\text { y cantábrica, } \\
\text { desplazándose la zona de } \\
\text { precipitación máxima en } \\
\text { el sentido de las agujas } \\
\text { del reloj, desde el área } \\
\text { del Estrecho (tipo B1), al } \\
\text { Cantábrico Oriental (tipo } \\
\text { B8). El tipo B9 } \\
\text { corresponde a } \\
\text { precipitaciones en } \\
\text { Baleares. }\end{array}$ \\
\hline $\begin{array}{l}\text { Grupo C: } \\
\text { advección } \\
\text { mediterránea }\end{array}$ & $\begin{array}{l}\text { Predominio de vaguadas, bajas o depresiones } \\
\text { aisladas en niveles altos (danas) en niveles medios, } \\
\text { acompañadas a menudo por embolsamientos fríos. } \\
\text { Así mismo, flujo superficial de componente este } \\
\text { (Levante), húmedo y cálido. Los forzamientos } \\
\text { dinámico y orográfico favorecen los ascensos. Dan } \\
\text { lugar a precipitaciones convectivas de distintas } \\
\text { escalas, desde células aisladas hasta complejos } \\
\text { convectivos de mesoescala. En otoño la advección } \\
\text { en superficie es cálida además de húmeda, }\end{array}$ & $\begin{array}{l}\text { En las vertientes } \\
\text { mediterráneas, } \\
\text { comenzando en el Bajo } \\
\text { Ebro (tipo C1) y } \\
\text { terminando en el sudeste } \\
\text { peninsular (tipo C3). Se } \\
\text { continúa con el mismo } \\
\text { criterio de } \\
\text { desplazamiento. }\end{array}$ \\
\hline
\end{tabular}




\begin{tabular}{|c|c|c|}
\hline & $\begin{array}{l}\text { aumentando la inestabilidad y por ende la } \\
\text { intensidad y escala de los fenómenos. Frecuencia } \\
\text { máxima en primavera y otoño. }\end{array}$ & \\
\hline $\begin{array}{l}\text { Grupo D: } \\
\text { bajas } \\
\text { térmicas } \\
\text { peninsulares }\end{array}$ & $\begin{array}{l}\text { En niveles medio-altos vaguadas o borrascas } \\
\text { móviles que dan forzamientos dinámicos. Flujo } \\
\text { superficial poco definido y, en general, bajas } \\
\text { térmicas en el interior peninsular. Se favorecen los } \\
\text { forzamientos térmicos e, indirectamente, } \\
\text { dinámicos, con flujos sobre cordilleras o flujos } \\
\text { convergentes. La precipitación es convectiva, } \\
\text { dependiendo su organización e intensidad de la } \\
\text { estabilidad y la humedad en la atmósfera. } \\
\text { Frecuencia superior en verano. }\end{array}$ & $\begin{array}{l}\text { Concentradas en el } \\
\text { interior peninsular, } \\
\text { desplazándose la zona de } \\
\text { precipitación máxima de } \\
\text { la Meseta Sur (tipo D1) a } \\
\text { Cataluña (tipo D5), 10.36 } \\
\text { cm también en sentido } \\
\text { horario. }\end{array}$ \\
\hline
\end{tabular}

Tabla 3: Clasificación objetiva de Ribalaygua y Borén (1995).

\subsection{Modelos conceptuales de precipitación}

De forma simplificada, los fenómenos de precipitación se producen por ascenso de masas de aire húmedo. Al ascender, el aire se enfría, alcanzando la saturación, favoreciendo así la condensación en gotitas de nube y gotas de agua. Los factores principales que intervienen en este proceso son:

1. Forzamientos que influyen en la masa de aire para ascender, de varios tipos: orográfico, térmico y dinámico. El dinámico se asume como cuasigeostrófico (Holton, 2012), e incluye los forzamientos frontales.

2. Estabilidad atmosférica. Cuanto más estable la atmósfera, más dificultad tendrá la masa de aire en ascender. El perfil vertical de estabilidad depende de la densidad del aire que, a su vez, depende de las distribuciones verticales de temperatura y humedad.

3. Contenido de humedad. La humedad es ingrediente básico en los procesos de condensación y su contenido en la atmósfera es relevante.

La caracterización sinóptica de Ribalaygua y Borén (1995) con Z500 y MSLP es tradicional y sencilla y, aunque no informa directamente sobre temperatura y humedad, parámetros importantes en los procesos de precipitación, sí que pueden inferirse cualitativamente algunos aspectos:

1. Los flujos de procedencia marina contienen mucha humedad.

2. En vaguadas y borrascas las temperaturas en niveles medios tienden a ser relativamente bajas, pudiéndose inferir muy poca estabilidad.

3. En el interior peninsular en grupos con baja térmica las temperaturas en superficie son siempre elevadas, pudiéndose inferir de nuevo muy poca estabilidad. 


\section{RECUPERACIÓN DE LA CLASIFICACIÓN DE FONT $(2000,1983)$}

\subsection{Técnica de presentación visual}

Para enriquecer la visualización y recuperar el trabajo de Font $(2000,1983)$ se han utilizado datos del reanálisis ERA40 del European Centre for Medium-range Weather Forecasts, ECMWF (Uppala et al., 2005) correspondientes a las 23 fechas o 23 tipos de Font. Se han reconstruido los mapas mediante la aplicación metview, específica del ECMWF para procesado y visualización de datos meteorológicos, siguiendo las pautas actuales (2018) de la intranet de AEMET, página del Área de Técnicas y Aplicaciones de Predicción (ATAP) de Visualización de Información Meteorológica (VIM), creación original de FELICIANO JIMÉNEZ, anteriormente Meteorólogo del ATAP. Como ejemplo, en la figura 6 se muestra uno de los casos de Font con la reproducción original de los mapas delineados (querer de la mano, figura 6.a) y la reconstrucción actual con los datos de ERA40 (querer de la máquina, figura 6.b). Se trata, en este caso, del 27 de febrero de 1975, situación tipo 11 de Font "Anticiclón centroeuropeo" con indicativo IMi, con mayor frecuencia en diciembre, enero y febrero. Podemos anticipar que, en primer lugar, el parecido entre el mapa manual y el automático es notable, como no podía ser de otra manera, subrayando así la grandísima capacidad profesional de los analistas y delineantes de la época. Podemos resaltar, además, algunos aspectos diferenciales. Para empezar, en los mapas manuales se dibujaban frentes mientras que en el automático hemos dibujado estructuras nubosas. Es también notable lo bien perfilados que estaban los frentes, no disponiendo en la época de imágenes de satélite, aunque en algunos patrones están mejor perfilados que en otros. Por otro lado, puede percibirse en el ploteo automático que se presentan algunas estructuras de menor escala que en el ploteo manual no aparecían, como por ejemplo un pequeño centro de baja presión en Argelia. Esta característica, en principio deseable por resaltar características mesoescalares, adolece sin embargo de cierta sensibilidad a los detalles del algoritmo de ploteo: por ejemplo, si ploteamos la presión cada $1 \mathrm{hPa}$ aparecen más estructuras, o estructuras diferentes, que si ploteamos cada 2 o cada $4 \mathrm{hPa}$; asimismo, el algoritmo de interpolación puede influir, a veces críticamente, en estas estructuras emergentes de menor escala. 

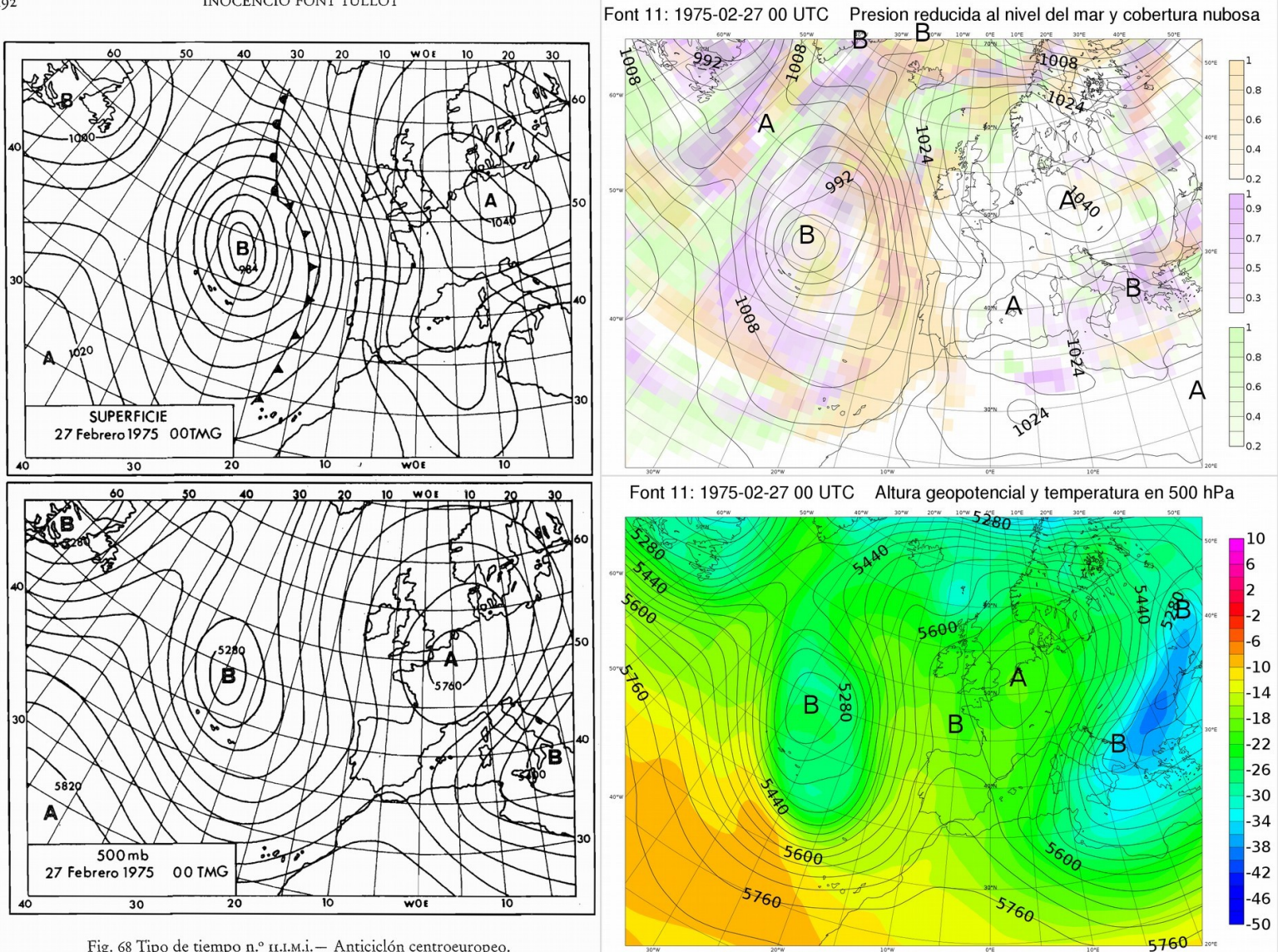

Fig. 68 Tipo de tiempo n.o urimi-Anticiclón centroeuropeo.

Figura 6: Situación del 27 de febrero de 1975 tipo 11 de Font "Anticiclón centroeuropeo", contrastando: a) la reproducción original de los mapas delineados (Font, 2000, 1983) y b) la reconstrucción actual con los datos de ERA40 y la aplicación metview.

\subsection{Los 23 patrones de Font $(2000,1983)$}

En el anexo A se presentan de modo completo los 23 patrones de Font $(2000,1983)$ tanto en su visualización original como con las técnicas modernas ya descritas, acompañados de texto detallado, de modo que se recupera y enriquece la clasificación original. Puede encontrarse la descripción original de los 23 patrones, tipos o situaciones meteorológicas en Font (2000, 1983). Para cada patrón se muestra la presentación original de Font junto con la visualización moderna basada en ERA40. Son complementarias, pues la de Font incluye frentes y la moderna estructuras nubosas coloreadas, así como temperaturas coloreadas en niveles medio-altos. Así mismo, se incluye el texto de Font $(2000,1983)$ detallado para cada patrón, intentando mantenerlo fiel al original, pero introduciendo algunas modificaciones mínimas. Por ejemplo, se intercala el término "DANA" para matizar términos no aconsejados como "gota fría", o el término "episodio de calor" para matizar el de "ola de calor" que, a día de hoy, tiene un significado más preciso que entonces.

En total, se incluyen los siguientes elementos:

- Mapa de Font en superficie: presión reducida al nivel del mar (isobaras) y frentes.

- Mapa de Font en altura: altura geopotencial (isohipsas).

- Mapa ERA40 en superficie: presión reducida al nivel del mar (isobaras) y cobertura nubosa (altas en rosa, medias en azul y bajas en verde).

- Mapa ERA40 en altura: altura geopotencial (isohipsas) y temperatura (color) en 500 $\mathrm{hPa}$. 
- Número, nombre Font e indicativo Font (ver tabla \{FACTORES FONT\}).

- Masas de aire predominantes

- Meses de presencia (predominantes y, si procede, más frecuentes).

- Descripción meteorológica en altura (500).

- Descripción meteorológica en superficie (SFC).

- Duración: duración aproximada.

- Tiempo sensible en lo referente a temperaturas.

- Tiempo sensible en términos de precipitaciones.

A modo de panorámica, en la figura 7 se presentan mosaicos con los 23 patrones de Font, en su versión original (7.a) y con la visualización actual (7.b).
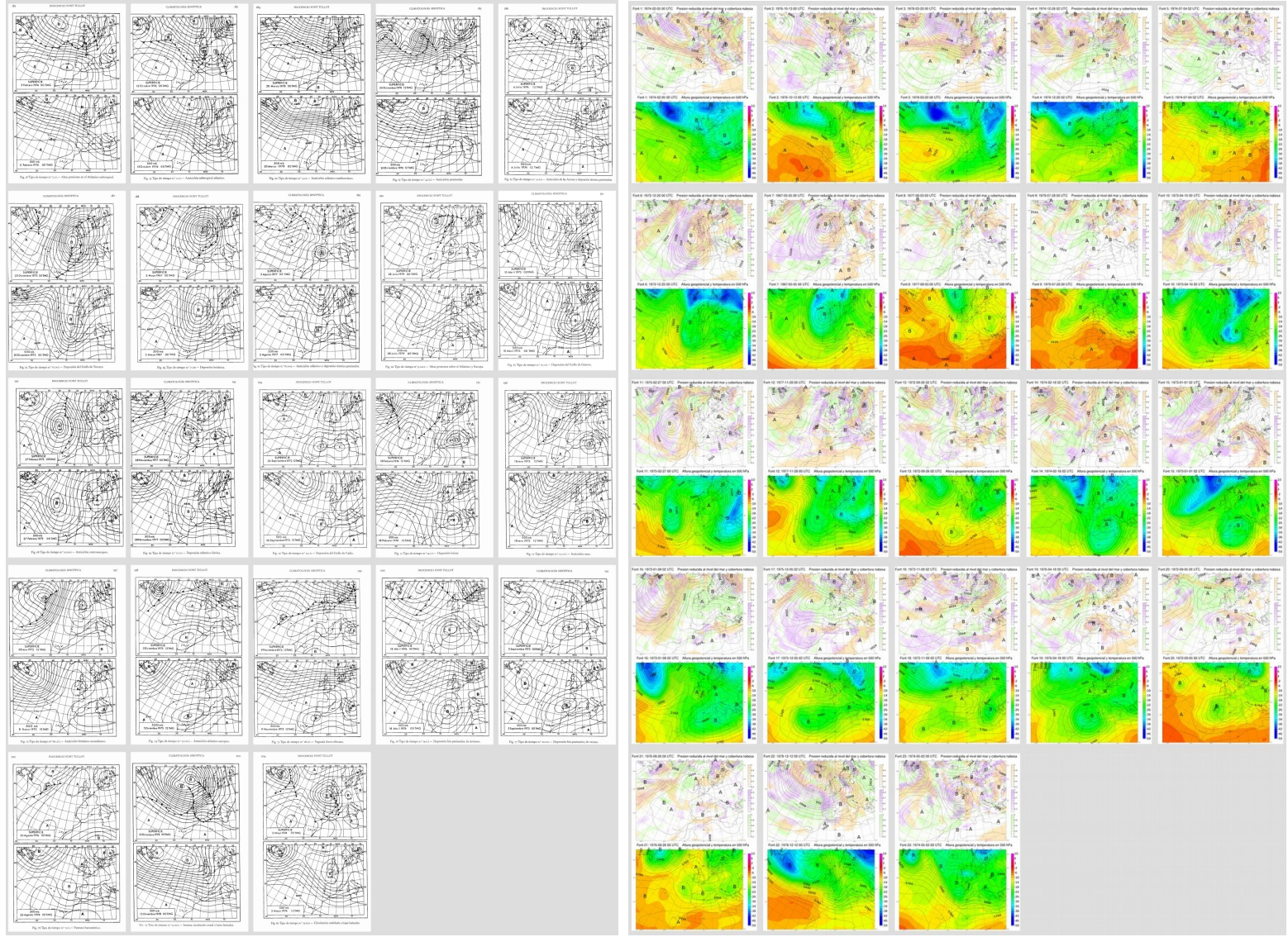

Figura 7: Los 23 patrones de Font. a) Reproducción original de los mapas delineados. b) Reconstrucción actual con los datos de ERA40 y la aplicación metview.

\section{CONCLUSIONES}

Las llamadas clasificaciones sinópticas ayudan a entender los fenómenos meteorológicos en esa escala sinóptica mediante patrones tipo. En la actualidad, sería conveniente una convergencia entre las clasificaciones objetivas (se muestra la de Ribalaygua y Borén, 1995, como ejemplo tradicional en AEMET, que no moderno), basadas en modelos numéricos y algoritmos de agrupamiento y las clasificaciones subjetivas, basadas en modelos conceptuales (se muestra la de Font, 2000, 1983, como ejemplo ampliamente conocido). En este estudio se recupera la clasificación de Font, utilizando datos del reanálisis ERA40 del 
ECMWF correspondientes a los 23 patrones de Font y ploteándolos con técnicas y pautas modernas de visualización de campos para su uso en predicción operativa. En Tveito et al (2011) puede encontrarse una exposición exhaustiva y comparativa de distintas clasificaciones de tipos de tiempo sobre Europa, así como aplicaciones de las mismas y formas de evaluarlas.

Este estudio, como punto de partida, plantea un abanico de líneas de investigación y aplicación. (1) La recuperación de conocimiento que supone el enriquecimiento visual de la clasificación de Font, así como la convergencia de enfoques (objetivo-subjetivo) encuentran aplicación directa en formación, divulgación y comunicación meteorológica, por lo que se sugiere su inclusión en cursos y su publicación en la web de AEMET. (2) La consistencia entre ambos enfoques (objetivo y subjetivo) puede explorarse ahora con mayor profundidad. (3) La aplicación de otras técnicas y parámetros de agrupamiento puede arrojar evidencias de las que sacar partido. (4) Se contribuye así a entender mejor la naturaleza de la variabilidad y diversidad de estos patrones meteorológicos.

\section{AGRADECIMIENTOS}

Las figuras y textos de los 23 patrones de Font, así como alguna figura adicional, corresponden a Font (2000, 1983), editado por Ediciones Universidad de Salamanca (EUSAL). Este material ha sido integrado en este trabajo por el enorme interés de ofrecer al lector una visión lo más completa y autodefinida posible dentro del marco de esta publicación y con permiso expreso de EUSAL. Agradecemos a José Luis de las Heras Santos y Modesto Antonio Sánchez Sacristán la amabilidad y diligencia para los trámites correspondientes.

El personal de Reprografía y de la Biblioteca de AEMET ayudó enormemente con el material gráfico y tramitación interna de la publicación, por lo que estamos en deuda con todos ellos.

Así mismo, valoramos enormemente la revisión del estudio realizada por Ernesto Rodríguez Camino, Jefe del Área de Modelización y Evaluación del Clima de AEMET, así como Olinda Carretero Porrís, Benito Elvira Montejo y Francisco Javier Díaz Bárcena, del Área de Predicción Operativa de AEMET.

\section{REFERENCIAS}

Borén Iglesias, R., Ribalaygua Batalla, J. y Balairón Ruíz, L., 1995. Método analógico de simulación de escenarios climáticos a escala comarcal. Informe Nº 4 del Servicio de Análisis e Investigación del Clima, INM, Madrid.

Calvo, J. 1993. Clasificación de flujos en 500 hPa sobre la península ibérica. Nota técnica $\mathrm{N}^{\mathrm{o}} 32$ del Servicio de Predicción Numérica, INM.

Casado et al., 2011. Evaluación de los modelos AR4 del IPCC sobre la P. Ibérica y su región EuroAtlántica. AEMET. http://hdl.handle.net/20.500.11765/3123.

Casado, M.J. and Pastor, M.A., 2012. Use of variability modes to evaluate AR4 climate models over the Euro-Atlantic region. Climate dynamics, 38(1-2), pp.225-237.

Fernández García, A. D. J., Martín Vide, J., Díaz Pérez, Y. A. y Mestre Barceló, A., 2003. Aplicación de los procesos sinópticos objetivos a la península ibérica en otoño. Investigaciones Geográficas (Esp), (31).

Ferranti, L. y Corti, S., 2011. New clustering products. ECMWF Newsletter, 127(6-11), 1-2.

Font-Tullot, I., 2000. Climatología de España y Portugal (Vol. 76). Universidad de Salamanca.

Font-Tullot, I., 1983. Climatología de España y Portugal. Instituto Nacionalde Meteorología, 1983. Madrid. 
Gutiérrez, J.M., Cofiño, A.S., Cano, R. y Rodríguez, M.A., 2004. Clustering methods for statistical downscaling in short-range weather forecasts. Monthly Weather Review, 132(9), pp.2169-2183.

Hartigan, J. A., 1975. Clustering algorithms (Vol. 209). John Wiley and Sons. New York.

Holton, J. R. y Hakim, G. J., 2012. An introduction to dynamic meteorology (Vol. 88). Academic press.

Jolliffe, I. T., 1986. Principal Component Analysis and Factor Analysis. In Principal component analysis (pp. 115-128). Springer, New York.

Jollife I. T. y Cadima J., 2016. Principal Component Analysis: a review and recent developments. Philos Trans A Math Phys Eng Sci.

Kalnay, E., Kanamitsu, M., Kistler, R., Collins, W., Deaven, D., Gandin, L., Iredell, M., Saha, S., White, G., Woollen, J. and Zhu, Y., 1996. The NCEP/NCAR 40-year reanalysis project. Bulletin of the American meteorological Society, 77(3), pp.437-472.

Linés, A., 1981. Perturbaciones típicas que afectan a la península ibérica y precipitaciones asociadas. INM, serie A, No 80 , Madrid.

Mass, C. F., Edmon, H. J., Friedman, H. J., Cheney, N. R. y Recker, E. E., 1987. The use of compact discs for the storage of large meteorological and oceanographic data sets. Bulletin of the American Meteorological Society, 68(2), 1556-1558.

Peña, J. C., Aran, M., Pérez Zanón, N., Casas Castillo, M., Rodríguez Solá, R. y Redaño Xipell, A., 2015. Análisis de las situaciones sinópticas correspondientes a episodios de lluvia severa en Barcelona. En XXXV Reunión Bienal de la Real Sociedad Española de Física. Libro de Resúmenes (pp. 450-451). Real Sociedad Española de Física (RSEF).

Persson, A., 2001. User Guide to ECMWF forecast products. ECMWF.

Petisco, E. y Martın, J. M., 1995. Caracterización de la circulación general atmosférica en la Península Ibérica y Baleares (Characterization of the atmospheric general circulation in the Iberian Peninsula and Balearic Islands). Service of Analysis and Research of Climate, Instituto Nacional de Meteorología, Tech. Service of Analysis and Research of Climate, Tech. Note 5.

Ribalaygua Batalla, J. y Borén Iglesias, R., 1995. Clasificación de patrones espaciales de precipitación diaria sobre la España peninsular y Baleárica. Informe $\mathrm{N}^{\mathrm{o}} 3$ del Servicio de Análisis e Investigación del Clima. INM. Madrid.

Ribalaygua Batalla, J., Borén Iglesias, R. y Balairón Ruíz, L., 1999. Clasificación de repartos de precipitación diaria sobre la España peninsular y baleárica: aplicación para la generación de clasificaciones atmosféricas de apoyo a la predicción de precipitaciones. Informe $n^{\circ} 4$. Servicio de Análisis e Investigación del Clima. INM. Madrid.

Rodríguez, A., 2014. Nuevas técnicas de agrupamiento de predicciones por conjuntos del ECMWF aplicadas a campos de superficie. Nota Técnica $n^{\circ} 1$. Área de Innovación. AEMET. Madrid.

Romero, R., Ramis, C. y Guijarro, J.A., 1999. Daily rainfall patterns in the Spanish Mediterranean area: an objective classification. International Journal of Climatology: A Journal of the Royal Meteorological Society, 19(1), pp.95-112.

Sánchez Rodríguez, J., 1993. Situaciones atmosféricas en España. INM. Madrid.

Santos y col., 2018. Física del caos en la predicción meteorológica. AEMET. Madrid.

Soriano Ortiz, C., Fernández, A. G. y Martín Vide, J., 2003. Sobre el uso de los procesos sinópticos objetivos y los modelos meteorológicos a alta resolución para el estudio de los patrones circulatorios a escala regional. Departament de Matemàtiques, Reports de recerca. Universitat Politècnica de Catalunya.

Strahler, A. y Strahler, A., 2007. Physical geography. John Wiley \& Sons.

Subías A., y Roa. A., 2018. Adaptación de la nueva técnica de clusters de ECMWF en AEMET. Sexto Simposio Nacional de Predicción. AEMET. 
Tveito, O.E., Huth, R., Beck, C., Demuzere, M., Esteban, P., Pasqui, M., Philipp, A. and Post, P., 2011. COST733-Harmonisation and Applications of Weather Types Classifications for European Regions. In European Conference on Applied Climatology/European Meteorological Services (EMS/ECAC) 2011, Berlin. http://cost733.met.no/ y http://cost733.geo.uni-augsburg.de/cost733wiki.

Uppala, S. M., Kållberg, P. W., Simmons, A. J., Andrae, U., Bechtold, V. D., Fiorino, M., Li, X. y coautores, 2005. The ERA $\square 40$ re $\square$ analysis. Quarterly Journal of the royal meteorological society, 131(612), 2961-3012. 


\section{ANEXO A: LOS 23 PATRONES FONT}
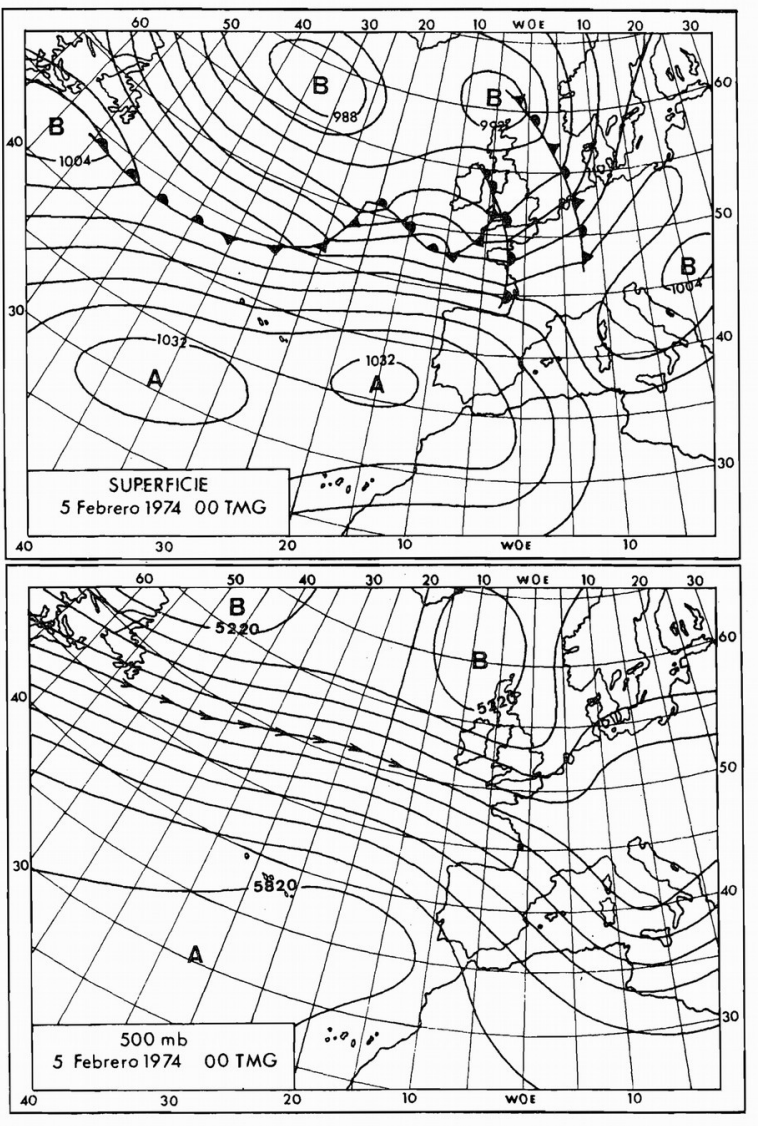

Fig. 58 Tipo de tiempo n. …r.z. - Altas presiones en el Atlántico subtropical

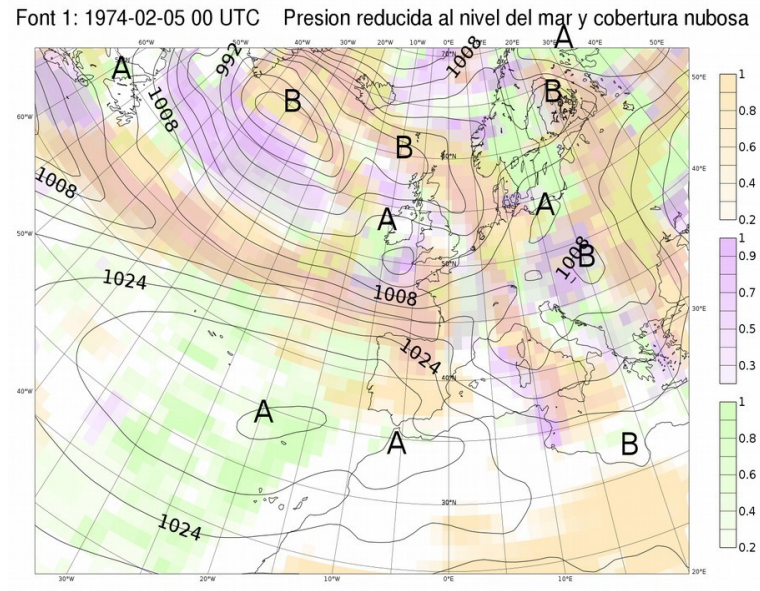

Font 1: 1974-02-05 00 UTC Altura geopotencial y temperatura en $500 \mathrm{hPa}$

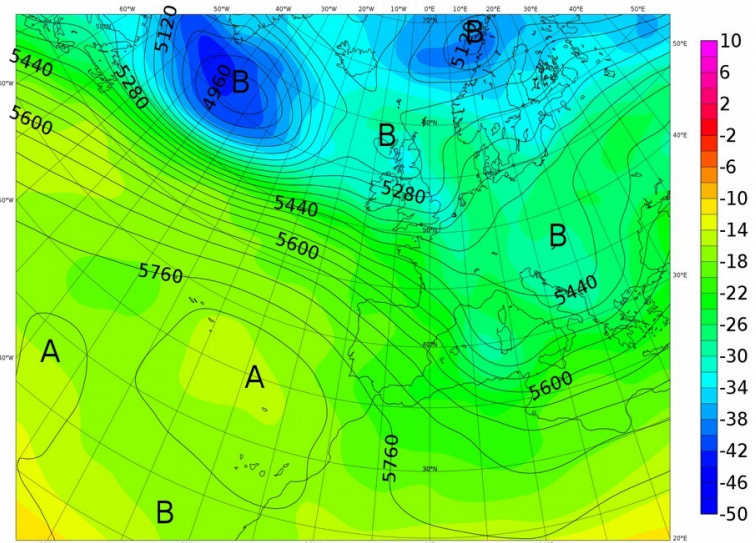

Tipo 1. IZ Altas presiones en el Atlántico subtropical

Las altas presiones subtropicales, alargadas en la dirección de los paralelos y centradas al sur de las Azores, alcanzan la Península, mientras a $500 \mathrm{hPa}$ la circulación general del oeste es intensa y persistente centrándose alrededor del paralelo $50^{\circ} \mathrm{N}$ la zona de vientos máximos (figura).

Generalmente se mantiene durante más de 5 días, siendo relativamente frecuente que sobrepase los 15 . Puede tener lugar en cualquier mes del año aunque raramente hace acto de presencia en el trimestre estival. Su máxima frecuencia se da de diciembre a marzo.

La procesión de depresiones atlánticas, alternando con cuñas anticiclonicas, en rápida sucesión, da lugar a que la "imagen bárica" de los mapas de superficie cambie notablemente de un día a otro. No obstante, las trayectorias de los centros depresionarios (borrascas) pasan claramente al norte de la Península, por lo que solo es afectada en su área septentrional por los sistemas de frentes asociados a estas depresiones, con una gran preponderancia de los fríos a los cálidos. Ocasionalmente y sobre todo al final del periodo de duración del tipo, cuando las trayectorias de las borrascas son más meridionales, los frentes pueden afectar a toda la Península, salvo en la vertiente mediterránea.

La masa de aire predominante es la $\mathrm{mT}$ (sub) alternando con la $\mathrm{mP}$ aunque muy suavizada, por lo que las temperaturas se mantienen suaves. Ocasionalmente va seguido de una irrupción de aire $\mathrm{mA}$ o $\mathrm{mP}$.

Las lluvias más importantes quedan generalmente limitadas a la región cantábrica y al noroeste de la Península, aunque en el resto de la vertiente atlántica puede haber chubascos intensos durante el paso de los frentes fríos. En verano la presencia de este tipo da lugar a periodos anormalmente frescos y se dejan sentir sobre todo en la mitad norte. 

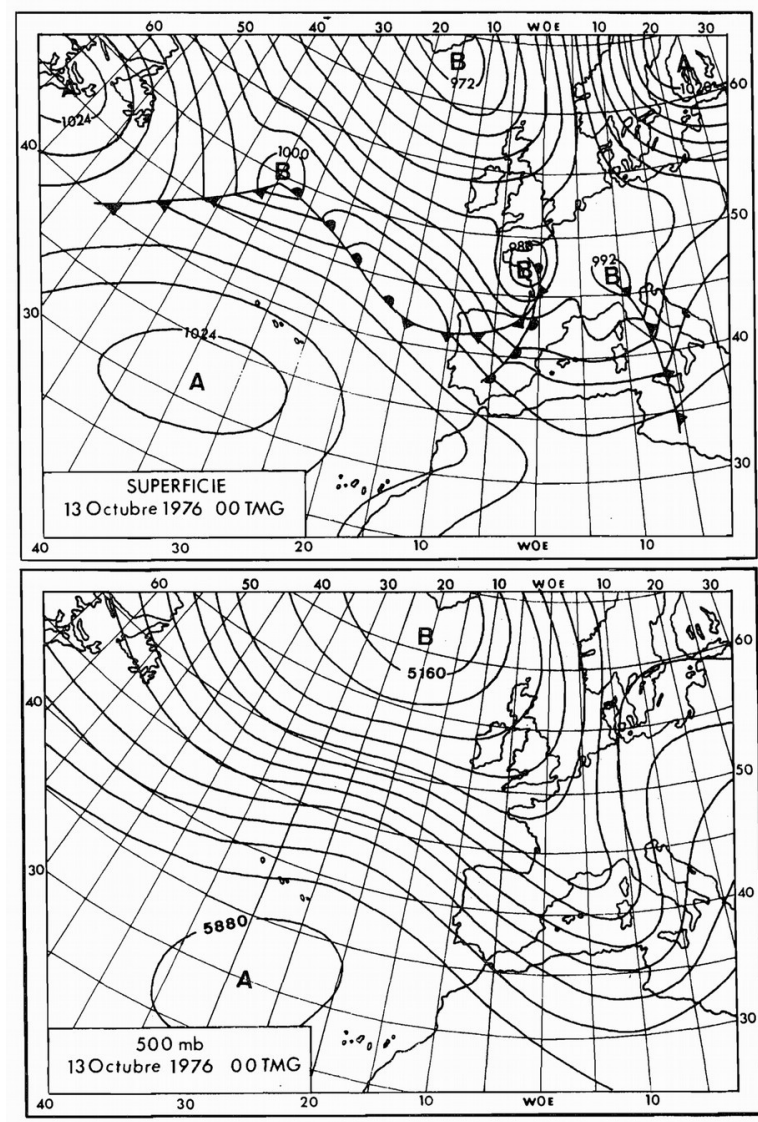

Fig. 59 Tipo de tiempo n. ${ }^{\circ}$ 2.1.z. - Anticiclón subtropical atlántico.

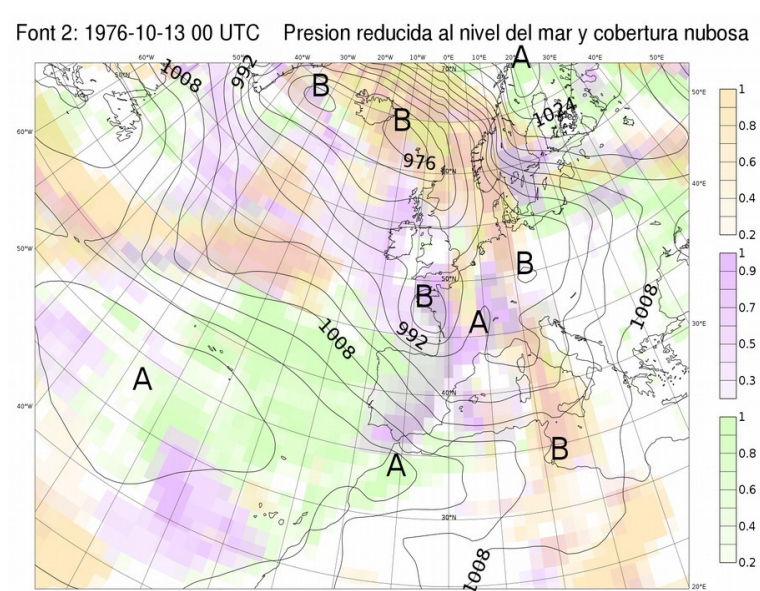

Font 2: 1976-10-13 00 UTC Altura geopotencial y temperatura en $500 \mathrm{hPa}$

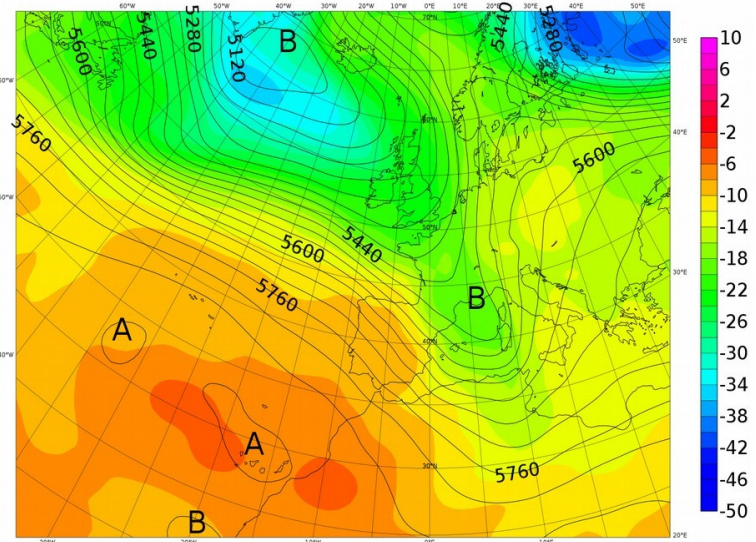

\section{Tipo 2. IZ Anticiclón subtropical atlántico}

Se distingue del tipo 1 en el alejamiento hacia el oeste de la Península de las altas presiones subtropicales, formando un claro centro anticiclónico al suroeste de las Azores. A $500 \mathrm{hPa}$ la situación se distingue del tipo 1 por una bien marcada vaguada que se extiende desde la región de Islandia hacia el Mediterráneo occidental (figura).

$\mathrm{Su}$ duración y frecuencia son similares a los del tipo 1, aunque con cierta preferencia por el mes de marzo.

El sentido de las trayectorias de las borrascas es hacia el sureste y aunque crucen Europa al norte de los Pirineos, los sistemas frontales que las acompañan suelen barrer la mayor parte de la Península.

La masa de aire $\mathrm{mP}$ es la predominante, y aun estando muy suavizada por su largo recorrido sobre el océano, su presencia da lugar a un descenso de la temperatura.

El mal tiempo, con abundantes precipitaciones, suele afectar a toda la Península, e incluso excepcionalmente al sudeste. En invierno puede dar lugar a copiosas nevadas en las zonas montañosas. Ocasionalmente, ha sido responsable de veranos relativamente lluviosos, como así fue en el año 1971. 

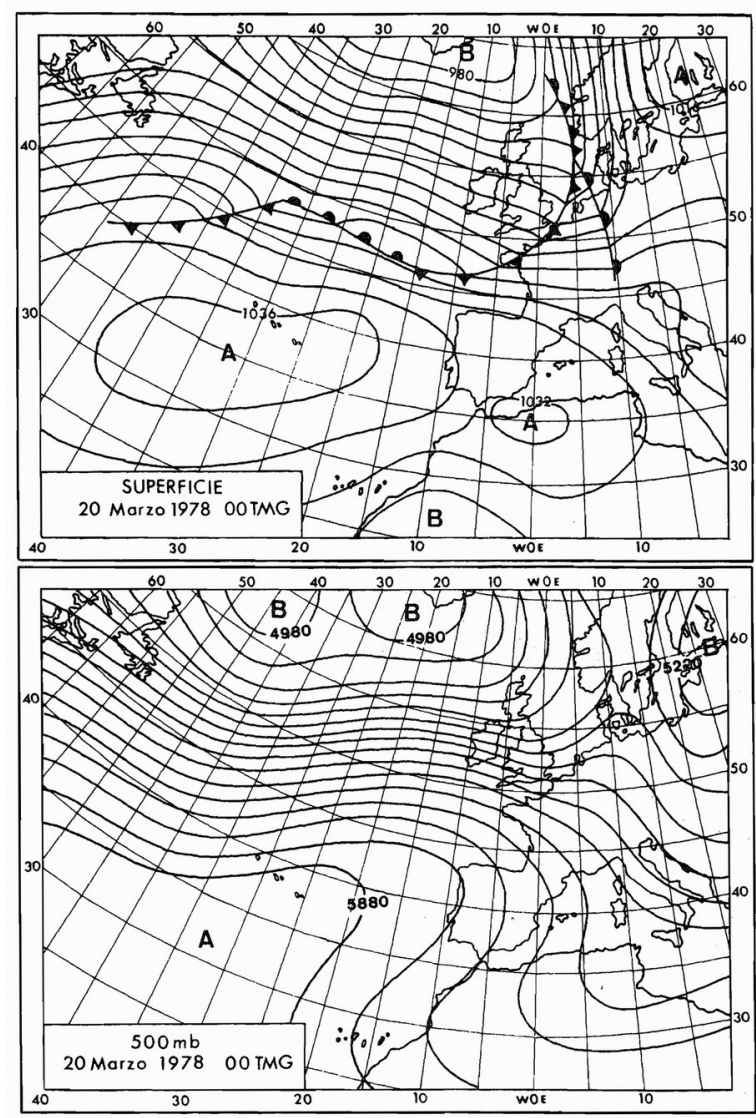

Fig. 60 Tipo de tiempo n. ${ }^{0}$ 3.I.z. - Anticiclón atlántico-mediterráneo.

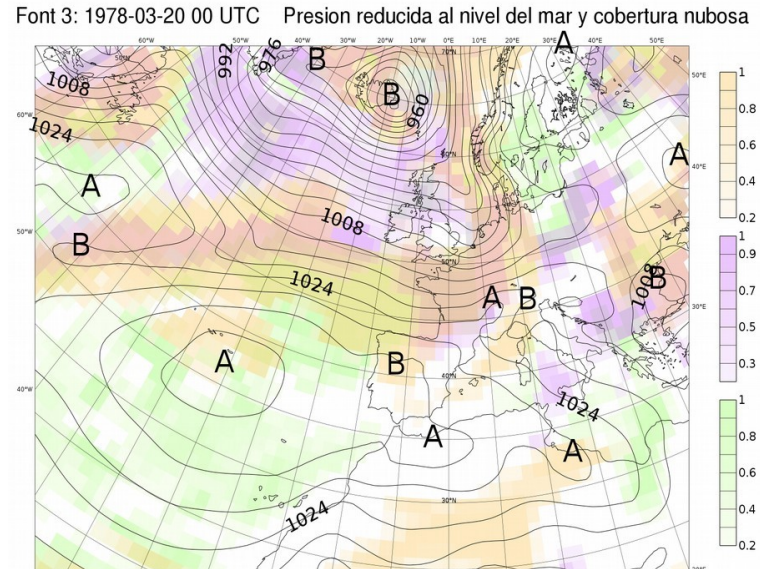

Font 3: 1978-03-20 00 UTC Altura geopotencial y temperatura en $500 \mathrm{hPa}$

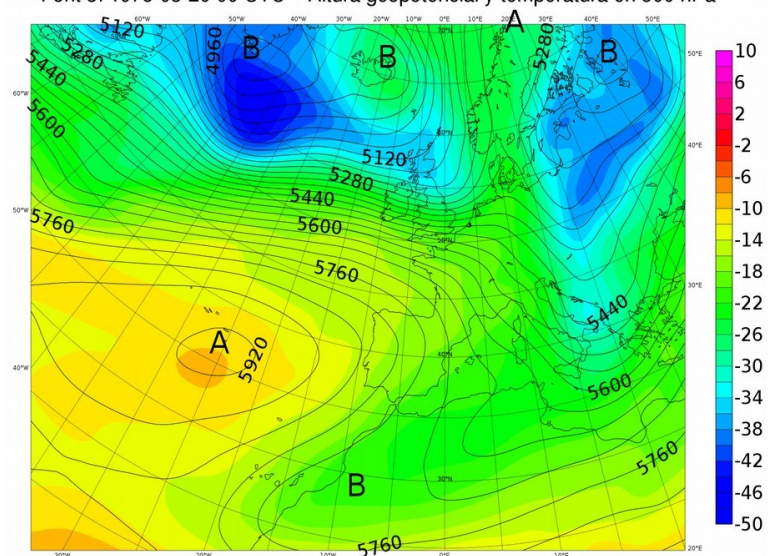

\section{Tipo 3. IZ Anticiclón atlántico-mediterráneo}

El anticiclón Atlántico, centrado al suroeste de las Azores, se extiende en forma de cuña hasta el Mediterráneo occidental, dando lugar a un flujo suave del noroeste sobre la Península o al predominio de las calmas como en el ejemplo de la figura.

En la mayoría de los casos tiene una duración de 5 a 10 días aunque, con relativa frecuencia, llega a alcanzar e incluso a superar los 30 días. Puede presentarse en cualquier estación del año salvo en verano, cuando es sustituido por el tipo 5. Su máxima frecuencia tiene lugar al final del invierno y en primavera.

La presencia de la masa $\mathrm{mT}$ (sub) es característica. Las temperaturas son suaves aunque con importantes oscilaciones diurnas en caso de calmas o vientos débiles.

Suele predominar el buen tiempo, aunque ocasionalmente se produzcan lloviznas o lluvias, generalmente débiles, en la periferia norte. En aquellas situaciones en que el anticiclón no se extiende tanto hacia el este, las perturbaciones mediterráneas pueden afectar a Cataluña y Levante. Cuando la corriente de oeste sobre la Península está bien definida el efecto catabático da lugar a notables subidas de temperatura en el litoral levantino. 

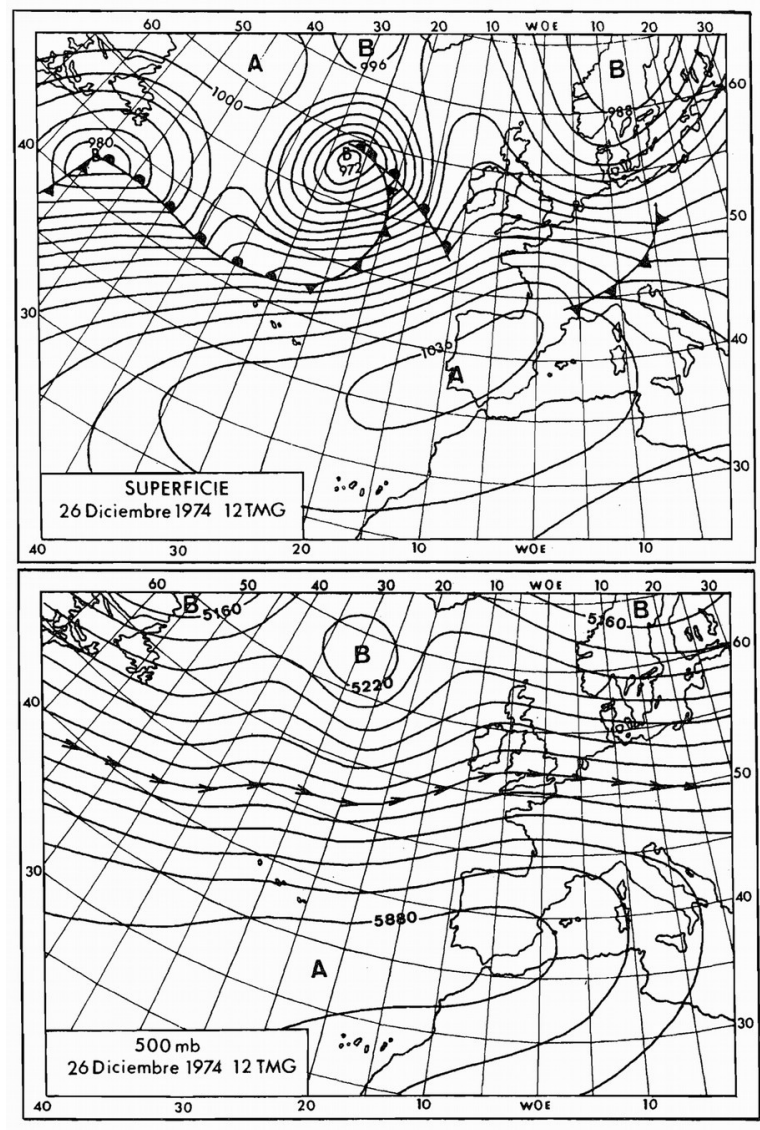

Fig. 61 Tipo de tiempo n. ${ }^{\circ}$ 4.r.z.i. - Anticiclón peninsular.

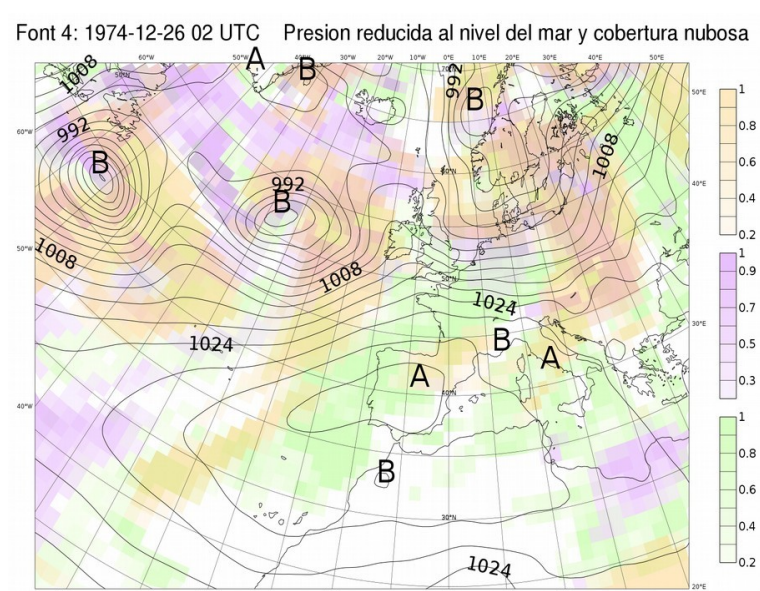

Font 4: 1974-12-26 02 UTC Altura geopotencial y temperatura en $500 \mathrm{hPa}$

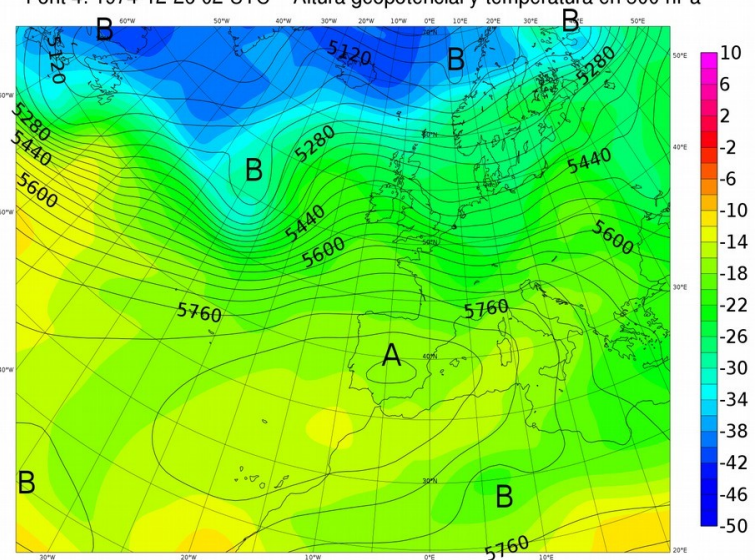

\section{Tipo 4. IZi Anticiclón peninsular}

El anticiclón subtropical, desplazado hacia el este, muestra una clara preferencia a centrarse sobre la Península (figura). En los periodos más largos de permanencia de este anticiclón pueden observarse debilitamiento y reforzamientos alternativos así como desplazamientos irregulares y aparentemente caprichosos de su centro. El que esto también se muestre claramente en altura demuestra la naturaleza dinámica del anticiclón, aunque el enfriamiento en la Península debe constituir un factor importante en su comportamiento.

Normalmente se mantiene durante unos 5 días, aunque su duración máxima puede superar los 30. Este tipo, esencialmente invernal, tiene su máxima frecuencia en enero y diciembre, aunque también puede presentarse en febrero, marzo y noviembre.

La masa de aire, originalmente $\mathrm{mT}$ (sub) experimenta un paulatino enfriamiento en el interior de la Península, hasta el punto de transformarse, en los casos de mayor permanencia, en una masa de aire relativamente fría y seca.

Buen tiempo en toda la Península, con amplias oscilaciones diurnas de la temperatura y frecuentes heladas en el interior, así como formación de nieblas continentales sobre todo en la meseta Norte y altas concentraciones de contaminantes en los centros industriales y urbanos. Ocasionalmente, ligeras precipitaciones en la periferia norte. 

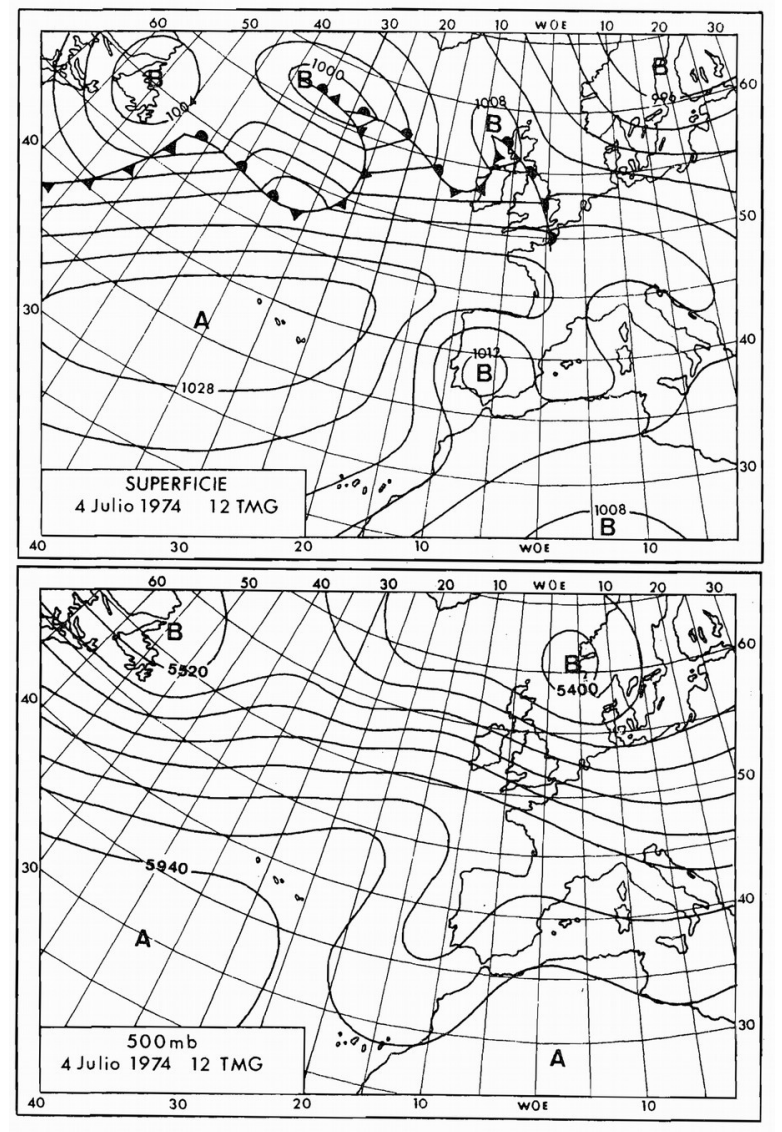

Fig. 62 Tipo de tiempo n. ${ }^{\circ}$ s.r.z.e. - Anticiclón de las Azores y depresión térmica peninsular.

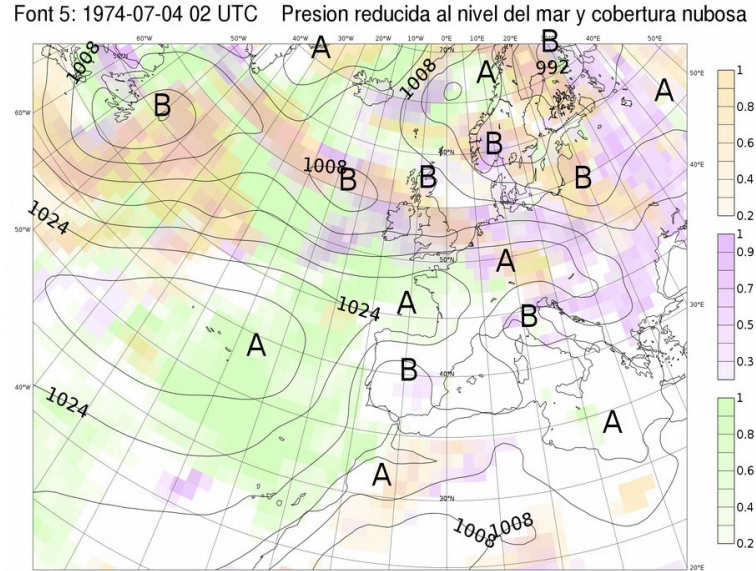

Font 5: 1974-07-04 02 UTC Altura geopotencial y temperatura en $500 \mathrm{hPa}$

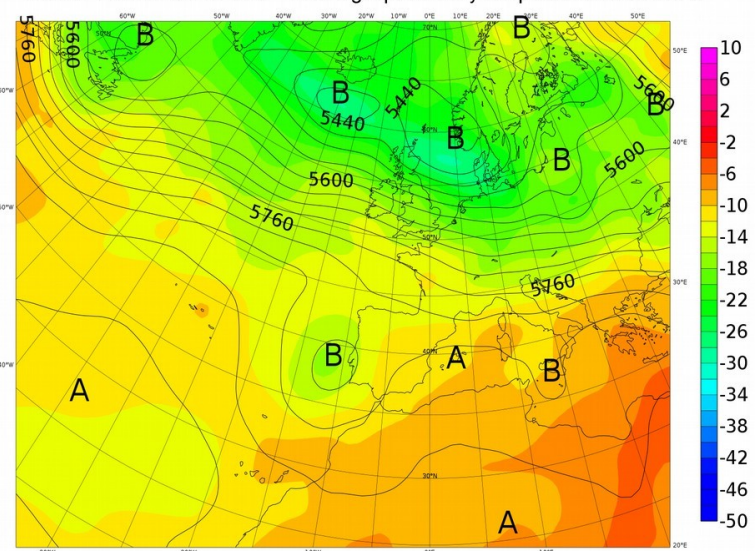

\section{Tipo 5. IZe Anticiclón de las Azores y depresión térmica peninsular}

En el mapa de superficie la depresión térmica, centrada generalmente sobre la meseta Sur, constituye la característica más sobresaliente de este tipo. Cuando la circulación en el margen oriental del anticiclón de las Azores es muy intensa, la baja no se desarrolla o queda reducida a una vaguada. En altura se distingue una vaguada cuyo eje se orienta de NW a SW tal como se ve en el ejemplo de la figura, vaguada a la que corresponde un flujo superior del SW sobre una gran parte de la Península, que sustituye al del NW característico de los tipos 1 y 2. Esta torsión de la circulación zonal es producida por el extenso anticiclón térmico superior que en verano se desarrolla sobre África como respuesta a la depresión térmica sahariana.

Estas situaciones suelen ser muy persistentes, no siendo raro que duren más de 2 semanas. Pueden presentarse desde finales de mayo hasta últimos de septiembre, aunque sean julio y agosto los meses en que son más frecuentes. En ellas entran en juego dos masas de aire muy distintas: (1) la mT (sub) sometida a la circulación en torno del anticiclón de las Azores pero que, a causa de los sistemas orográficos del N y NW de la Península, se ve obligada a contornearla, por lo que solo las periferias cantábrica y atlántica occidental quedan bajo sus influencias. En la periferia cantábrica el factor orográfico de lugar a precipitaciones débiles que ocasionalmente son muy persistentes, mientras que en la periferia occidental la constancia de los vientos templados del $\mathrm{N}$ constituye la característica principal. (2) la cT africana-peninsular que afecta al resto de la Península y que en las situaciones más persistentes se transforma en una masa autóctona. Frecuentemente, en aquellas situaciones en que la vaguada superior aparece desplazada hacia el este, el aire frío sobre la Península a niveles altos crea la inestabilidad necesaria para que se desarrollen las típicas tormentas de verano, principalmente al final de la tarde y primeras horas de la noche y en cuya localización la orografía y la naturaleza del suelo son factores determinantes. La baja térmica da lugar a que en la periferia suroriental sople el levante. Las "olas de calor" (episodios de calor), bajo estas situaciones, son frecuentes sobre todo en el cuadrante suroriental de la Península. 

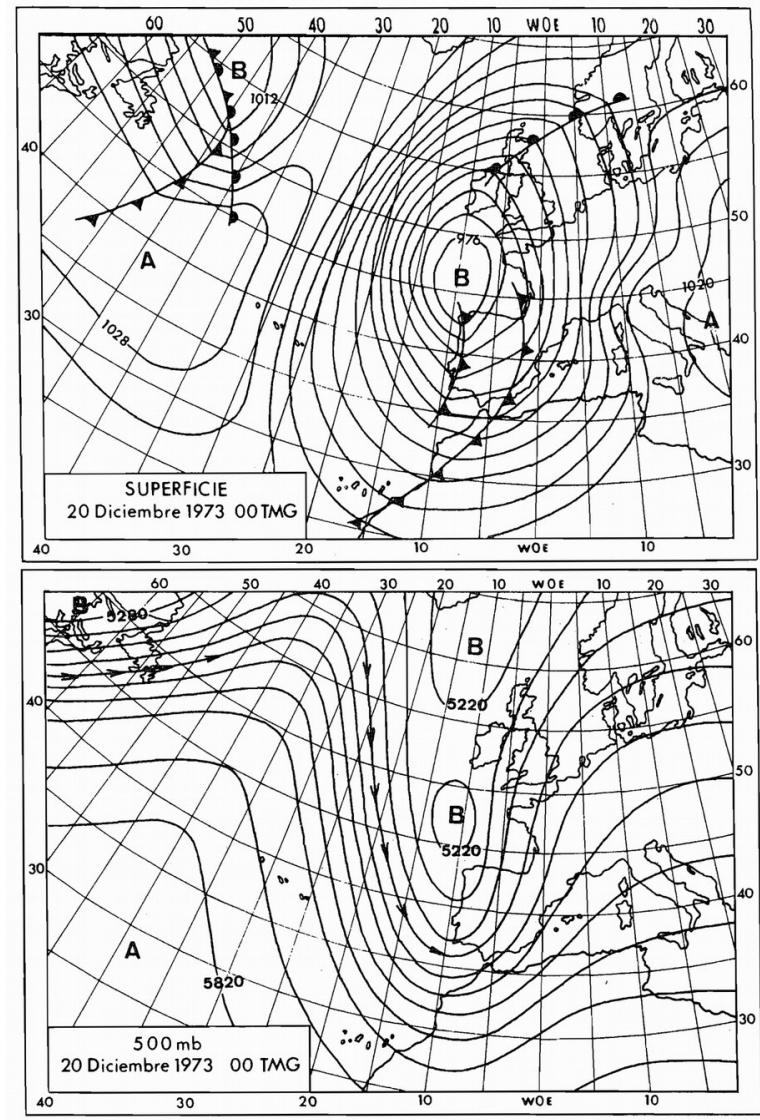

Fig. 63 Tipo de tiempo n. ${ }^{\circ}$ 6.r.m.i. - Depresión del Golfo de Vizcaya.

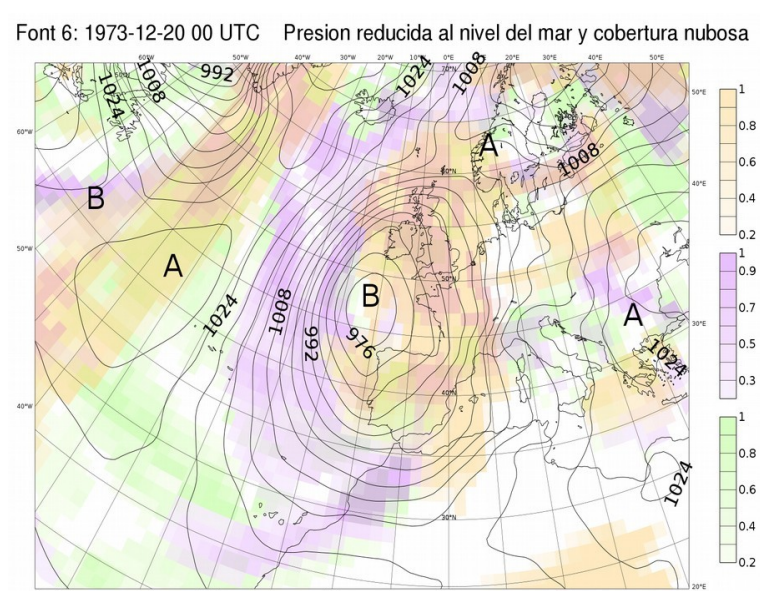

Font 6: 1973-12-20 00 UTC Altura geopotencial y temperatura en $500 \mathrm{hPa}$

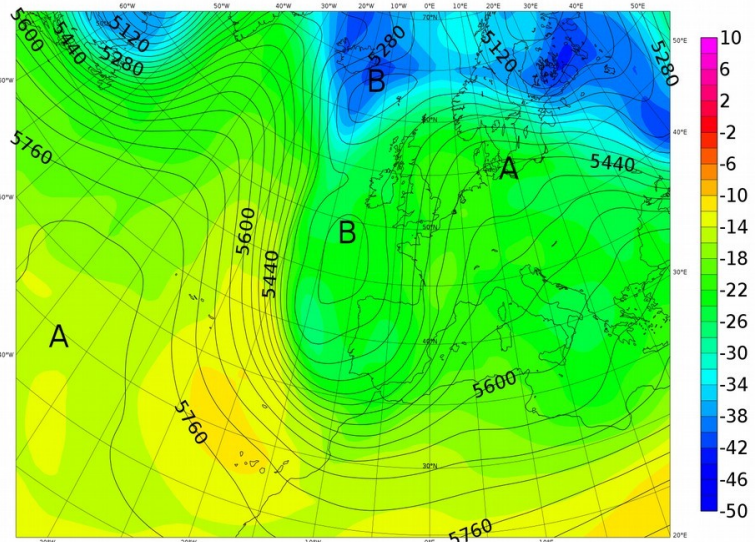

\section{Tipo 6. IMi Depresión del golfo de Vizcaya}

Las extensas y profundas depresiones atlánticas características de este tipo tienen su centro al norte o noroeste de la Península, pero por debajo del paralelo $50^{\circ}$, manifestándose en altura por extensos meandros con sus ejes orientados de norte a sur, a longitudes alrededor de los $10^{\circ} \mathrm{W}$ como se ve claramente en la figura.

Su duración es de 3 a 6 días y no es muy frecuente, quedando su presencia prácticamente limitada al invierno y principio de la primavera.

A su comienzo, la Península es invadida por la masa de aire $\mathrm{mT}$, a veces de origen netamente tropical, a la que suceden la $\mathrm{mP}$ o la $\mathrm{mA}$, después del paso del frente frío, el que marca un cambio radical en el carácter del tiempo. Antes del paso del frente los vientos cálidos y húmedos del suroeste dan origen a importantes precipitaciones sobre toda la mitad sur de la Península y en los Pirineos, siendo esta situación responsable de algunos de los temporales de lluvia más fuertes de la depresión del Guadalquivir y de los Pirineos oscenses y leridanos. En la mitad norte las precipitaciones son aminoradas a sotavento de las cordilleras e incluso anuladas en la cornisa cantábrica, donde el efecto Foehn da lugar a que la temperatura alcance ocasionalmente valores estivales. Después del paso del frente, es la mitad norte la que registra el peor tiempo, frío y revuelto, con fuerte actividad convectiva. Ocasionalmente se producen "olas de frío" (episodios de frío). 

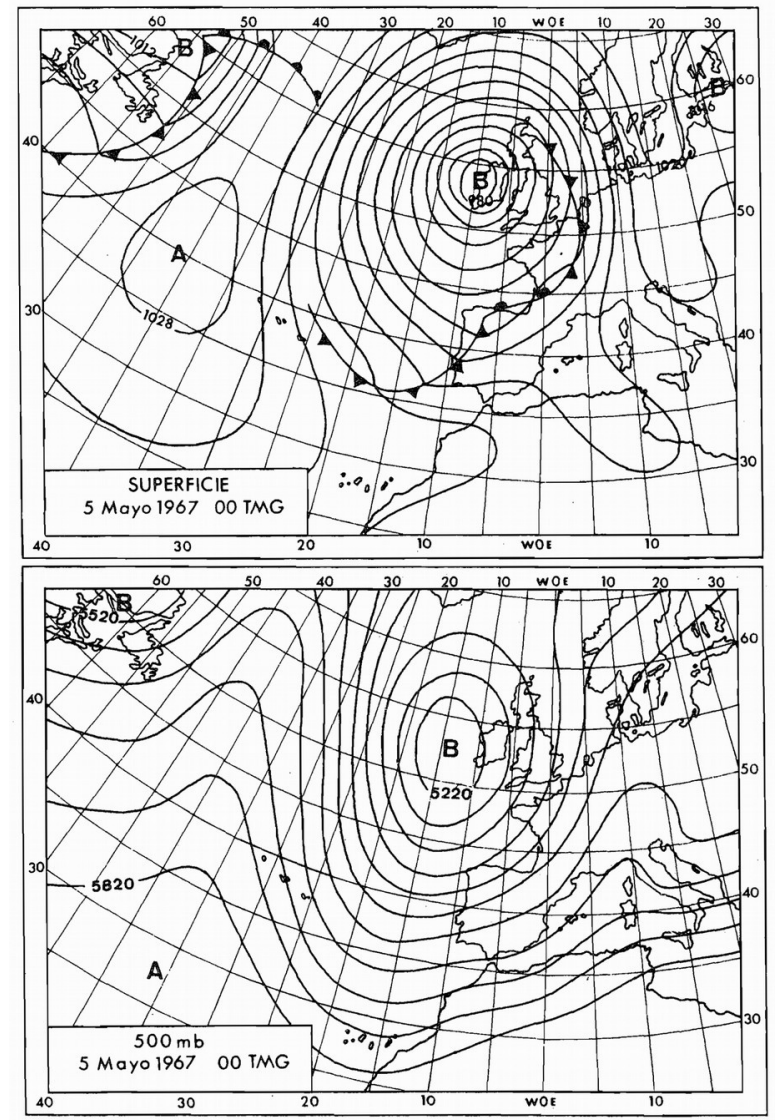

Fig. 64 Tipo de tiempo n. ${ }^{\circ}$ 7.I.M. - Depresión británica.

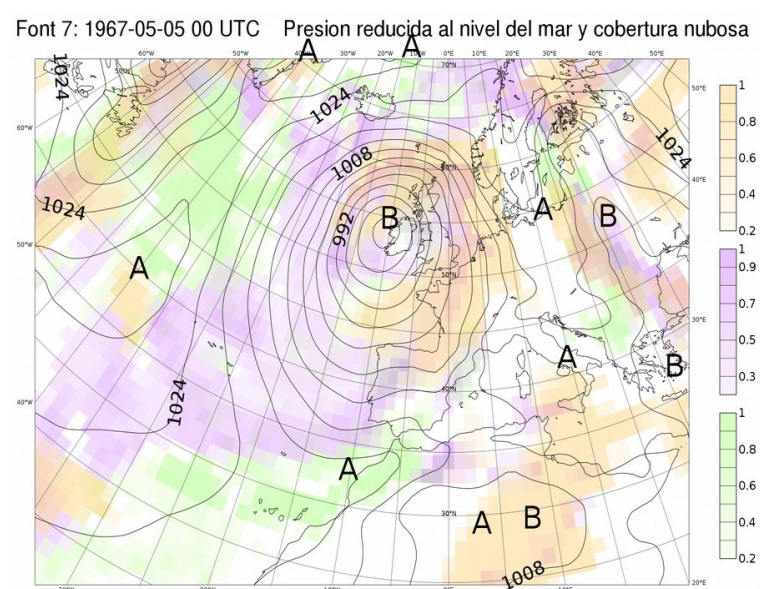

Font 7: 1967-05-05 00 UTC Altura geopotencial y temperatura en $500 \mathrm{hPa}$

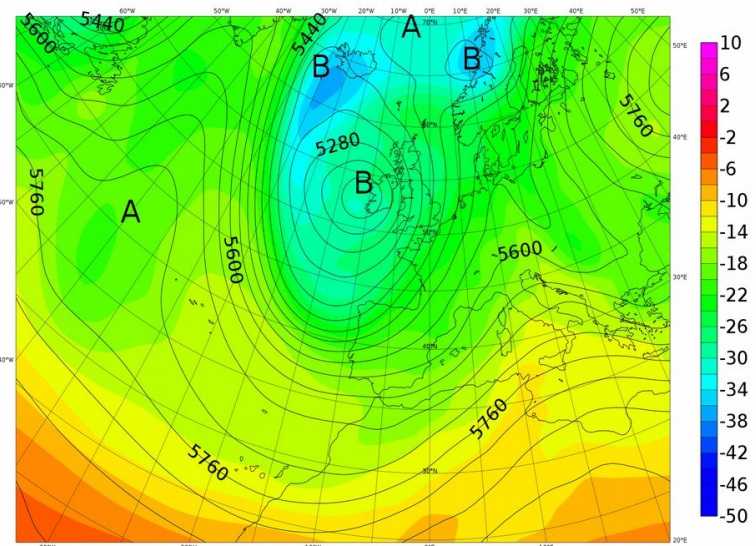

\section{Tipo 7. IM Depresión británica}

Aparentemente solo se distingue del tipo 6 en la posición más septentrional de la depresión (figura). No obstante, ocasionalmente el factor diferencial más importante consiste en que al final del periodo la depresión se intensifica al desplazarse hacia el este a la par que se desarrolla una depresión secundaria a latitudes más bajas, que generalmente se centra en el Mediterráneo occidental y a veces sobre la Península o norte de África.

Su duración es de 3 a 5 días. Puede presentarse en cualquier estación del año, salvo en verano, aunque solo es relativamente frecuente en abril y mayo.

Las masas de aire $\mathrm{mP}$ o $\mathrm{mA}$ predominan claramente. La actividad convectiva que las acompaña normalmente solo afecta la mitad norte de la Península, salvo en el caso señalado de ciclogénesis meridional cuando el mal tiempo es general. 

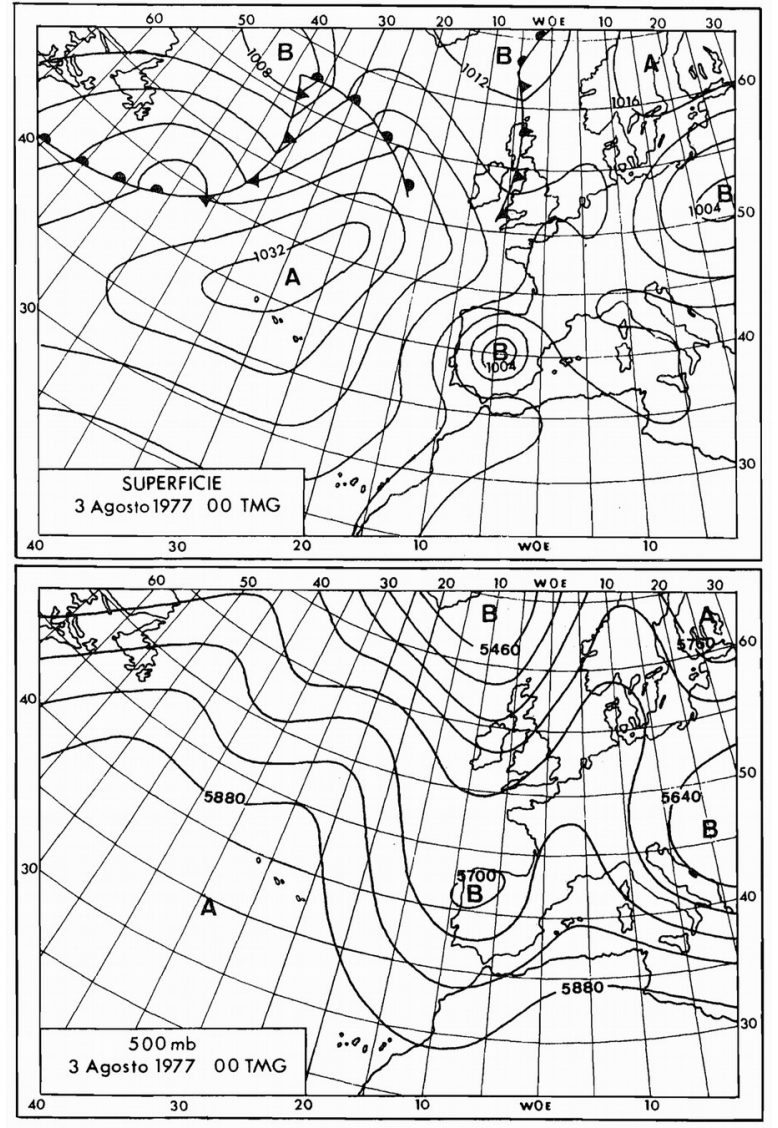

Fig. 65 Tipo de tiempo n. ${ }^{\circ}$ 8.r.M.e. - Anticiclón atlántico y depresión térmica peninsula

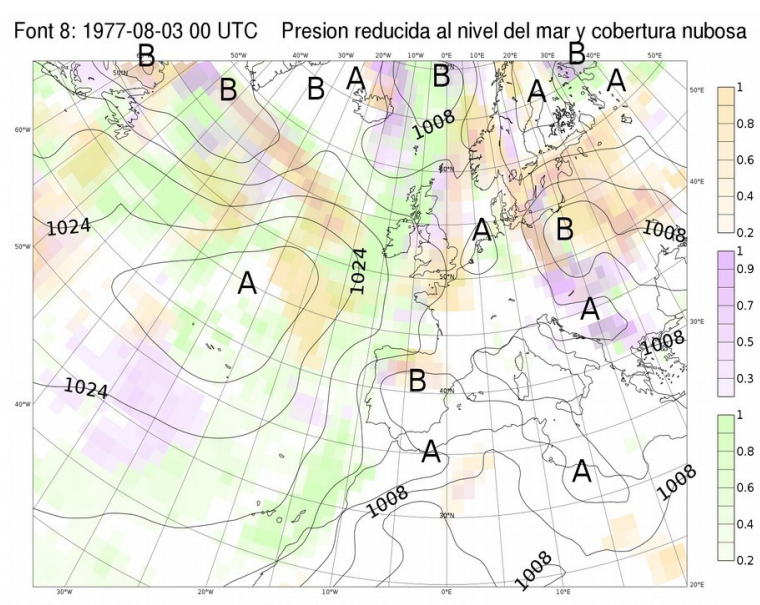

Font 8: 1977-08-03 00 UTC Altura geopotencial y temperatura en $500 \mathrm{hPa}$

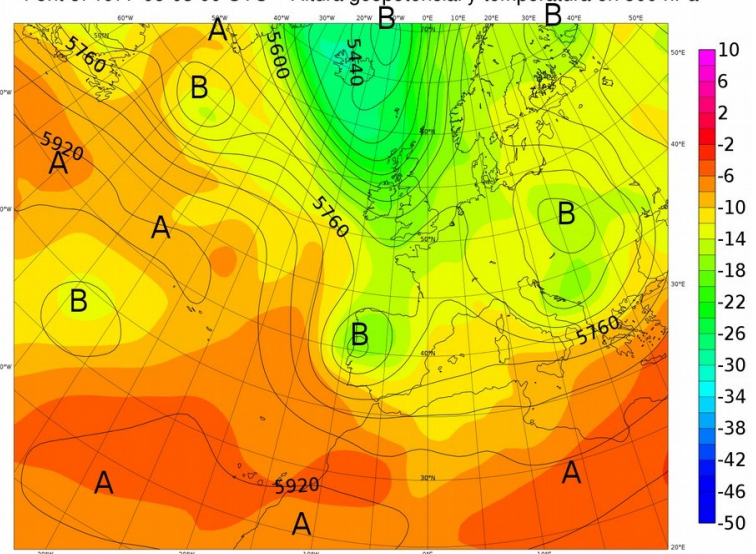

\section{Tipo 8. IMe Anticiclón atlántico y depresión térmica peninsular}

Este tipo se diferencia del 5 en que en superficie, la corriente del norte, al oeste de la Península, procede de latitudes más altas, mientras que en altura la vaguada, próxima o sobre la Península, es más profunda apareciendo fusionada con el meandro del vórtice circumpolar, con la formación incluso de pequeñas depresiones frías, como puede observarse en el ejemplo de la figura.

Esta situación es menos persistente que la del tipo 5, ya que pocas veces se mantiene durante más de 5 días. Su presencia queda prácticamente limitada al trimestre de julio a septiembre.

Respecto a las masas de aire podemos repetir lo dicho para el tipo 5, pero con la importante salvedad de que esta situación no es propicia a la formación de la masa autóctona, debido al fuerte intercambio vertical con el aire frío superior inherente a la fuerte inestabilidad que la caracteriza y que ocasionalmente se manifiesta en un notable aumento de la actividad tormentosa. En consecuencia, no solamente no se producen "olas de calor" (episodios de calor) sino que incluso sucede que, durante la permanencia de este tipo, las temperaturas suelen ser inferiores a sus valores medios, en el interior de la Península. 

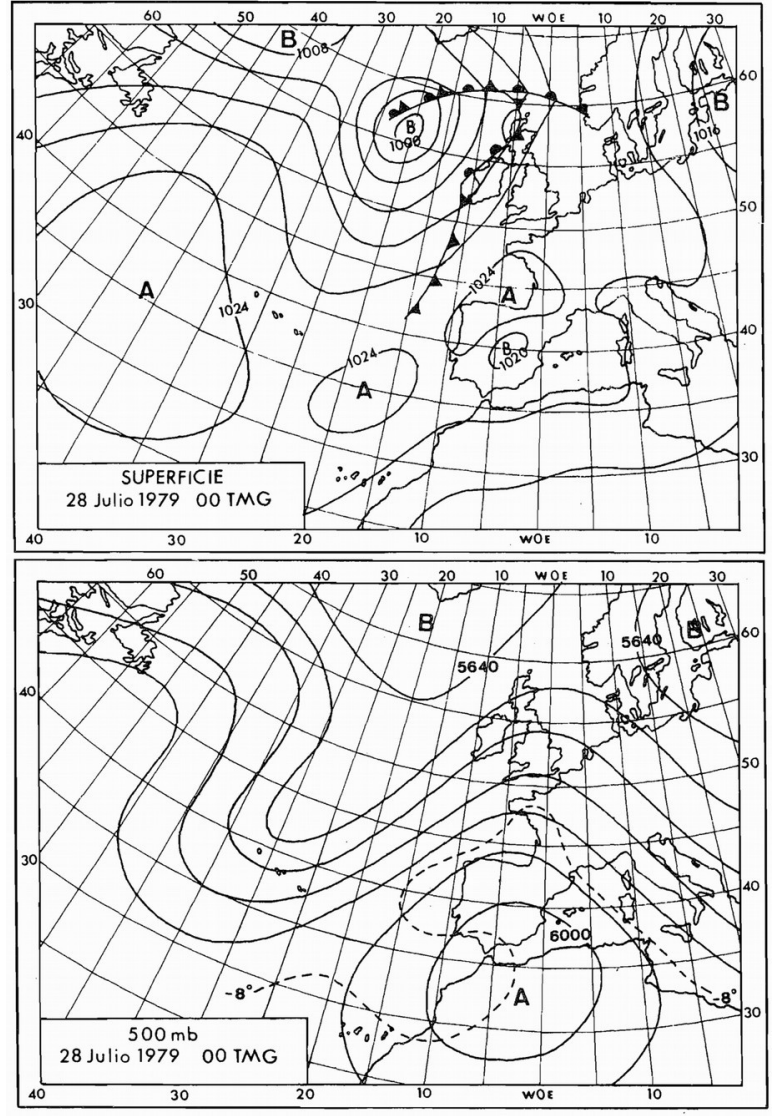

Fig. 66 Tipo de tiempo nº 9.I.M.E. - Altas presiones sobre el Atlántico y Europa.

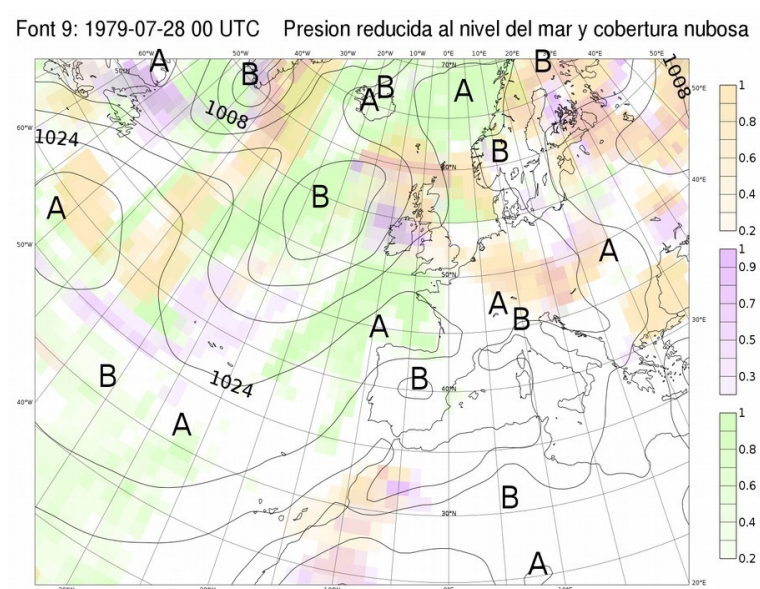

Font 9: 1979-07-28 00 UTC Altura geopotencial y temperatura en $500 \mathrm{hPa}$

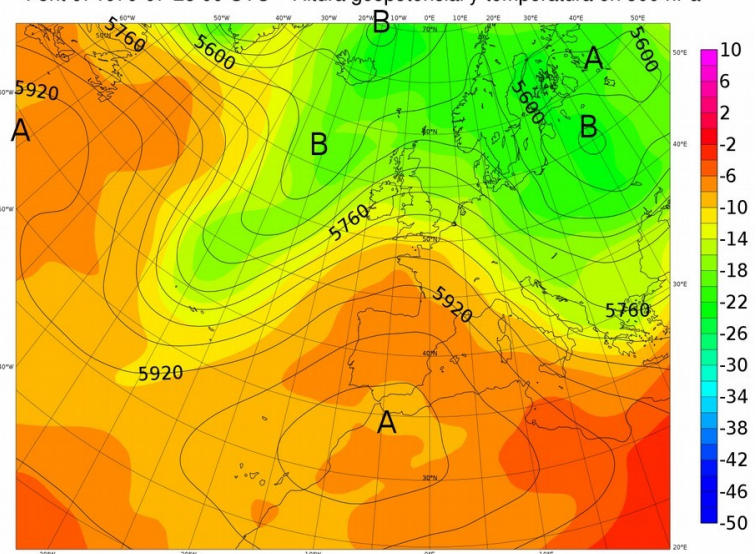

\section{Tipo 9. IMe Altas presiones sobre el Atlántico y Europa}

En superficie este tipo se caracteriza por el alejamiento hacia el oeste del anticiclón de las Azores y por la extensión de las altas presiones hacia el este, cubriendo la mayor parte de Europa y del Mediterráneo, mientras en altura el anticiclón africano, desplazado hacia el norte, cubre toda la Península dentro de su radio de acción.

Suele durar alrededor de una semana y, aunque puede presentarse desde finales de mayo a principios de octubre, solo es relativamente frecuente en julio y agosto.

La falta de los vientos del norte en el oeste de la Península da lugar al predominio absoluto de la masa de aire cT recalentada. Además, la presencia de aire caliente en altura que, en forma de lengua, se extiende sobre la Península (señalada en el ejemplo de la figura por la isoterma de $-8^{\circ} \mathrm{C}$ ), crea una gran estabilidad que reduce el intercambio vertical de aire a una capa superficial relativamente delgada, donde se acumula el calor producido por el calentamiento diurno del suelo, con lo que la temperatura del aire alcanza valores muy altos. Además, al no haber corrientes ascendentes, no se forman los característicos cúmulos, por lo que la mayor radiación favorece el calentamiento del suelo. Para que todo esto suceda no se precisa que haya una inversión de temperatura en altura; basta con que exista una capa isoterma o una reducción importante en el gradiente vertical.

Es durante esta situaciones cuando tienen lugar las "olas de calor" (episodios de calor) más importantes, de las que únicamente se libran las regiones costeras cantábrica y atlántica noroccidental. 

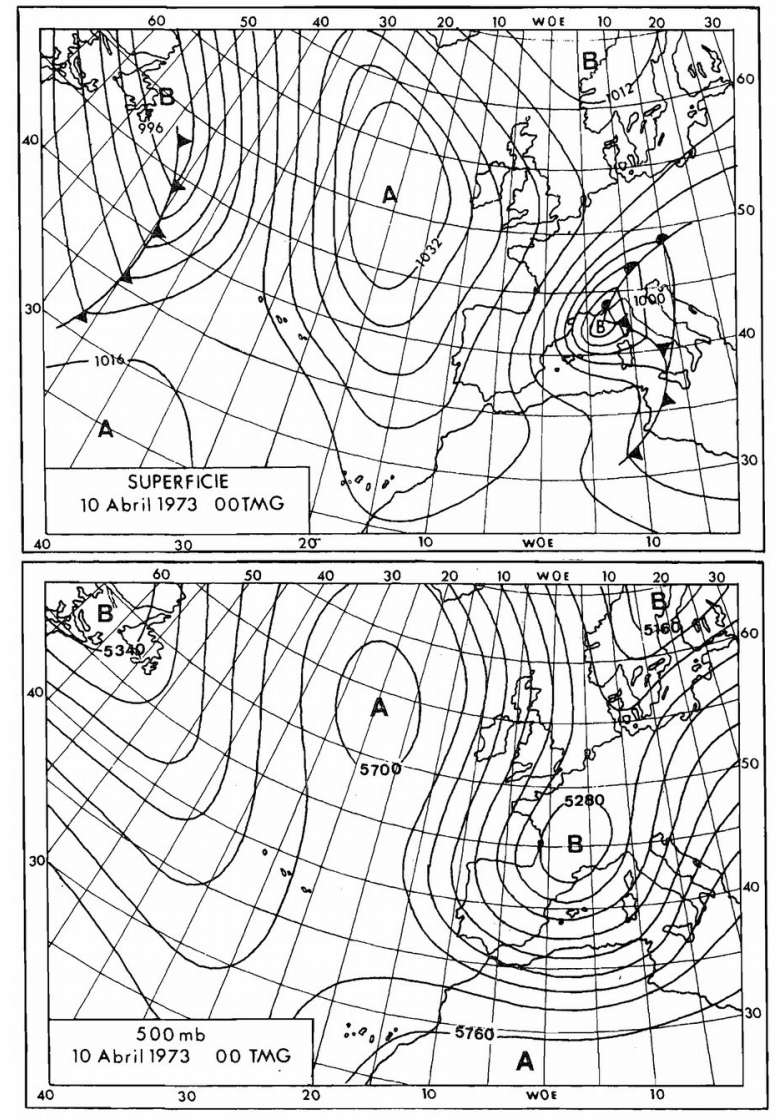

Fig. 67 Tipo de tiempo n. ${ }^{\circ}$ ro.I.M. - Depresión del Golfo de Génova.

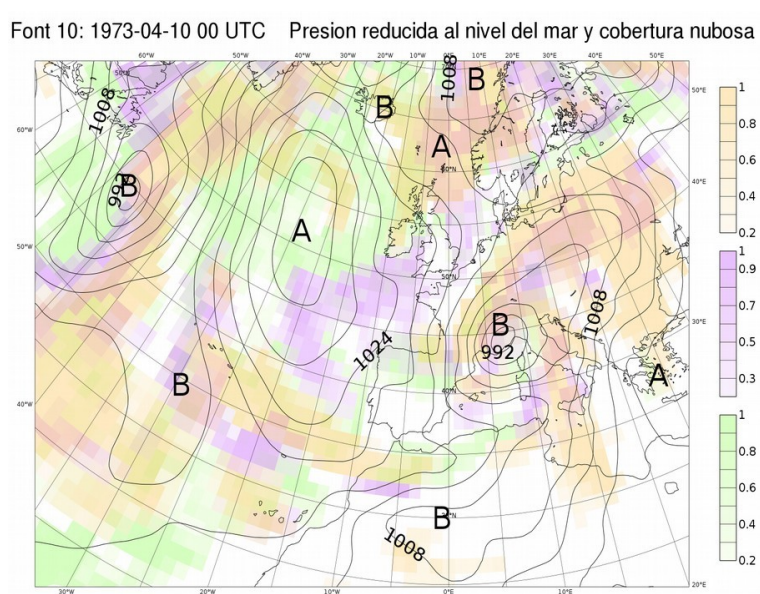

Font 10: 1973-04-10 00 UTC Altura geopotencial y temperatura en $500 \mathrm{hPa}$

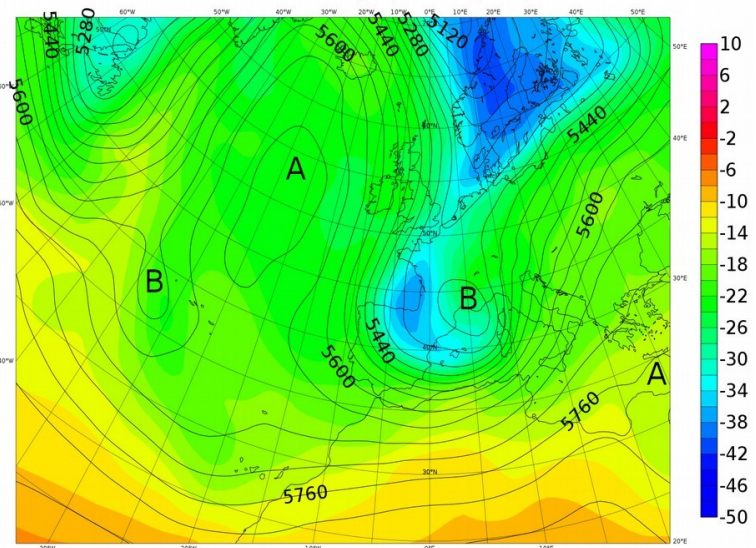

\section{Tipo 10. IM Depresión del golfo de Génova}

Tanto en superficie como en altura, el anticiclón atlántico, extendido en la dirección de los meridianos y la intensa circulación del norte a longitudes peninsulares caracterizan este tipo (figura). La génesis de las depresiones en el golfo de Génova o, menos frecuentemente, en el de León, es rapidísima, pero no así su posterior traslación hacia el este, que suele ser lenta, a la par que dichas depresiones pierden intensidad y aumentan en extensión.

Tiene una duración de 3 a 5 días, siendo relativamente frecuentes en cualquier mes del año salgo en el trimestre estival, aunque ocasionalmente se presenta esporádicamente en agosto, entrando entonces en juego la masa de aire $\mathrm{mP}$.

La masa de aire cP es la predominante, aunque en la mitad occidental de la Península adquiere un carácter más bien marítimo, que puede dar lugar a precipitaciones orográficas en la cornisa cantábrica. En el resto de la Península el tiempo prevalece seco y frío, con vientos fuertes del sector norte en el nordeste y en las Baleares, donde ocasionalmente van acompañados de una intensa actividad convectiva con los correspondientes chaparrones. Ocasionalmente también dan lugar a lluvias importantes en la mitad norte de la vertiente mediterránea. 

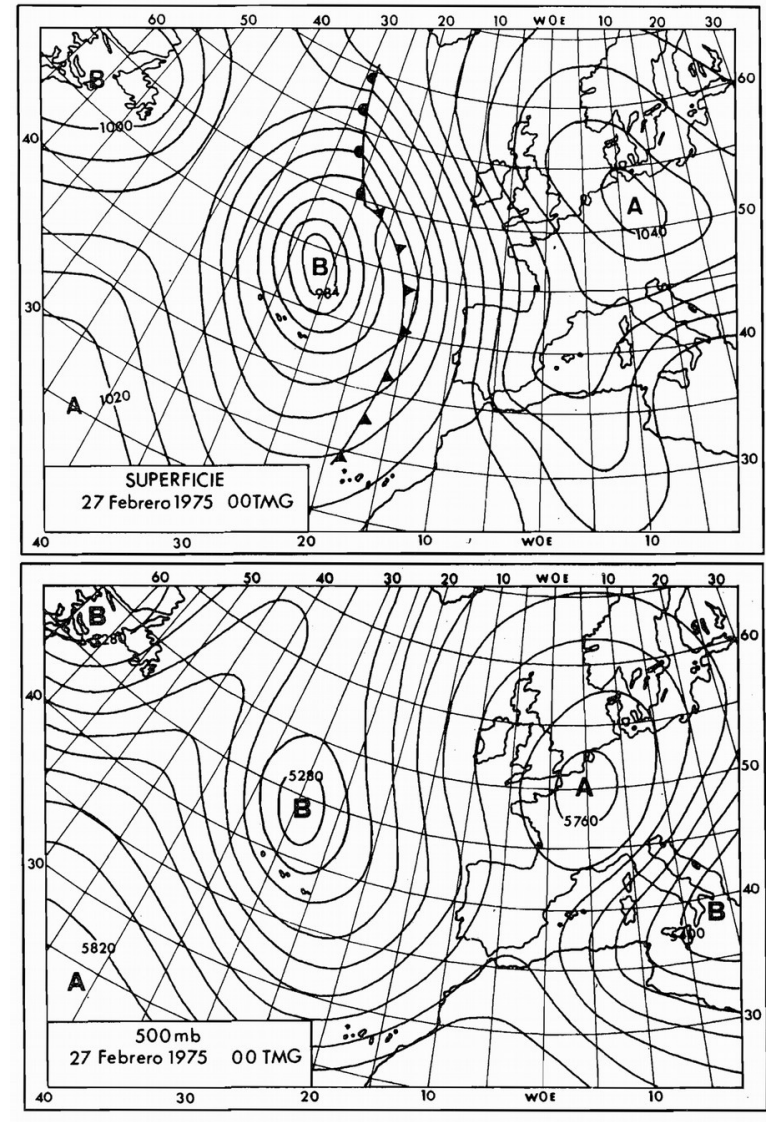

Fig. 68 Tipo de tiempo n. ${ }^{\circ}$ II...m.i. - Anticiclón centroeuropeo.

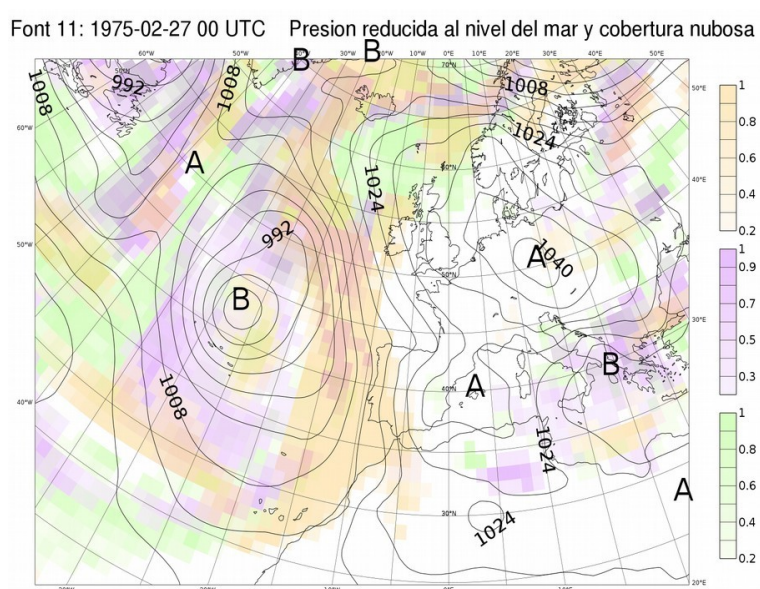

Font 11: 1975-02-27 00 UTC Altura geopotencial y temperatura en $500 \mathrm{hPa}$

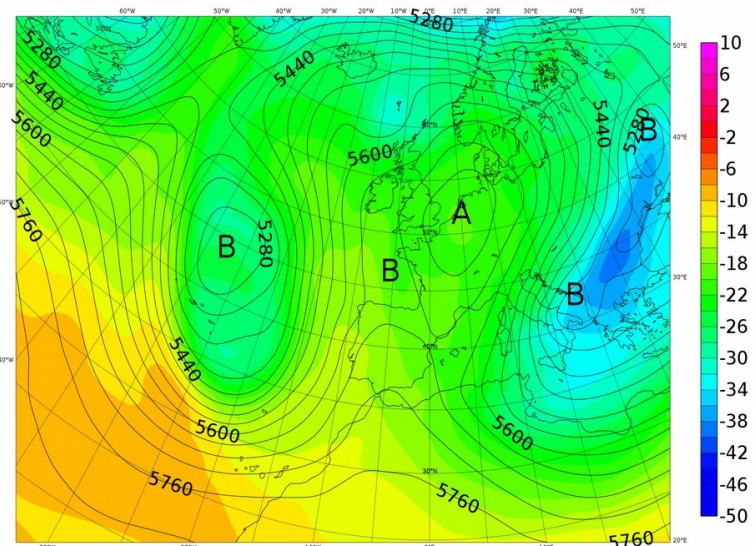

\section{Tipo 11. IMi Anticiclon centroeuropeo}

Tanto en superficie como en altura se manifiestan por un lado, un potente anticiclón europeo $\mathrm{y}$, por otro, una profunda depresión atlántica dando lugar en superficie a un intenso flujo del sur (figura).

Su duración es de 3 a 5 días, aunque ocasionalmente puede mantenerse hasta 10 días. Es poco frecuente y claramente invernal, aunque en raras ocasiones también puede presentarse en primavera y otoño.

La masa mT predomina en la mitad occidental de la Península, mientras que en la vertiente mediterránea la $\mathrm{cT}$ de origen africano suele prevalecer.

La característica sobresaliente del tiempo son las altas temperaturas, que alcanzan valores muy superiores a los normales, sobre todo en la vertiente cantábrica debido al efecto Foehn. En el cuadrante suroccidental y principalmente en la cuenca del Guadalquivir, las lluvias suelen ser abundantes mientras que, por el contrario, en el suroriental predomina el tiempo seco y caluroso. 

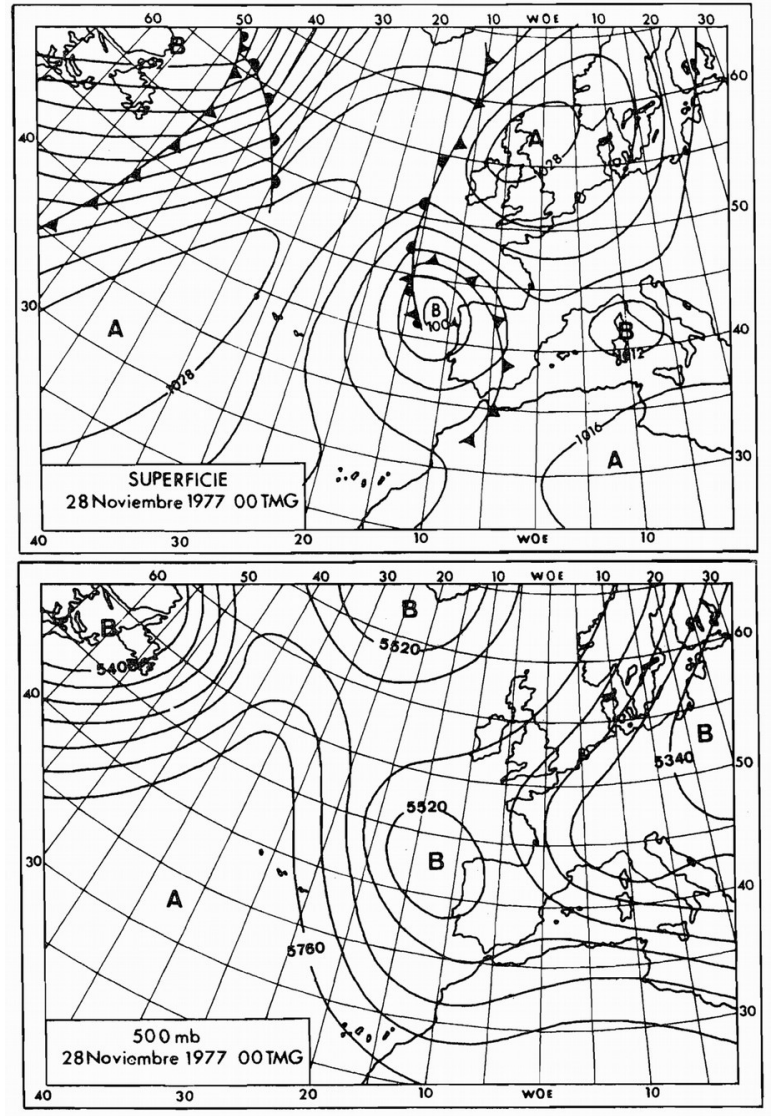

Fig. 69 Tipo de tiempo n.ำ $22.1 . D .-$ Depresión atlántico-ibérica.

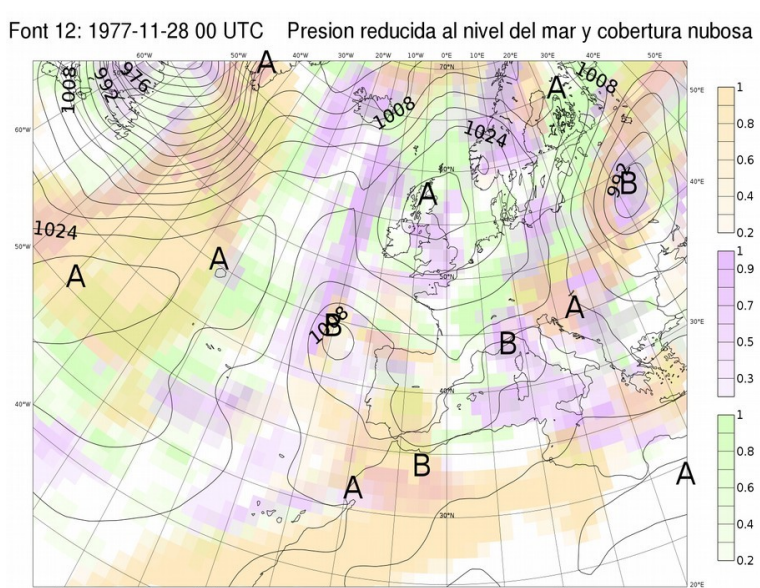

Font 12: 1977-11-28 00 UTC Altura geopotencial y temperatura en $500 \mathrm{hPa}$

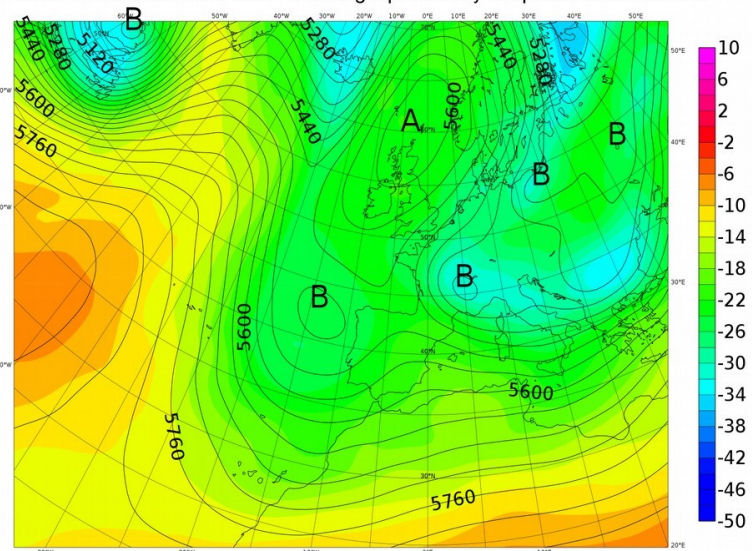

\section{Tipo 12. ID Depresión atlántico-ibérica}

Estas situaciones van precedidas por la presencia en superficie de una vaguada de gran extensión meridiana, con su eje a la longitud de aproximadamente $20^{\circ} \mathrm{W}$, entre dos grandes anticiclones, el uno centrado al oeste de las Azores y el otro cerca de Europa. La vaguada se transforma en una depresión de rápido desarrollo, que se mueve hacia el sureste para situarse en el golfo de Cádiz y pasar luego al Mediterráneo, aunque ocasionalmente la trayectoria de su centro cruza la Península. En altura, la situación se caracteriza por una profunda vaguada al oeste de la Península, que acaba por desarrollarse en una depresión fría (DANA), tal como vemos en el ejemplo de la figura.

La duración de este tipo viene dada por el número de días en que al menos una gran parte de la superficie peninsular queda dentro del radio de acción de la depresión, que suele ser de 3 a 12 días. No es muy frecuente, pudiendo presentarse en cualquier mes del año salvo de junio a agosto.

Las masas $\mathrm{mT}$ y $\mathrm{mP}$ invaden sucesivamente a la Península, siendo en ciertos casos la $\mathrm{mT}$ la predominante y en otros, como nuestro ejemplo, lo es la $\mathrm{mP}$.

La característica general del tiempo es una gran inestabilidad, con fuertes temporales de lluvia y ocasional actividad tormentosa. 

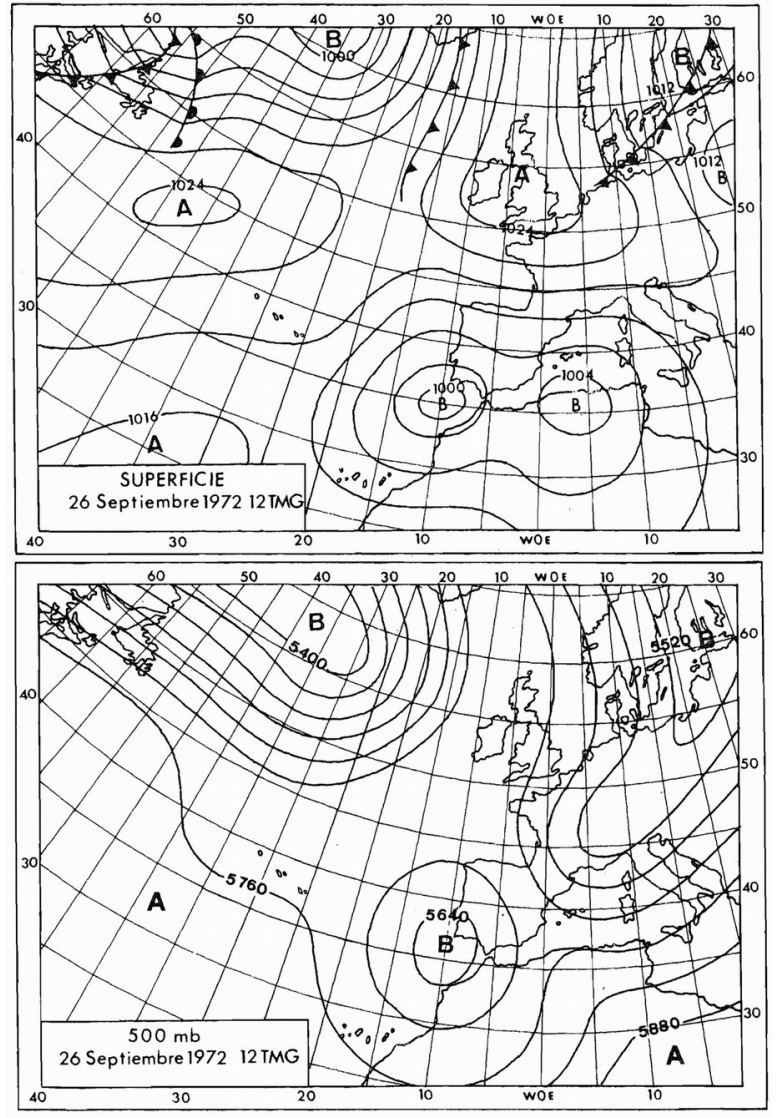

Fig. 70 Tipo de tiempo n. ${ }^{\circ}$ x3.I.D. - Depresión del Golfo de Cádiz.

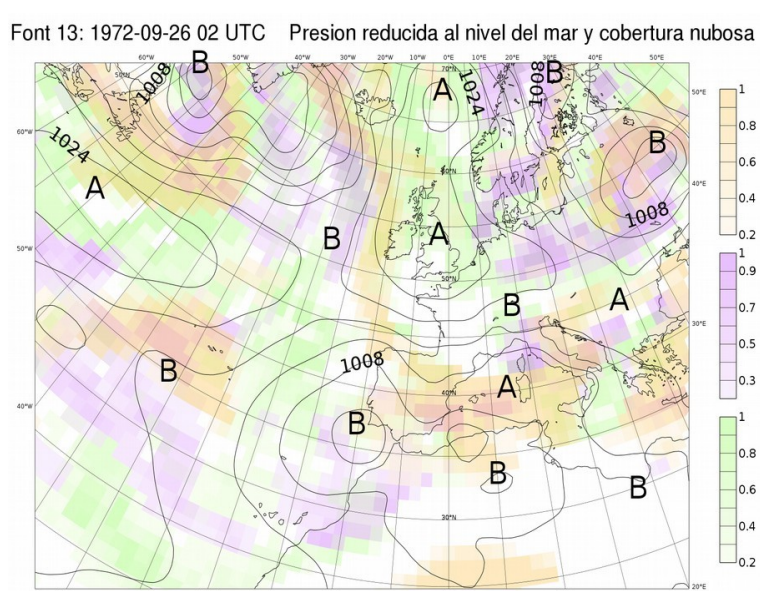

Font 13: 1972-09-26 02 UTC Altura geopotencial y temperatura en $500 \mathrm{hPa}$

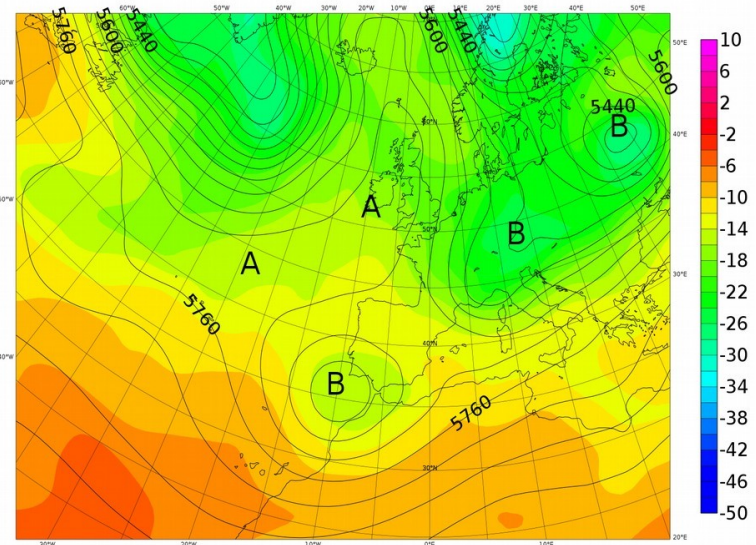

\section{Tipo 13. ID Depresión del golfo de Cádiz}

Las depresiones en el golfo de Cádiz constituyen uno de los factores más influyentes del tiempo atmosférico peninsular, dependiendo en gran parte de su frecuencia las cantidades anuales de precipitación en el cuadrante SW de la Península. No obstante, su identificación como tipo de tiempo se hace muy difícil bajo el punto de vista dinámico, dados los distintos procesos que conducen a la presencia de dichas depresiones, entre los cuales señalamos los dos siguientes: (1) Desarrollo similar al de las clásicas depresiones del frente polar, pero que tiene su génesis en un frente subpolar que ocasionalmente se establece entre $\operatorname{los} 30^{\circ}$ y $40^{\circ}$ de latitud, incluso a latitudes más bajas. Las trayectorias de los centros de estas depresiones cruzan el estrecho de Gibraltar pero es en el golfo de Cádiz dónde se profundizan, para pasar luego al Mediterráneo, ya debilitadas. (2) Desarrollo similar al de las depresiones del tipo 10, aunque en este caso la vaguada donde se genera la depresión se encuentra más hacia el oeste. La depresión, a medida que se va desarrollando, se dirige hacia el SE, yendo a parar al golfo de Cádiz, dónde se intensifica y se mantiene estacionaria, soliendo ocurrir, como en el ejemplo de la figura, que en lugar de pasar al Mediterráneo se desarrolla una baja secundaria centrada en el litoral argelino. En la intensificación de la depresión y en su estacionamiento contribuyen la propia configuración orográfica del golfo de Cádiz y la presencia de la "gota fría" (DANA) en altura.

Aunque no son muy frecuentes, estas depresiones pueden presentarse en cualquier mes, salvo en julio y agosto, y su permanencia en el golfo de Cádiz rara vez pasa de 3 días. Como quiera que este tipo ha ido precedido del desplazamiento de masas de aire $\mathrm{mP}$ hasta latitudes subtropicales, generalmente, es esta masa la única que entra en juego, aunque calentada, siendo frecuente que, como en el caso de nuestro ejemplo, carezca de sistemas de frentes. Estas situaciones dan lugar a lluvias importantes en la mitad sur de la Península y en la vertiente mediterránea, que pueden ser muy intensas en Levante y en el sudeste, acompañadas de tormentas. 

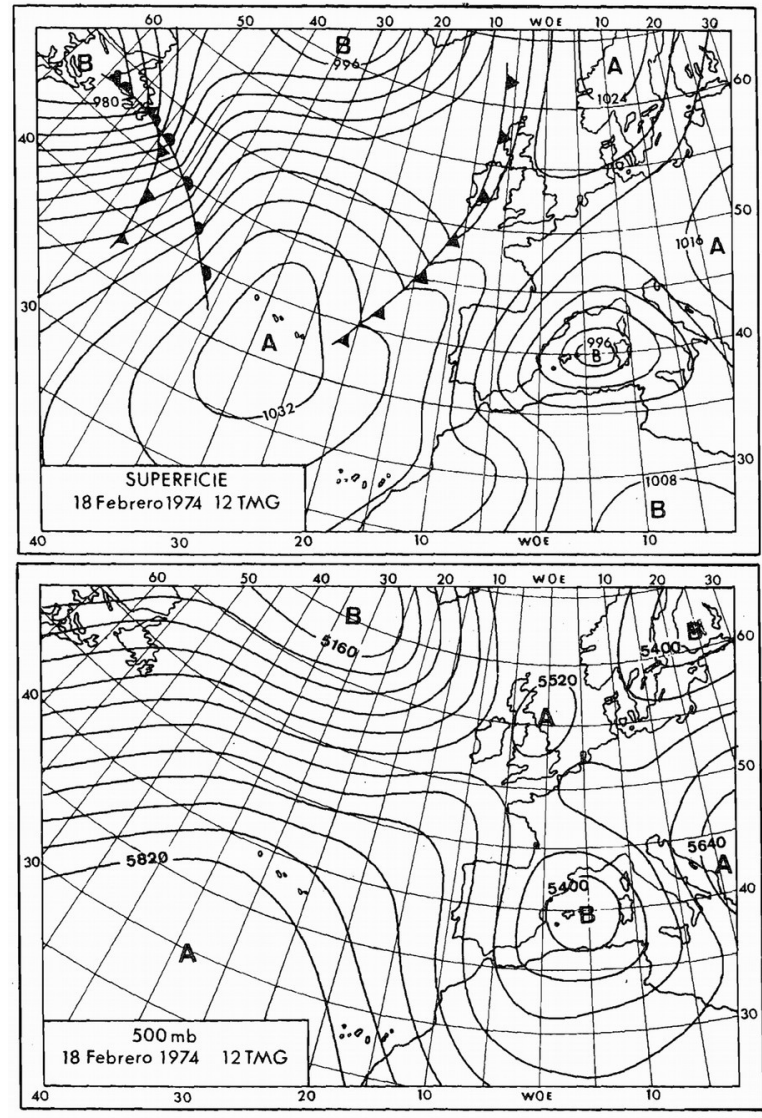

Fig. 71 Tipo de tiempo n.. ${ }^{\circ}$ T4.I.D. - Depresión balear.

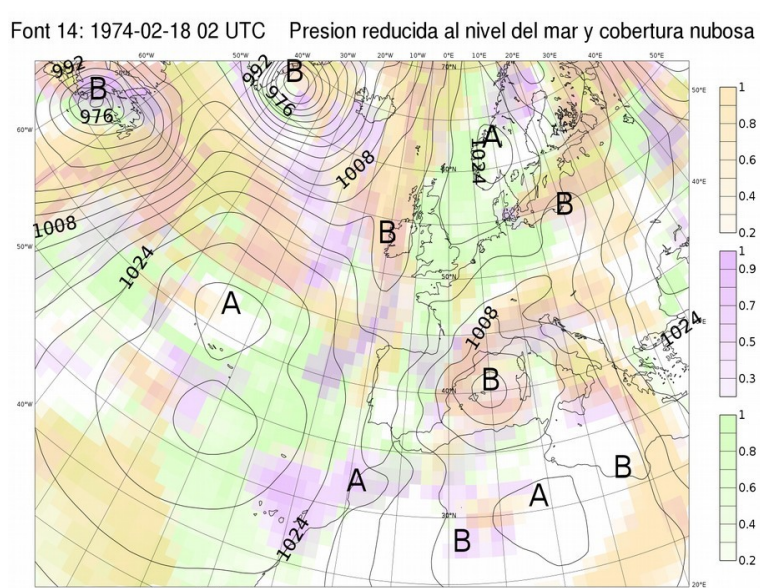

Font 14: 1974-02-18 02 UTC Altura geopotencial y temperatura en $500 \mathrm{hPa}$

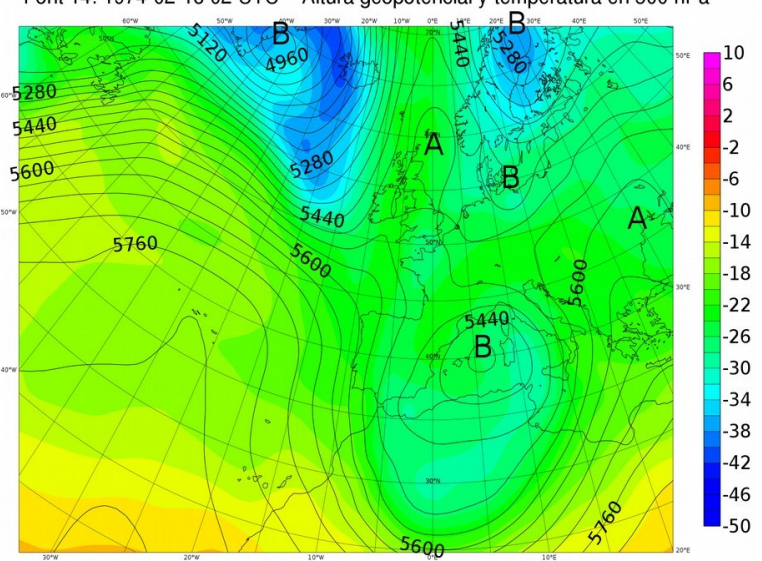

\section{Tipo 14. ID Depresión balear}

La presencia de una profunda depresión mediterránea, generalmente centrada entre las Baleares y Cerdeña, constituye la característica fundamental. La situación en altura muestra claramente el desarrollo de una depresión fría desprendida del vórtice circumpolar, mientras que como puede verse en el ejemplo de la figura, sobre el Atlántico la circulación zonal ha quedado ya restablecida.

Su duración es de 4 a 10 días, pudiendo presentarse en cualquier mes, aunque cuando ocurre en verano su permanencia es corta, ya que su desplazamiento hacia el este es mucho más rápido.

A diferencia del tipo 10, la masa de aire sobre la Península es relativamente templada a pesar del flujo del noreste; casi puede hablarse de una masa de aire mediterránea, separada de la $\mathrm{cP}$ sobre Europa por los sistemas montañosos alpino y pirenaico, aunque cuando está masa es de considerado espesor acaba por invadir la Península.

El tiempo en la vertiente mediterránea y en Baleares suele ser muy inestable; sobre todo al final del verano y en otoño, cuando la superficie caliente del mar combinada con la "gota fría" (DANA) en altura puede ocasionar una fuerte actividad convectiva con fuertes temporales de lluvia que ocasionalmente llegan a afectar toda la Península. En invierno también pueden dar lugar a copiosas nevadas, principalmente en la vertiente mediterránea, meseta Norte y alto Ebro. 

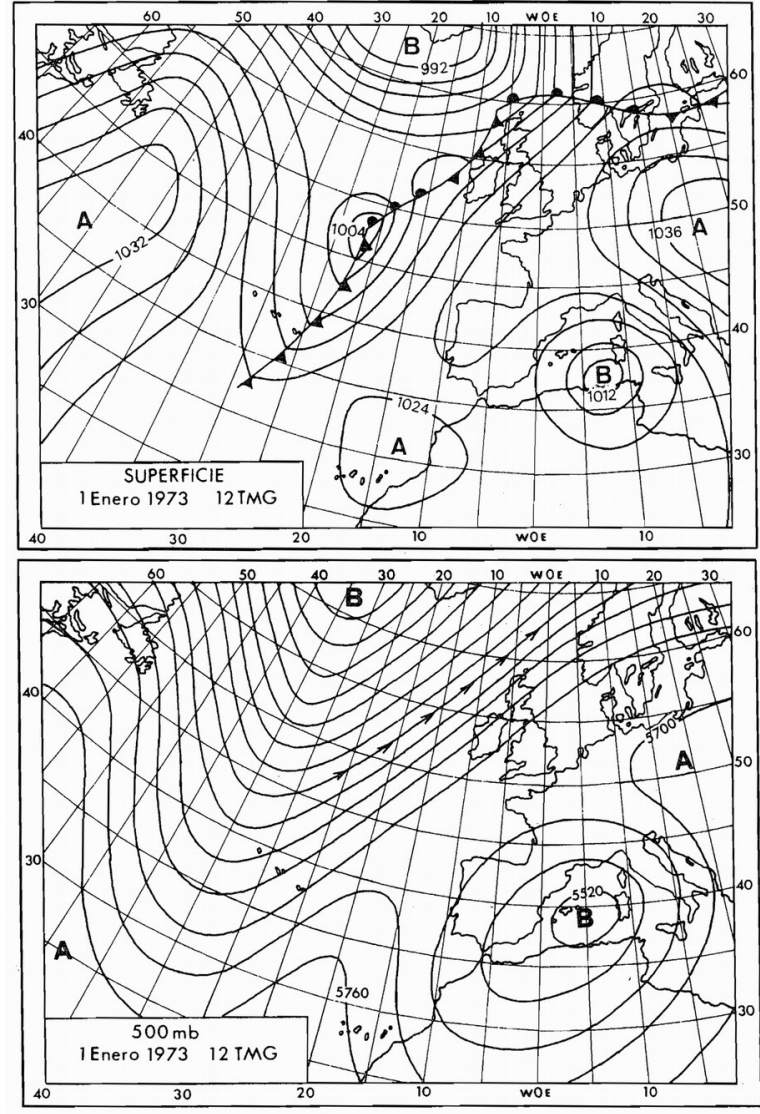

Fig. 72 Tipo de tiempo n.o ${ }^{0}$ s5...D.i. - Anticiclón ruso.

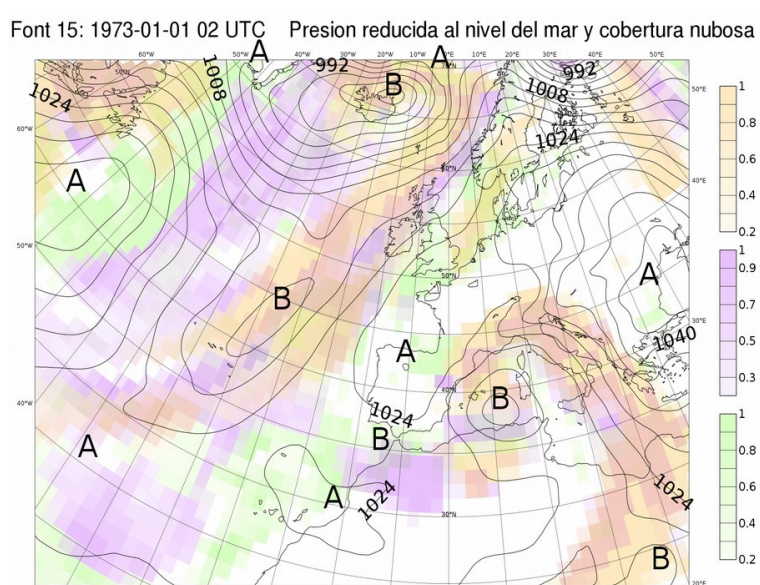

Font 15: 1973-01-01 02 UTC Altura geopotencial y temperatura en $500 \mathrm{hPa}$

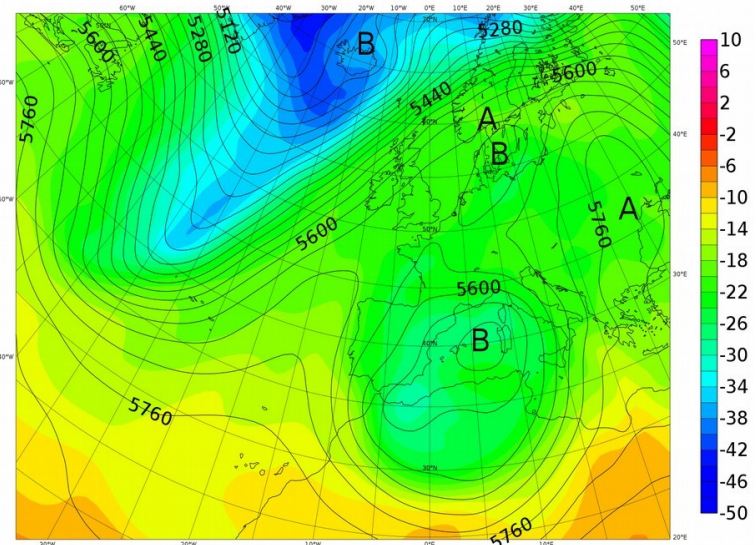

\section{Tipo 15. IDi Anticiclón ruso}

Un potente anticiclón frío está centrado sobre Rusia, extendiéndose en forma de dorsal hasta la Península, mientras en el Mediterráneo se presenta un centro de bajas presiones, reflejo de una extensa y profunda depresión fría en altura (figura).

Con una duración máxima de 10 días, es un tipo claramente invernal, cuya aparición queda limitada de noviembre a marzo.

Claro predominio de la masa $\mathrm{cP}$, a veces muy fría. El tiempo sobre la Península es seco y frío e inestable en las Baleares. La intensidad del frío está supeditada al grado de efectividad del efecto protector de la barrera pirenaica-alpina, que depende fundamentalmente del espesor de la masa de aire. 

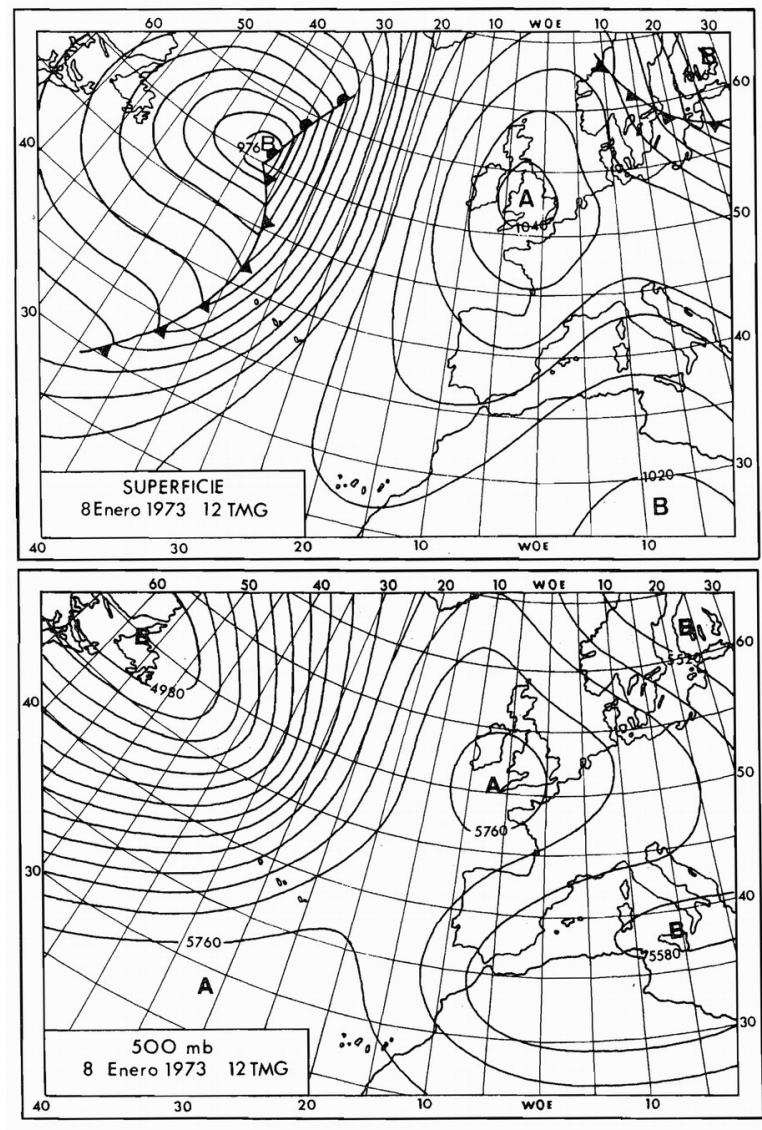

Fig. 73 Tipo de tiempo nº 16.I.D.i. - Anticiclón británico-escandinavo.

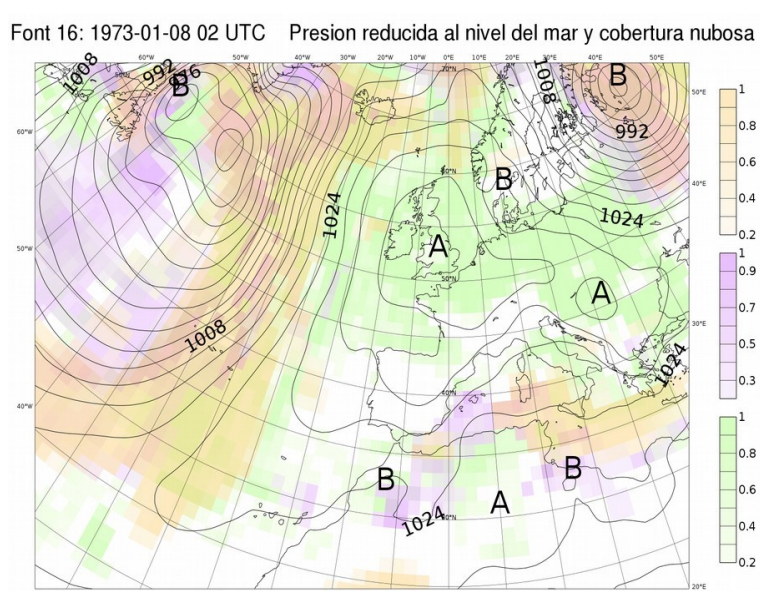

Font 16: 1973-01-08 02 UTC Altura geopotencial y temperatura en $500 \mathrm{hPa}$

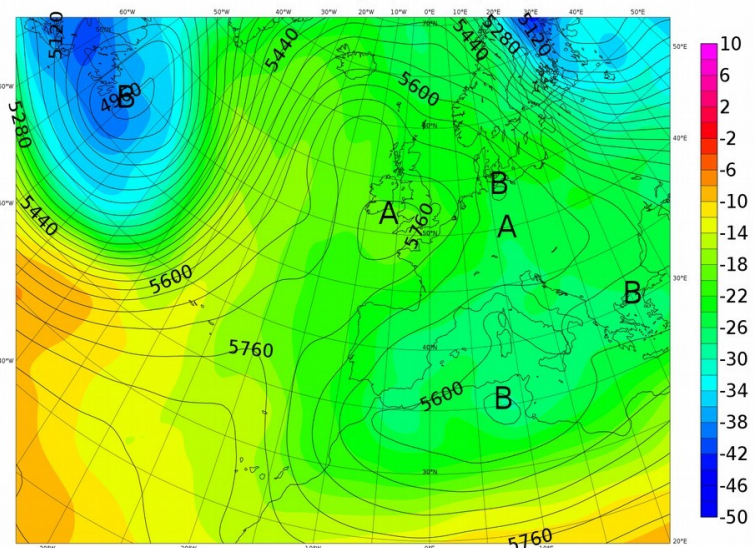

Tipo 16. IDi Anticiclón británico-escandinavo

Un potente anticiclón en superficie y altura, así como una depresión fría sobre el Mediterráneo, con el correspondiente predominio de los vientos del este sobre la Península, caracterizan este tipo (figura).

Con una duración máxima de una semana, es poco frecuente. Su presencia queda prácticamente limitada al semestre invernal, pero con preferencia al periodo de noviembre a marzo.

Ocasionalmente, la región nororiental de la Península es afectada por la masa cP, aunque generalmente la barrera pirenaica-alpina la defiende lo suficiente para que toda la Península quede bajo la influencia de una masa de aire templada a causa de su recorrido sobre el Mediterráneo. En consecuencia, el tiempo suele ser seco y soleado, aunque con cierta inestabilidad sobre las Baleares. En ocasiones, cuando el flujo sobre el Mediterráneo es más del este, puede haber lluvias importantes en el litoral mediterráneo. 

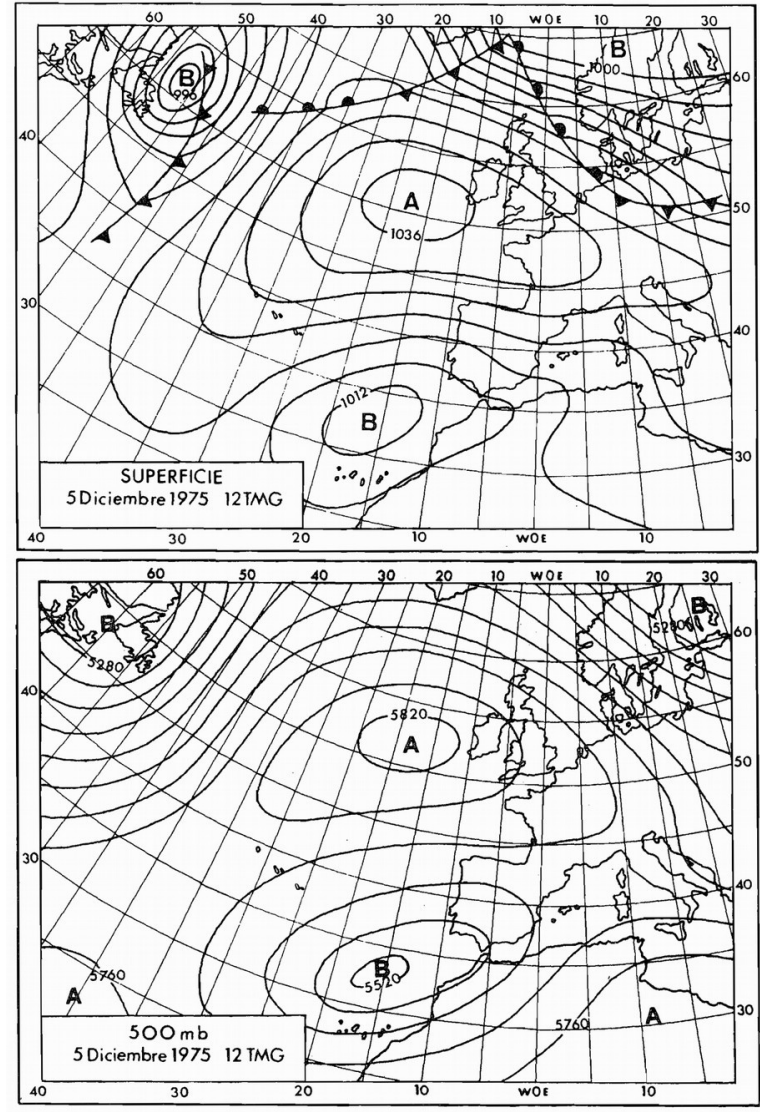

Fig. 74 Tipo de tiempo n. ${ }^{\circ}$ 17.I.D.i. - Anticiclón atlántico-europeo.

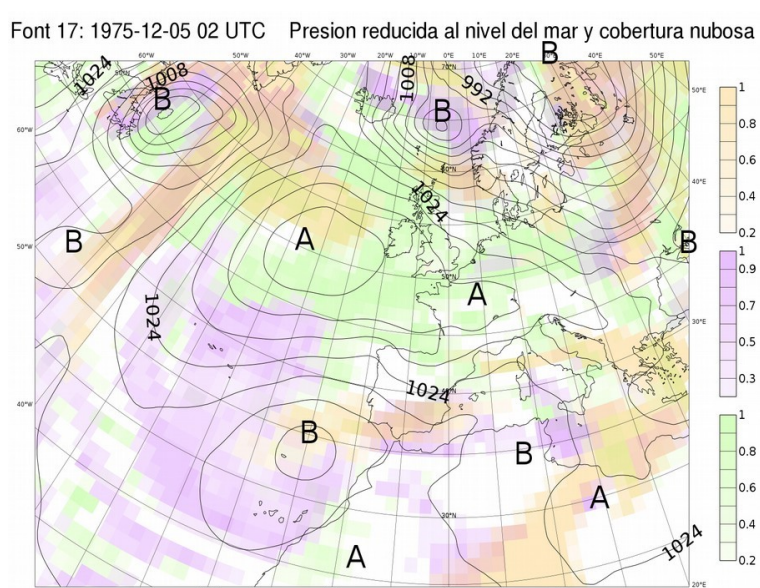

Font 17: 1975-12-05 02 UTC Altura geopotencial y temperatura en $500 \mathrm{hPa}$

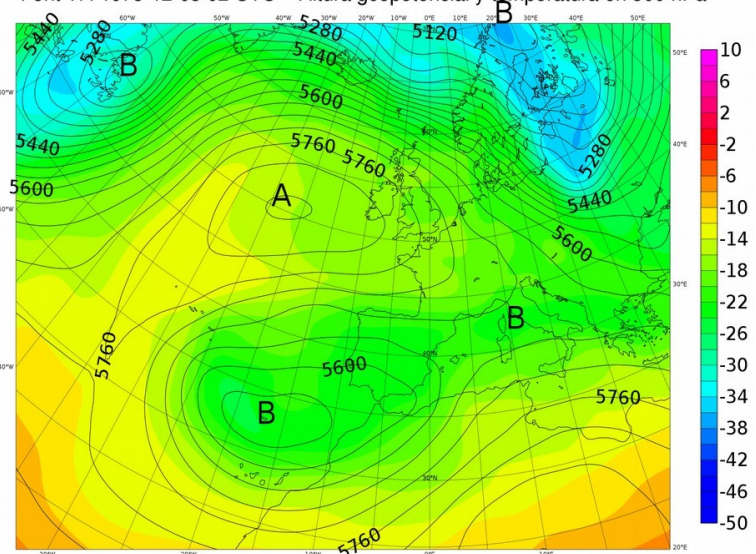

\section{Tipo 17. IDi Anticiclón atlántico-europeo}

Es una situación típica de "gota fría" (DANA), claramente puesta de manifiesto por la mayor profundidad y extensión de la depresión en altura que en superficie, la cual está centrada entre Canarias y la Península, e incluso sobre ella misma (figura).

La duración es de 3 a 10 días y su aparición quede prácticamente limitada a los meses de noviembre a febrero.

La masa de aire, originalmente $\mathrm{cT}$, ha perdido su carácter continental al alcanzar la Península, después de su largo recorrido sobre el Mediterráneo, donde se ha cargado de vapor de agua. Esta circunstancia, unida a la presencia de la "gota fría" (DANA) en altura, crea una gran inestabilidad que ocasionalmente da lugar a lluvias muy intensas en la mitad sur de la Península y en la vertiente mediterránea, donde el factor orográfico juega un papel decisivo. 

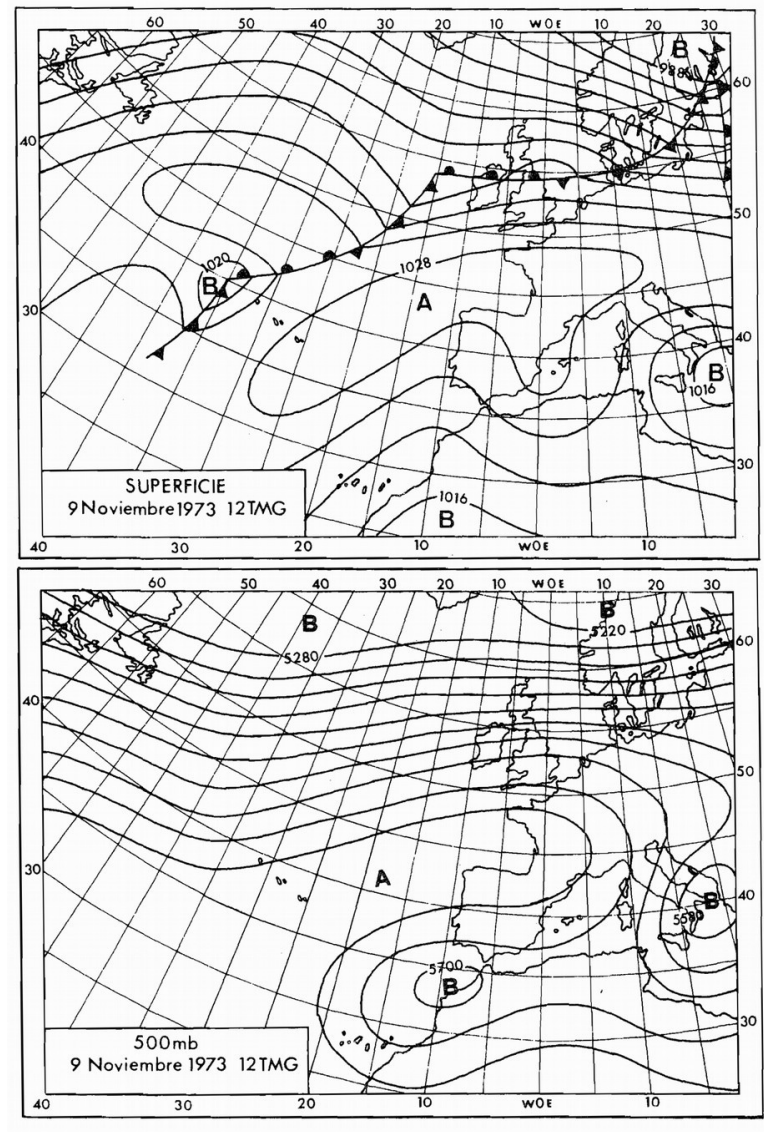

Fig. 75 Tipo de tiempo n. ${ }^{\circ}$ 18.I.D. - Vaguada ibero-africana.

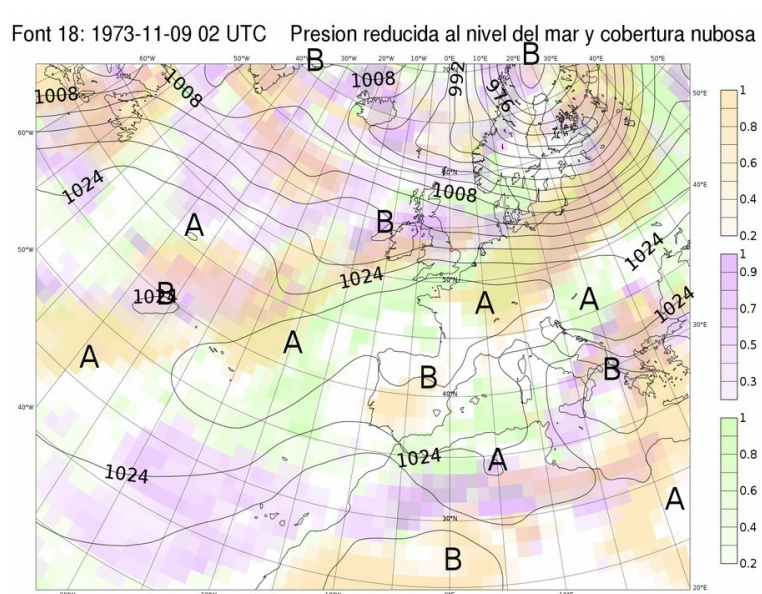

Font 18: 1973-11-09 02 UTC Altura geopotencial y temperatura en $500 \mathrm{hPa}$

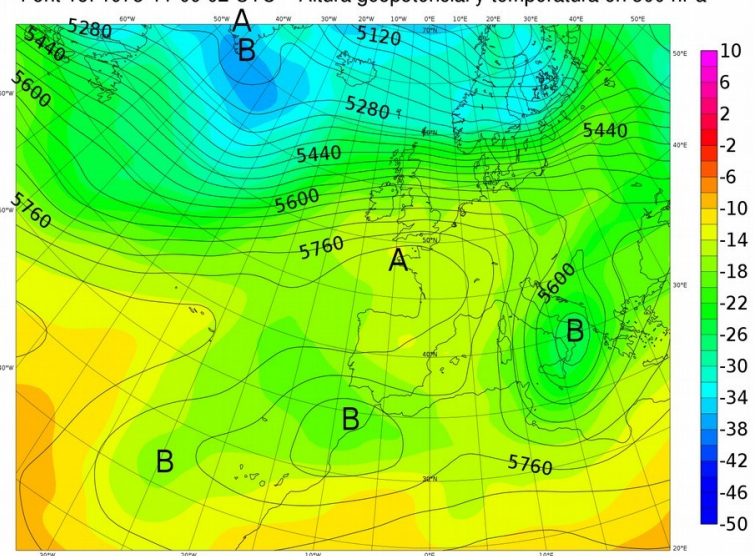

\section{Tipo 18. ID Vaguada ibero-africana}

Tanto en superficie como en altura se define un extenso anticiclón atlántico-europeo, parecido al que caracteriza el tipo 17, pero existiendo dos hechos diferenciales muy notables, como son: (1) el restablecimiento en altura de la circulación zonal y (2) la presencia en el mapa de superficie de una vaguada, con su eje orientado según los meridianos.

Estas vaguadas son el reflejo en el campo bárico de las conocidas ondulaciones que se forman en la corriente general del este en el margen meridional de las altas presiones subtropicales. En nuestro caso (figura) la vaguada se ha originado sobre África, trasladándose lentamente hacia el oeste, intensificándose al acercarse al Atlántico y entrar en juego la masa de aire marítimo y desvaneciéndose después de haber alcanzado un máximo desarrollo, lo que suele suceder a la longitud de Canarias.

Con una duración mínima de 3 días y máxima de unos 25 días, es uno de los tipos más frecuentes, sobre todo en los meses de noviembre a marzo y también en junio. Su menor frecuencia tiene lugar en abril y de julio a septiembre.

Con la excepción del verano, en el resto del año la masa de aire $\mathrm{mT}$ (sub) es la predominante sobre la Península, aunque más o menos desecada. El tiempo es generalmente bueno, con posibles nieblas continentales. No obstante, el área más meridional puede sufrir los efectos de la "depresión fría" (DANA) en altura, dando lugar a fuertes tormentas locales.

En verano domina claramente la masa cT, siendo frecuentes las "olas de calor" (episodios de calor). 

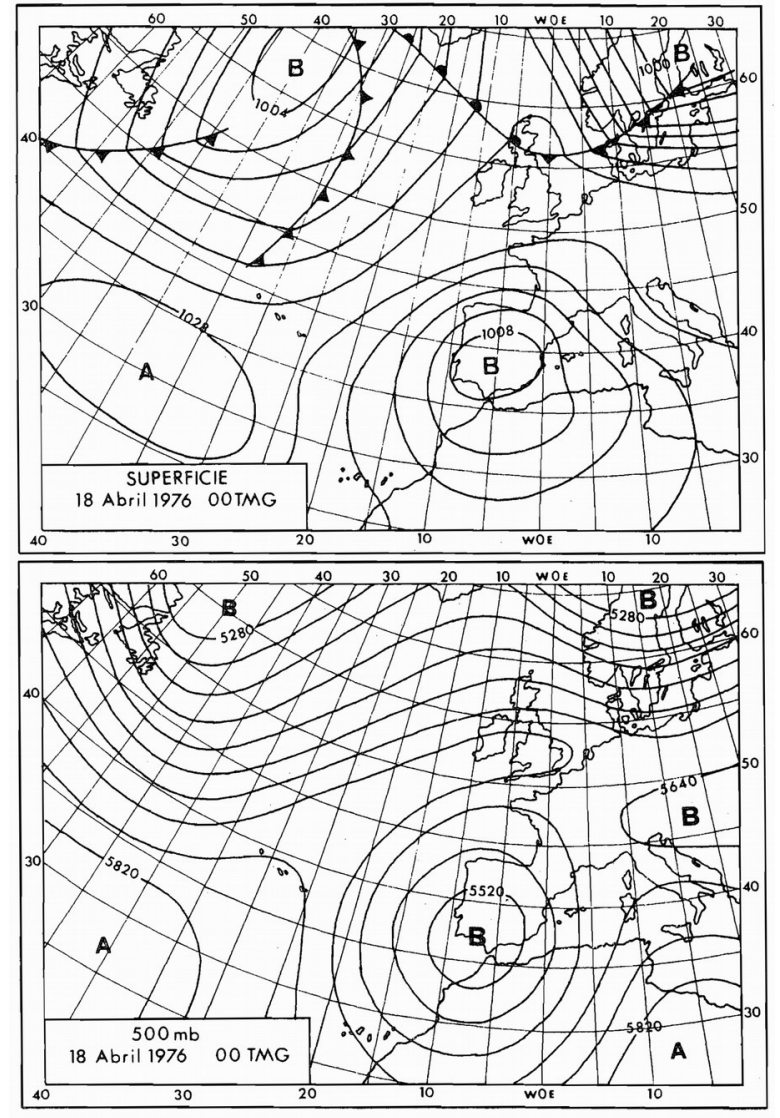

Fig. 76 Tipo de tiempo n. ${ }^{\circ}$ t9.r.i. - Depresión fría peninsular, de invierno.

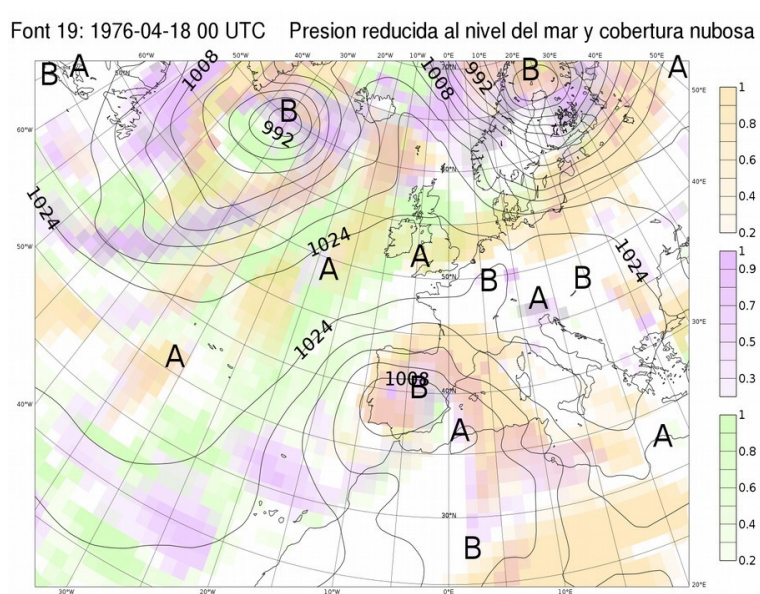

Font 19: 1976-04-18 00 UTC Altura geopotencial y temperatura en $500 \mathrm{hPa}$

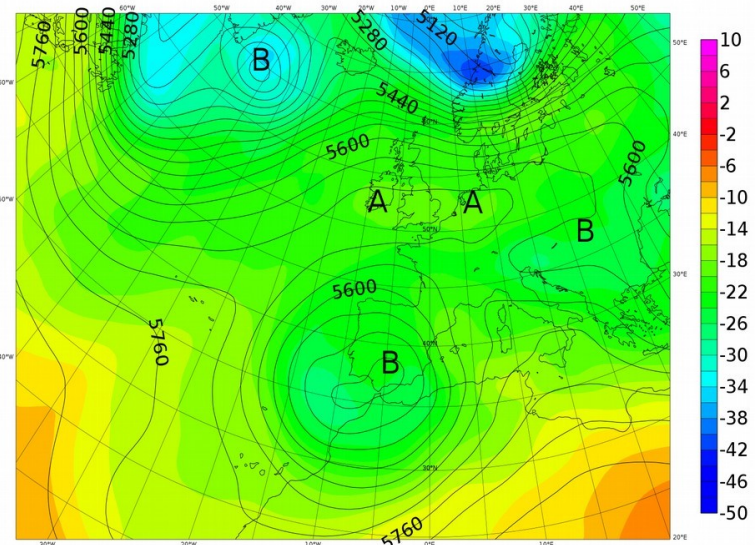

\section{Tipo 19. IIi Depresión fría peninsular de invierno}

Finalizado el ciclo del vórtice circumpolar y restablecida la circulación zonal a latitudes superiores a las normales, ocurre circunstancialmente que las depresiones frías desprendidas del vórtice que se mantengan durante algunos días estacionadas a bajas latitudes mientras se van rellenando. Cuando la depresión aparece centrada sobre la Península o en sus inmediaciones, queda definido el tipo en cuestión (figura).

$\mathrm{Su}$ presencia raramente supera los 5 días y queda prácticamente limitada al semestre invernal.

Las masas de aire pueden ser mT (sub) o mT, aunque modificadas.

La inestabilidad es generalmente muy fuerte. Sus efectos sobre el tiempo varían mucho, ya que en gran parte dependen de la posición de la depresión fría, aunque los chubascos suelen ser generales. Ocasionalmente se han registrado cantidades de precipitación muy importantes en la mitad meridional de la Península, Levante, depresión del Ebro y meseta Norte. 

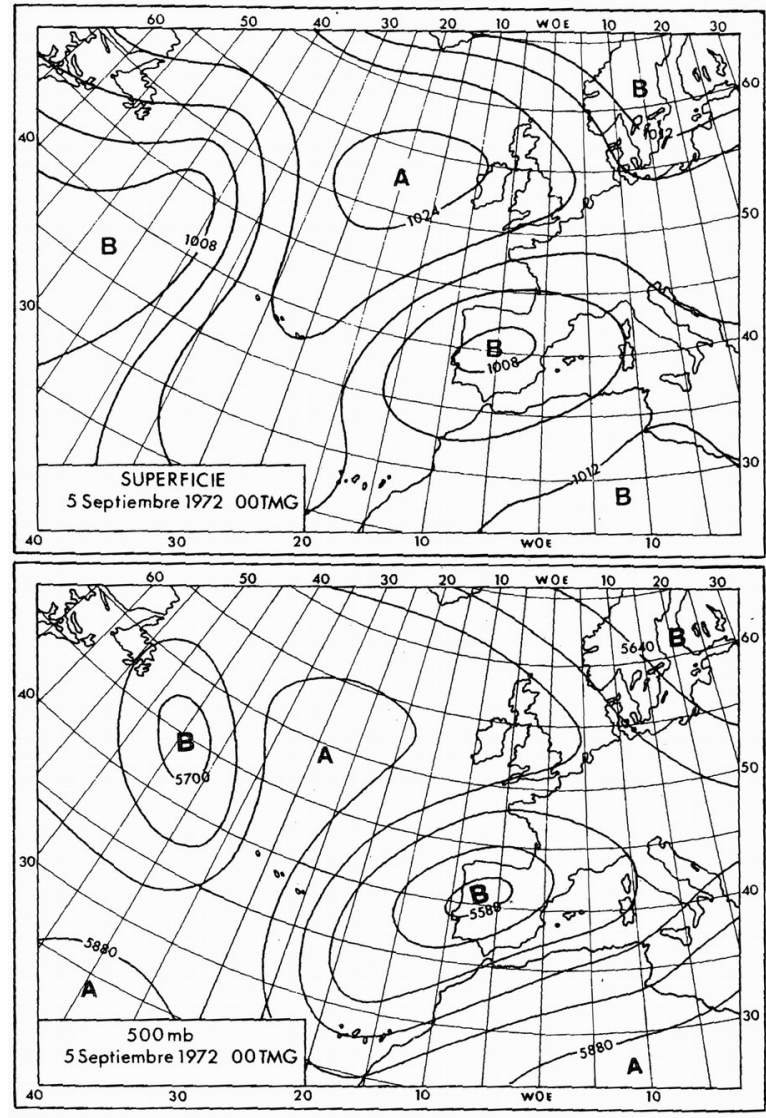

Fig. 77 Tipo de tiempo n. ${ }^{\circ}$ 2o.II.e. - Depresión fría peninsular, de verano.

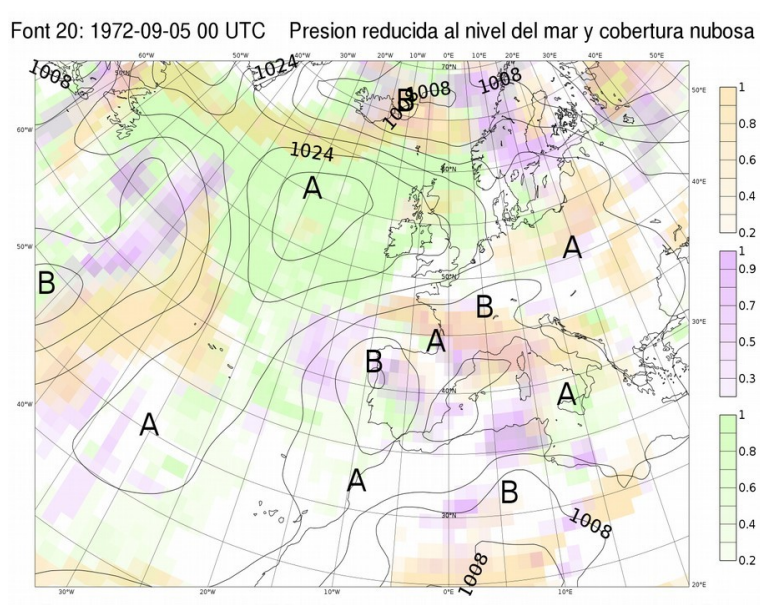

Font 20: 1972-09-05 00 UTC Altura geopotencial y temperatura en $500 \mathrm{hPa}$

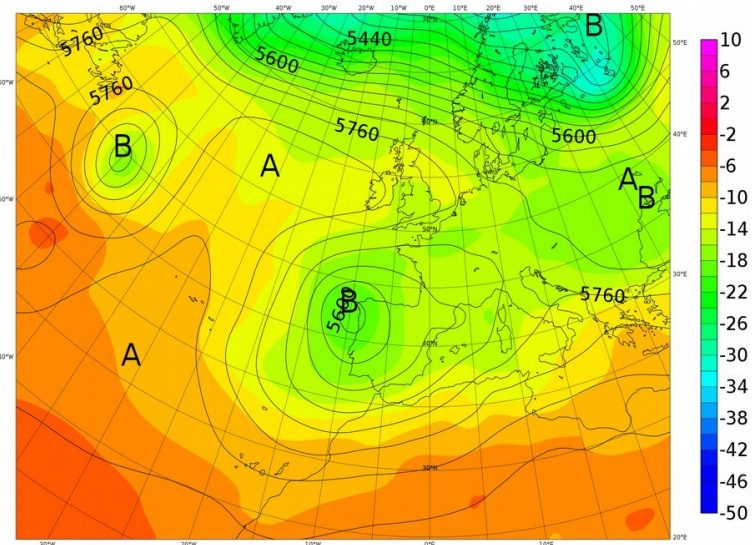

\section{Tipo 20. IIe Depresión fría peninsular de verano}

Este tipo se diferencia del 19 en que la circulación zonal en altura es mucho más débil y está localizada a latitudes más septentrionales, lo cual es propio de la estación estival (figura).

Con una duración de unos 3 días, su presencia relativamente poco frecuente queda limitada a la segunda mitad del verano.

La masa de aire es mT (sub) enriquecida en vapor de agua. Junto a la importante "gota fría" (DANA) en altura crea una gran inestabilidad que se traduce en la intensa actividad tormentosa general característica de este tipo. La consecuente mezcla vertical del aire da lugar a que las temperaturas sean inferiores a las normales. 

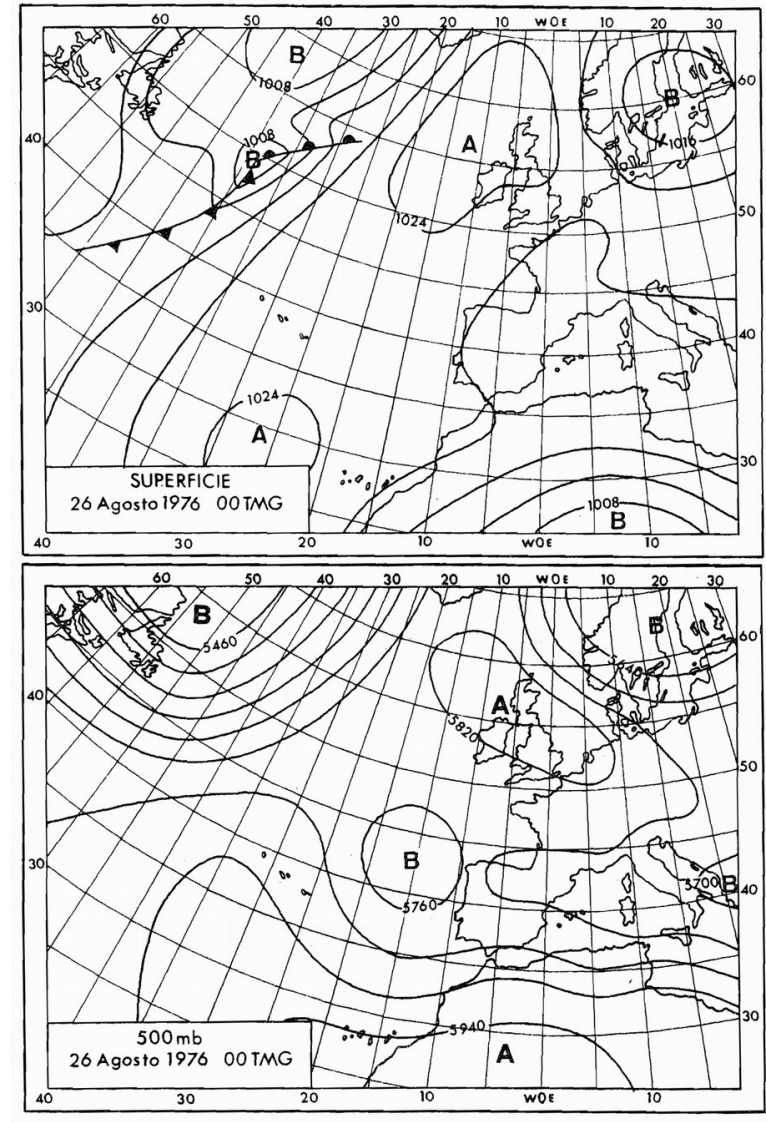

Fig. 78 Tipo de tiempo n. ${ }^{\circ}$ 21.II. - Pantano barométrico.

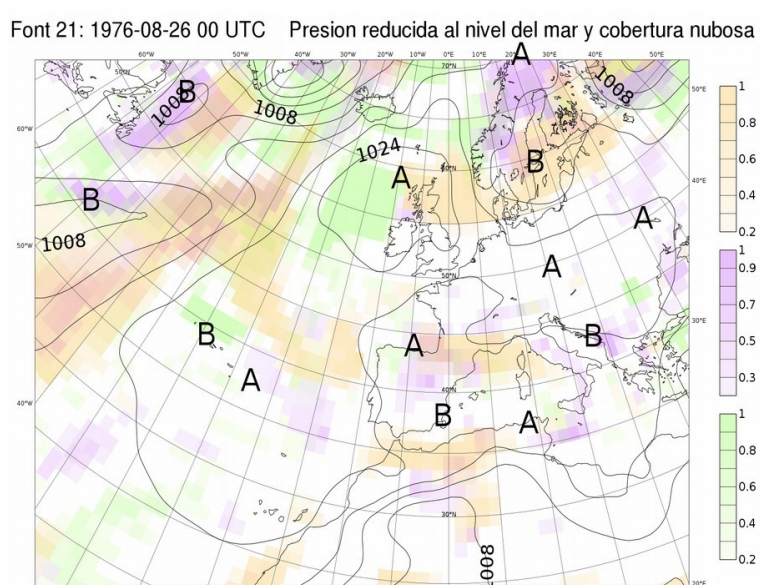

Font 21: 1976-08-26 00 UTC Altura geopotencial y temperatura en $500 \mathrm{hPa}$

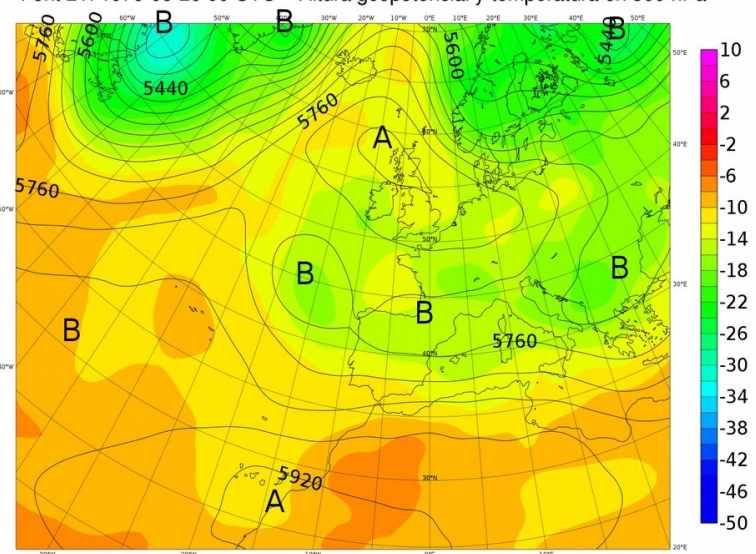

\section{Tipo 21. II Pantano barométrico}

En superficie, la falta de gradiente barométrico en una extensa área alrededor de la Península constituye su característica distintiva general, mientras que en altura predominan las calmas. En verano, la situación se distingue por la presencia de varios centros de altas presiones sobre el Atlántico y por la corriente superior del Este a latitudes inferiores a los $40^{\circ}$, como puede observarse en el ejemplo de la figura.

Con una duración de 3 a 15 días, puede presentarse en cualquier mes, pero con una clara preferencia por los meses estivales.

La masa de aire mT (sub) puede modificarse sustancialmente sobre la Península hasta convertirse en una masa autóctona.

El tiempo es generalmente bueno, aunque con ocasionales tormentas, sobre todo en la mitad norte y vertiente mediterránea.

Los veranos en que este tipo es más frecuente de lo normal, como lo fue el del año 1976, se caracterizan en la Europa occidental y central por su sequedad, dando lugar a una de las anomalías más espectaculares de su clima. 

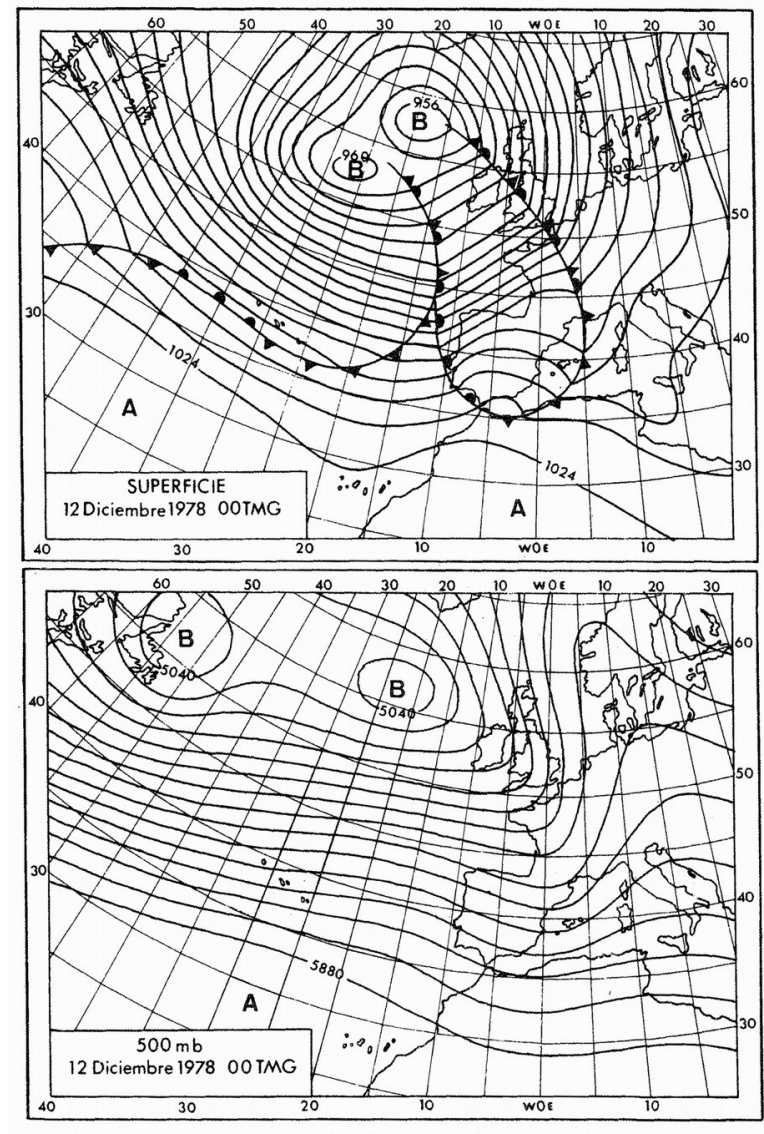

Fiø. 70 Tino de tiembo n. ${ }^{\circ}$ 22.III.i. - Intensa circulación zonal a baias latitudes.

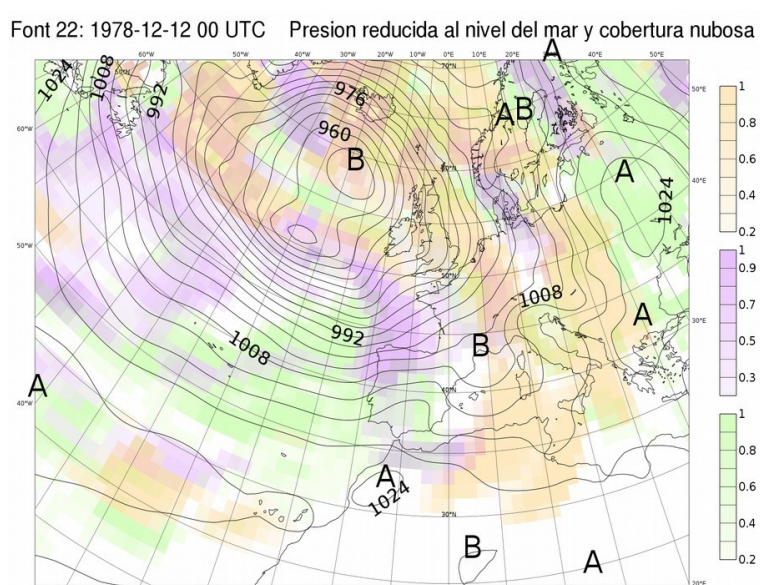

Font 22: 1978-12-12 00 UTC Altura geopotencial y temperatura en $500 \mathrm{hPa}$

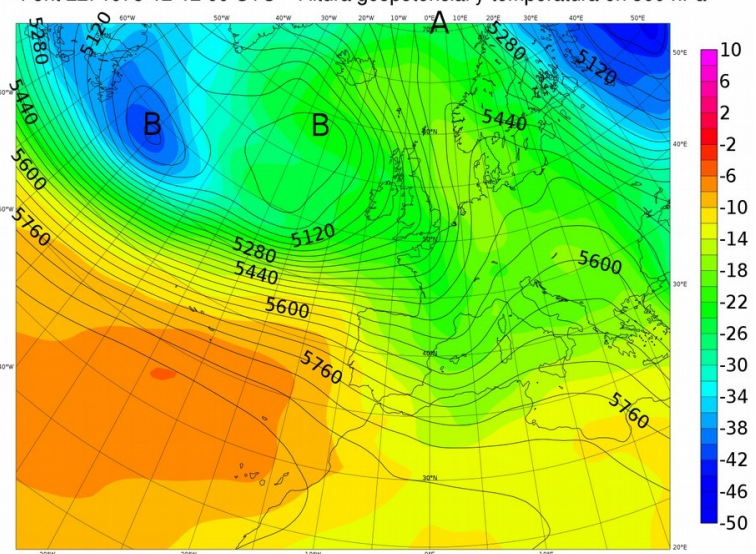

Tipo 22. IIIi Intensa circulación zonal a bajas latitudes

La amplia e intensa circulación del oeste que se manifiesta tanto en superficie como en altura, entre aproximadamente los paralelos $30^{\circ}$ y $50^{\circ}$, barriendo en consecuencia la Península, constituye su característica fundamental.

$\mathrm{Su}$ frecuencia es pequeña, pero cuando se establece, preferentemente en el trimestre invernal de diciembre a febrero, tiene generalmente una larga vida pudiendo mantenerse, aunque con algunas interrupciones, hasta seis semanas.

La masa de aire predominante es la mT (sub).

Este tipo es responsable de los periodos más largos de precipitaciones generales sobre la Península, pudiendo ir acompañado de fuertes temporales de lluvia en la vertiente atlántica y en la región cantábrica. Su presencia implica un cambio radical en las condiciones climáticas de la Península, dando lugar a inviernos suaves y lluviosos, como ocurrió en el invierno 1978-79, al que corresponde el ejemplo de la figura.

En las raras ocasiones en que hace acto de presencia en verano, la circulación del oeste es, naturalmente, mucho menos intensa, dando lugar a veranos frescos y relativamente lluviosos, como así fue el de 1977. 

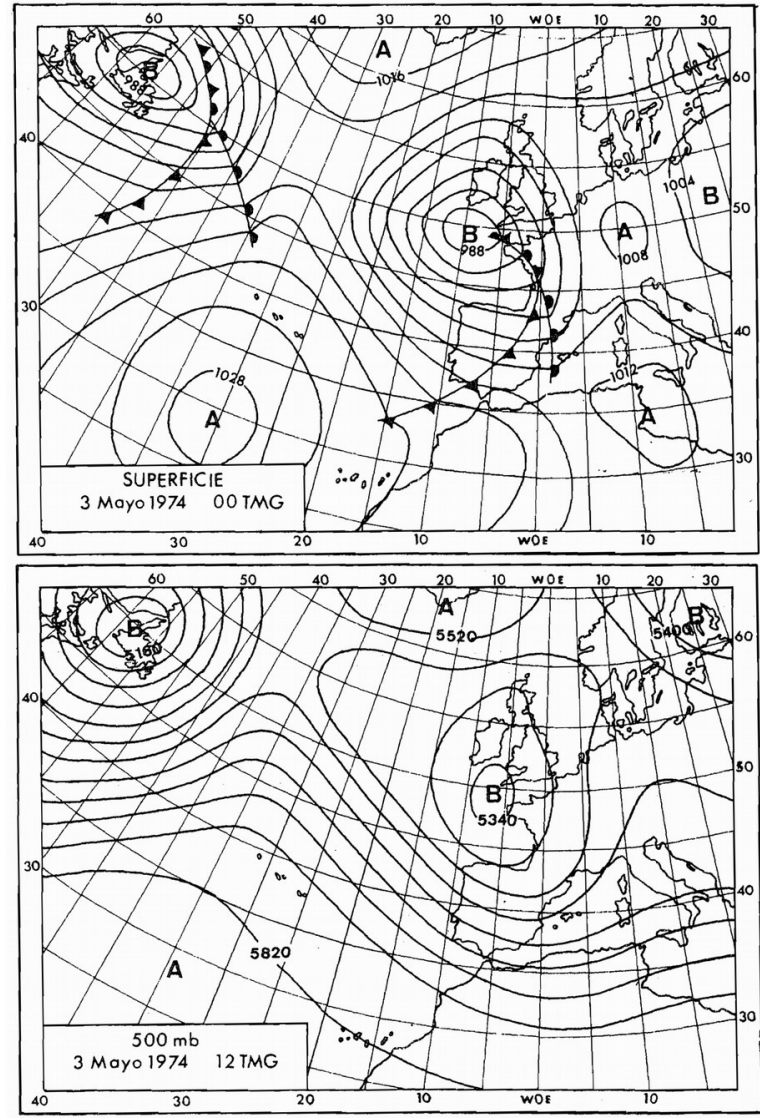

Fig. 80 Tipo de tiempo n. ${ }^{\circ}$ 23.rI..i. - Circulación ondulada a bajas latitudes.

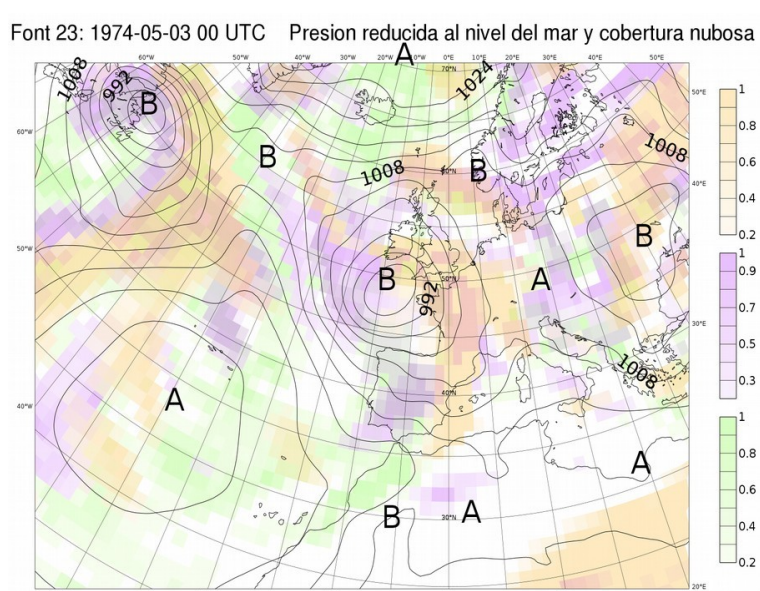

Font 23: 1974-05-03 00 UTC Altura geopotencial y temperatura en $500 \mathrm{hPa}$

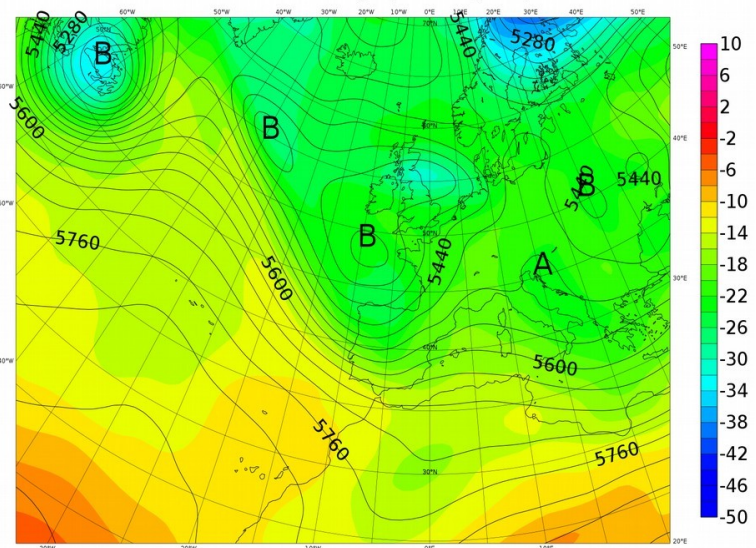

\section{Tipo 23. IIIi Circulación ondulada a bajas latitudes}

Se distingue del tipo anterior en la ondulación del vórtice circumpolar expandido, dibujándose claramente en el mapa de superficie el anticiclón atlántico centrado al sur de las Azores, así como otro a latitudes boreales. Entre ambos anticiclones, una secuencia de borrascas se traslada hacia el sureste, llegando a abarcar la Península dentro de su radio de acción, en el momento de su máximo desarrollo (figura). Sus trayectorias a veces cruzan la Península, pero más frecuentemente pasan al norte de los Pirineos y menos frecuentemente cruzan el Estrecho. En este último caso suele ser en el golfo de Cádiz donde la baja se manifiesta más profunda, siendo entonces la situación parecida a la del tipo 13.

La secuencia de las depresiones puede mantenerse durante varias semanas. Es un tipo específicamente invernal que no se presenta de junio a agosto y solo raramente en mayo y septiembre.

Las masas $\mathrm{mT}$ (sub) y $\mathrm{mP}$ van alternando con predominio de la segunda, aunque muy atenuada.

El tiempo es muy revuelto y variable, aunque Andalucía y Levante solo son afectadas por aquellas depresiones que siguen las trayectorias más meridionales y que ocasionalmente dan lugar a importantes nevadas. 